
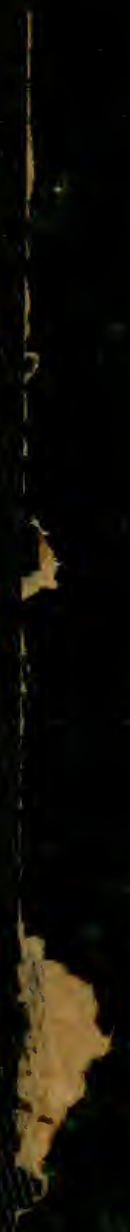
H. DE BOIVOLLOIR.

$1-18$

DPFORERTY OF 


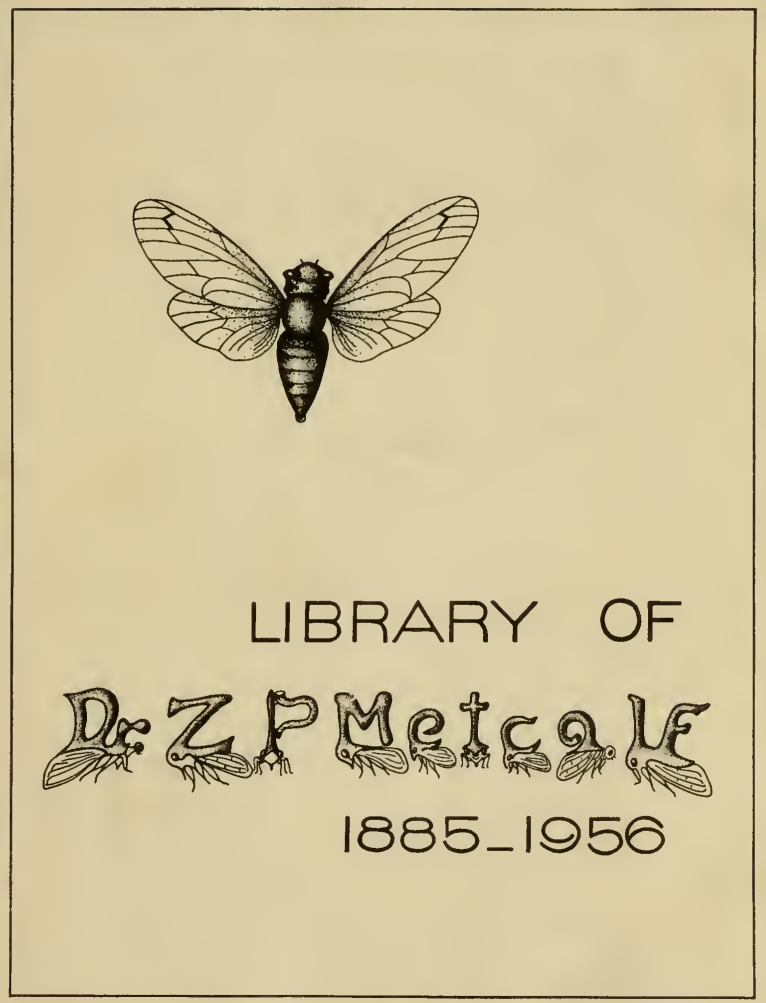



IOH. CHRIST. FABRICII HIST.OR. NAT. OECON. ET CAMERAL. PROF. CHILONIENS. ACAD. HAF NIENS. NORWEG. ET BEROLINENS. SOC.
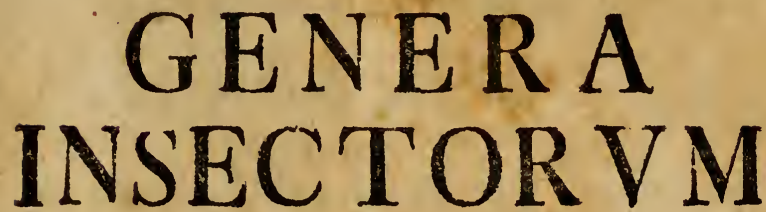

EORVMQVE

CHARACTERES NATVRALES SECVNDVM

NVMERVM, FIGVRAM,

SITVM ET PROPORTIONEM OMNIVM PARTIVM ORIS A D IECTA

MANTISSA SPECIERVM NVPER DETECTARVM.

\section{H I I O N I I}

I.ITTERIS MICH.. FRIEDR。 BARTSCHII. 
Ignorato genere proprio, nulla defcriptio, quamuis accurate tradita, certum demonftrat, fed plerumque fallit. Caeralpin. 


\title{
PRINCIPI SERENISSIMO
}

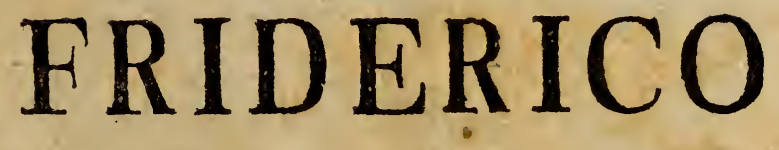

REGIO DANIAE NORWEGIAE HEREDI,

REGIS OPTIMI OPTIMO FRATRI,

SALVTIS PVPLICAE, RELIGIONIS,

\author{
A R T IVM
}

SCIENTIARVMRVE FAVTORI

ATQVE STATORI.

D. D. D.

KILIAE

CVLTOR DEVOTISSIMVS

I. C. FABRICIVS. 


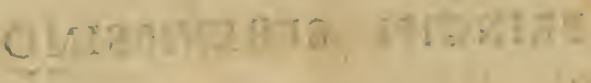

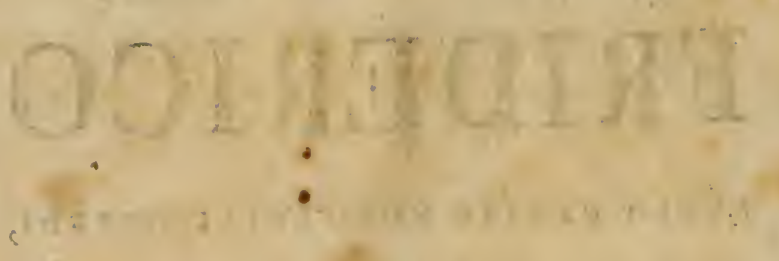

x.

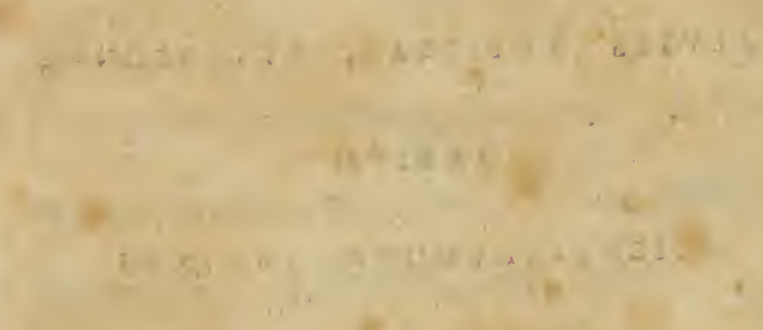

$$
\begin{aligned}
& +4=4,2+2 y=
\end{aligned}
$$

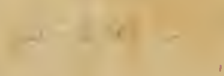

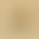

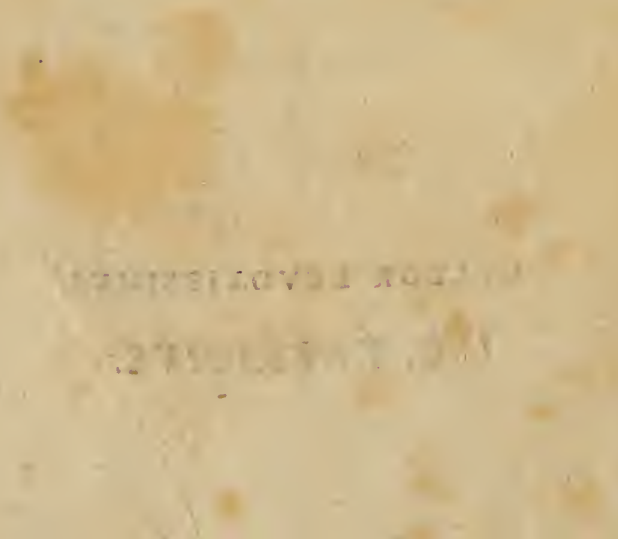




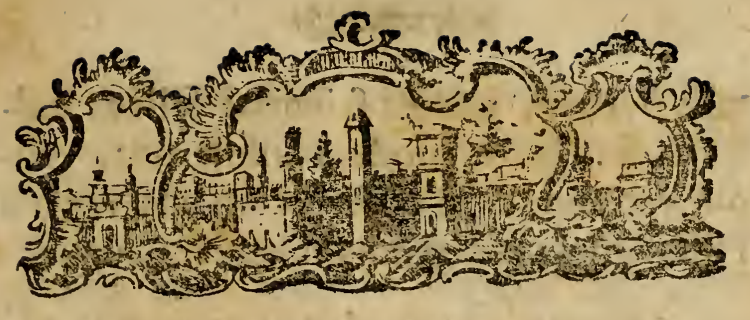

\section{PROLEGOMENA.}

\section{S}

- ytema primum hiftoriae naturalis continet fundamentum \& hoc füblato tota ruit fpecierum notitia, numero ipfo naturalium oppreffa, Me non fugit multos huius faeculi feriptores fyftema fpernere leuioris fcientiae amatores, at foliditatem \& certitudinem omnino amittunt. Impoffibile fane erit tantum fpecierum numerum, tot figuras, tot defcriptiones fpecificas, quae in dies augentur, in memoriam reuocare, nifi in ordinem redigantur. Mammalia quidem maiora, pauciora facilius diftinguuntur, at plantae \& in fecta fere innumera, ipfo fyftemate adiuuante, dificilius rite determinantur \& absque fyftemate confufum omnino chaos praeberent. Omnes ideo hiftoriae natu-

$$
x_{3}
$$

ralis 


\section{पन करण}

ralis heroes, omnes fcientiae felices cultores fyftemate quodam infifterunt, reliqui vero empirici obferuationibus vagis a fyltematicis redigendis fcientiam augent.

Syftemati entomologiae pauciora numerantur, at plura adhuc defiderantur. Quo plura enim elaborantur, eo maiorem foliditatem \& certitudinem attingit fcientia. Sequens fyfematicus antecedentis humeris infiftens altius circumfpicit.

Characteres generum fyftematis continent effentiam \& fcientiae foliditatem. praebent. In his ideo conftuendis fumma adhibenda diligentia, ne characteribus hifce vacillantibus accumulatis totum tandem ruat fyftema.

Characteres generum notas communes diftinctirum fpecierum fiftunt $\&$ a partibus diftinctis, determinatis defumendi. Quo confantiores funt hae partes ad diftinctionem generum affumtae, eo maiorem certitudinem \& praeftantiam habebit fyftema. In his anteceffores omnes aberrant. Ante fummum a Linné vix vllum 


\section{ของ}

genus fixum rite determinatum inuenimus, vt illi merito inuentionis gloriam circa genera concedere debeamus. At immortalis ipfe a Linné, qui in generibus. plantarum coudendis regulas tam arcte confrixit, qui characteres generum a folo fore defumendos tam Arenue affeuerauit in Entomologia eosdem characteres vndequaque collegit. Antennae, pedes, Thoráx, onmes animalculi partes hic in confiderationem veniunt, omnes characteres praebent generieos. Quae quaefo fyftema plantarum, fi mox a radice, mox a caule, mox a foliis aut flore characteres generum defumerentur. Eadem Entomologiae eft ratio. Inde oriuntur tot confufiones, tot contradictiones characteris fpecifici cum generico, quae nunquam evitantur, nif $a b$ omni fere fpecie proprium conderetur genus. Perfpexit perbene fummus vir hurc fyntematis defeftum, ideoque rarius noua genera condidit \& magis habitui quam characteri confdit.

Omnes Linnaei fuccefores fundamensum fyftematis vacillans haud rite cogno-

fcentes 


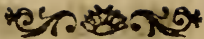

fcentes magis fyftemati adhaeferunt, genera multa partibus variis diftincta introduxerunt, quo ipfo determinatio difficilior \& denominatio incertior.

Nouifimi ideo entomologi ad figuras refugiunt, fyftema relinquunt, fpernunt \& folis figuris praeftantifimis infecta determinare ftudent. Gratiffmam fcientiam hoc ipfo in libri memorialis formam, memoria tantum retinendam, redigant. Omnes hos libros euoluere, omnes figuras examinare ad denominationem vnius cuiusque infecti neceffe eft $\&$ tamen determinatio ob varietates, quae nunquam figuris ex primi poffunt, faepius incerta euadit. Dolent hanc fcientiae incertitudinem omnes hiftoriae naturalis amatores. Nomina enim fi pereunt, perit $\&$ cognitio rerum.

Nouam tentaui viam \& infrumenta ci. baria ad determinanda genera introduxi Praeftant ob vifum, quem praebent. PraeAant ob numerum \& certitudinem char cternm, quos offerunt. Praeftant deniqne ob affinitatem cum characteribus reliquo- 
rum animalium a dentibus defumtiș. Me non fugit partes hafce oris faepius minutiffimas difficilius erui oculoque armato diftinguendas efre, at haud mirum mihi videtur, quod infectorum characteres, quae ipra nudo oculo vix conf́picua, armato defcribendi fint. Inftrumenta certe cibaria infectorum floribus plantarum habita ratione magnitudinis corporum inter fe multo funt maiora, \& characteres e partibus oris Lucani Cerui facilius eruuntur quam e floribus maximae Quercus Omnia, quae hic defcripfi, genera micrafcopio paruo fimpliciffimo examinaui \& gratus iucundusque fuit labor.

Inftrumenta cibaria plures continent partes ad difinctionem generum omnium detectorum \& vnquam detegendorum fufficientes. Inuenimus enim I Palpos duos, quatuor, fex eorumque articulos, 2 Clypei difcum, limbum. 3 Mandibulas transuerfales earumque dentes apicesque 4 . Maxillas transuerfales earumque dentes, lacinias. 5 Galeam. 6 Labii numerum, diuifionem, difcum, limbum. 7.Linguam 


\section{की}

fpiralem conuolutam. 8. Roftri vaginam eiusque articulos. 9. Roftri fetas, 10. HauAtelli vaginam eiusque valuulas. I 1 . HauAtelli fetas. 12 Probofcidis fipitem. I3. Probofcidis capitulum bilabiatum. Omnes hae partes numero, figura, proportione, fitu, differunt \& characteres generum conftantes praebent omnino fufficientes.

In paucis generibus a quibusdam partibus oris characteres defumferunt Linné, Scopoli, vti in Antliatoran clafe, quare non in omnibus \& ab omnibus, quum genera \& in eorum fyfrematibus a partibus oris determinata reliquis multo funt certiora, multo funt naturaliora.

Antennas, quibus anteceffores omnes tanti faciunt, femper generum characteribus appofui. Minus tanien ad diftinguenda genera valent, quam plerique eftimant. Characteres pricbent pauciores, faepius inconftantes, incertos. In eadem fpecie interdum differunt \& quibusdam generibus antennae omnino defunt. Ad ordines claffum determinandos magis valere 


\section{- करा}

valere videntur quam ad generum determinationem.

Metamorpho/is infectorum triplex in conftruendis generibus femper confulenda. Nunquam quidem characterem proprium generum intrabit, attamen ad genera naturaliora viam monftrat. Infecta, quae metamorphofi differunt, nunquam idem genus \& forte ne eundem quidem claffem intrabunt. Vnicum tantum exemplum Pulicis in contrarium habernus, attamen forte, fi plura infecta Pulici coniungenda detegerentur, propriam claffem conftituerent.

Larsae \& Puppae fructura nimis a fe inuicem differentes itidem vix vnquam fub eodem genere militabunt. Idem eft animal aetate tantum $\&$ forma mutatum $\&$ differens iuuentus differentem lenectutem indicare videtur. lure ideo Hydrophilum a Dytifcis aut Aeshnam \& Agrion a Libellulis feparaui. Differunt charactere, differunt \& Aructura laruae \& puppae. Metamorphofi tamen \& fructura laruae \& puppae magis adhaerere quam charactere abfur- 


\section{एकम}

abfurdum foret, quo ipfo primum fyftematis rueret fundamentum.

Habitus Infectorum in confruendis generibus occulte obfervandus. Raro hic aberrabimus \& rarifime infecta habitu ni. mis a fe inuicem differentia, idem genus intrabunt. Genera naturalia funt \& talis differentiam mifcela femper generum \& fyftematis defectum monftrat, Habitus tamen loco characteris nunquam affumendus \& fpecies charactere fecundum affumta Lyftematis principia differentes nullo modo fub eodem genere collocandae. Vacillat alias fyftema \& tandem totum ruit aedificium proprio pondere generum incertorum oppreffum. Summus hiftoriae naturalis princeps ipfe a Linné hic paululum impegiffe mihi videtur in reliquis omnibus excellens. Naturae nimis adhaerens fyrtematis filum ariadneum faepius amifit, vnde genera vacillant \& differentiae fpecificae charactere generico faepius contradicunt.

Icones nullas ad didi. Ad genera determinanda nullo modo valent. Multas 


\section{-}

facpe fpecies continent genera, quas omnes character genericus comprehendit. Characterem vero hunc icone exprimere omnino impoffibile, quum plures faepe fpecies eiusdem generis in quibusdam partibus oris a fe inuicem differunt, quamuis charactere generico conueniunt. Omnes hafce differentias eodem icone exprimere haud valemus. Confufionem ideo praeberent omnes icones ad generum determinationem confectas, quum femper quibusdam fpeciebus diffimiles effent.

character genericus fecundum a Linné principia triplex inuenitur; effentialis nempe, artificialis \& naturalis.

Effentialis character nota vnica, propria genus a reliquis omnibus diftinctum tradit. Character hic omnium optimus commendat fe breuitate, certitudine \& hoc dato genera facillime determinantur. Exempla huius characteris Syftema noArum Entomologiae praebet vti in Melolontha, Lucano, Onifco, Scorpione, Oeftro aliisque; at in omnibus generibus 


\section{เอเสละ}

characterem obtinere effentialem vix ac ne vix quidem poffibile erit.

Artificialis character effentiali fubftituitur, vsque dum hic eruitur. Diftinguit genus vnica nota aut pluribus a reliquis generibus fub eodem ordine militantibus. Nouo ideo detecto genere faepius mutandus, vt etiam $a b$ hoc genere diftinguat. Charactere effentiali femper inferior, attamen vbi hic haud inuenitur, ille femper fuccedaneus adhibendus.

Naturalis character generum, quem hic trado, praebet notas omnes in inftrumentis cibariis omnibus fpeciebus eiusdem generis communes. Defcribit numerum, figuram, proportionem \& fitum omnium partium oris, quibus omnes fpecies fub eodem genere militantes conueniunt. Offert ideo hic character plurimas generis notas, continet characterem effentialem \& artificialem \& rite elaboratus certitudinem \& foliditatem fyftematis \& fcientiae efficit. Omnibus methodis adhuc conficiendis applicabilis erit, fi mo- 


\section{-}

do iisdem inftrumentis cibariis fuperftruuntur.

Nomisa generica antecefforum fancte femper feruaui. Verba valent praetio determinato \& characteres effentiam, nomina tantum fonum generis continent. Confufionem praebet femper talis nominum mutatio \& nomine indeterminato, vago, vti pleraque funt, aliud nomen vagum fubftituere fuperuacaneum foret. Omne vero nomen genericum charactere proprio effentiali diftinguere hic labor, hoc opus. Plura vbi nomina eodem genere impofita funt, optimum vetuftiffmum retinendum.

Auctorum defcriptiones, figuras nunquam ad generum determinationem adhibere valui. Omnes oris partes plane omiferunt, ideoque quamuis figurae accurate traditae, tamen ad genera determinanda nullo modo valent.

Species infectorum in Syftemate Entomologiae Flensburgi 1775 dedi. Mantiffam tantum fpecierum nuper detecta- 


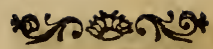

rum hic addidi. Communicatae funt nouae hae fpecies partim a fautoribus, amicis Anglis \& Germanis, partim a commilitonibus Chilonienfibus an iciffimis, quibus omnibus me obftrictiffimum fateor.

Rationem \& leges fyftematis noftrae, fi fata velint, in philofophia entomologica dabo. Kiliae die XXvi Decem. I776.

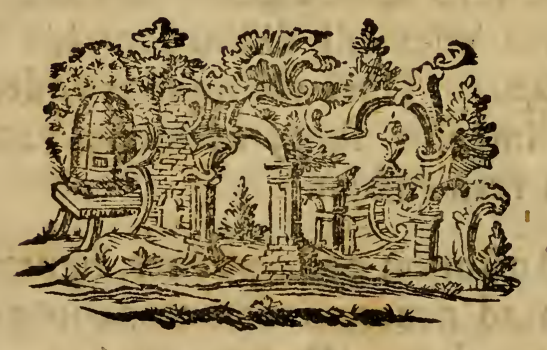




\section{म정 \\ Claffi $I$. \\ ELEVTERATA.}

s maxillis palpisque.

Palpi articulati, cornei faepius quatuor? anterioribus adhaerentibus maxillae dorio, pofterioribus labio.

Interdum fex, anticis duobus breuioribus maxillae incumbentibus, cum intermediis maxillae dorfo infertis, pofticis labio.

Clypeus horizontalis, corneus, rotundatus, os fuperne tegens.

Mandibulac duae transuerfales, corneae; mobiles latera oris fuperne includentes.

Maxillae duae; liberae, transuerfales; fae pius membranaceae, compreffae, lare. raoris inferne includentes.

- Labium porrecum, liberum, mox cortneum, mox membranaceum, os infer $\mathrm{r}^{\mathrm{r}}$ ne claudens.

Antennac inter oculos infertaes 
GENERA Claffis I.

I. LVCANVS. - 24. NITIDVLA.

2. SCARABAEVS. 25. COCCINELLA.

3. TROX.

26. CASSIDA.

4. MELOLONTHA 27. ALVRNVS.

5. TRICHIVS.

28. CHRYSOME-

6. CETONIA.

LA.

7. HISTER.

8. APATE.

29. CRYPTOCEPHALVS.

9. DERMESTES.

IO. MELYRIS.

I I. BOSTRICHVS.

12. BYRRHVS.

13. ANTHRENVS.

14. ANOBIVM.

15. PTINVS.

16. BRVCHVS.

17. ELOHHORVS.

18.SPHAERIDIVM.

19. TRITOMA.

19. * IPS.

20. HISPA.

21. NICROPHO-

RVS.

22. SILFHA.

23. OPATRVM.

3I. CISTELA.

32. CRIOCERIS.

33. EROTYLVS.

34. LAGRIA.

35. ZYGIA.

36. ZONITIS. -

. 37. APALVS.

38. CVRCVLIO.

39. ATTELABVS.

40. CLERVS.

4I. NOTOXVS.

42. SPONDYLIS.

43. PRIONVS.

44. CERAMBYX.

45. LAMIA.

46.STENOCORVS.

47. CALOPVS.

48. RHA- 
48. RHAGIVM.

49. SAPERDA.

50. CALLIDIVM.

5I. DONACIA.

52. LEPTVRA.

53. LAMPYRIS.

54. PYROCHROA.

55. LYMEXYLON.

56. CVCVIVS. 57. CANTHARIS. 75. EKODIVS. 58. MALACHIVS.

59. NECYDALIS.

60. ELATER.

6r. BVPRESTIS.

62. CICINDELA.

63. ELAPHRVS.

64. HYDROPHI-

LVS.

65. DYTISCVS.
66. GYRINVS. 67. CARABVS. 68. SCARITES. 69. SEPIDIVM. 70. PIMELIA. 7 I. SCAVRVS. 72. BLAPS. 73. TENEBRIO. 74. HELOPS. 76. MELOE. 77. LYTTA. 78. MYLABRIS. 79. CEROCOMA. 80. MORDELLA. 8I.STAPHYLINVS 82. OXYPORVS. 83. PAEDERVS. 


\section{LVCANVS Linné; Platycerus}

\section{Geoffroy.}

Os maxillis palpisque quaruor.

$P_{a l p i}$ inaequales, filiformes articulis obconicis: fecundo longiore.

antcriores longiores, adhaerentes maxil. lae dorfo.

pofferiores fub labio abfconditi, adnati penicillis duobus, elongatis, fub filiformibus, baficonnatis, ad bafin labii infertis.

Mandibula porrecta, cornea, arcuata, dentata.

Maxilla porrecta, membranacea, tota fe. tofa, medio vnidentata.

Labium porrefum, coriaceum, apice rotundatum, emarginatum, palpos pofteriores tegens.

Antennac undecim articulatae: articulo recundo longifino, vltimis quatuor porrecto ímellatis.

Larua hexapoda, annulata, nuda abdomine apice veficulofo, capite corneo.

Puppa intra glebam quiefcens abriomine fpinis duabus caudalibus, rigidis, articulatis, mobilibus.

Victus laruae e ligno putrefcente, acidulo, imaginis e foliis arborum.

Obf. Mandibulae maris in quibusdam fpeciebus longiffimae, corniformes. 
2. SCARABAEVS Linné Geoffioy.

Copris Geoff.

Os maxillis palpis que quatuor. Palpi fubaequales, filiformes.

Anteriores vix longiores, quadriarticula-

ti articulo primo breuiffimo adhaerentes maxillae dorfo.

pofferiores triarticulati articulis aequalibus

labii apicibus prominentibus inferti.

Mandibula porrecta, cornea, arcuata, inermis, apice obtufa.

Maxilla elongata, membranacea, ad infertionem palporum vnidentata.

Labium porrectum, corneum, fubcylindricum, apice emarginatum.

Antcnnae clauatae, lamellatae, articulis vndecim: vltimis tribus lamellis porrectis obtufis.

Larua hexapoda, annulata, pilofa, abdomine fubtus veficulofo, capite corneo. Puppa intra glebam quiefcens, abdomine yeficulofo, ecaudato.

Victus laruae \& imaginis e ttercore animalium.

Obf. I. Mandibula Scarab. Thyphoei apice tridentata.

2. Maxilla in quibusdam fpeciebus apice dilatata, rotundata.

3. Copris Geoffroy tantum defectli fcutelli differt.

4. Antennae rarius lamellis feptem.

$$
\text { A } 3 \text { 3. TROX. }
$$




\section{कำ}

\section{TROX. Scarabaeus Linné.}

Os maxillis palpisque quatuor.

Palpi inaequales, capitati.

anteriores longiores, quadriarticulati, articulis aequalibus; vltimo oblongo craffiori adhaerentes maxillae.

pofteriores triarticulati: articulo vltimo oblongo, craffiori labii apici inferti.

Mandibula breuis, cornea, craffa, obtufa, edentula.

Maxilla cylindrica, membranacea, recta, bifida: laciniis fubaequalibus acutiufculis, fetolis.

Labium porrectum, corneum, rotundatum, apice membranaceum, emarginatum.

Antennac brenes: articulo primo craffiori, pilofo, vltimis tribus ouatis, lamellatis.

Metamorplofis \& Victus ignotae. 
4. MELOLONTHA. Scarabaeus Linné. Geoffr.

Os maxillis palpisque quatuor.

Palpi inaequales, filiformes.

anterieres longiores, quadriarticulati: articulo primo tertioque breuifimis, quarto longiori oblongo adhaerentes maxillae dorfo.

poffcriores breues, triarticulati: articulis fubaequalibus labii parieti interiori inferti.

Mandibula breuis, cornea, arcuata, apice compreffa, acutiufcula, vix dentata.

Maxilla cornea, breuis, rigida, fubarcua-

ta, apice obtufa, multidentata.

Labium porrectum, corneum, cordatum, apice fubemarginatum.

Antennae breues clauato lamellatae: articulo primo globofo, craffiori.

Larua hexapoda, annulata, fubpilofa, abdomine, apice veficulofo, capite corneo. Puppa quiefcens intra glebam, abdomine apice acuminato.

Victus laruae e plantarum radicibus, imaginis ex arborum foliis.

Obf. I. Melolonthae folftitialis labium magis emarginatum quam in reliquis.

2. Antennarum claua in quibusdam lamellas feptem gerit.

$$
\text { S. TRI. }
$$


5. TRICHIVS. Scarabaeus Linné.

Os maxillis palpisque quatuor.

Palpi aequales, filiformes: articulo vltimo longiori.

anteriares quadriarticulati, .adhaerentes maxillae dorfo.

pofteriores triarticulati medio laterali la. bii inferti.

Mandibule cornea, craffa, obtufa, edentula.

Maxilla cylindrica vsque adbafin bifida: laciniis aequalibus, obtufiufculis apice fetofis.

Labium cylindricum, elongatum, corneum, emarginatum: apicibus aequali, bus, acutiufculis.

Antennac clauato lamellatae: lamellis tri. bus ouatis, articulo primo craffiori pilofo,

Metamorphofis ignota.

Imago delectatur floribus inprimiṣ vm. bellatarum.

Obf. Trichius fafciatus labio gaudet hirfuto.

6. $\mathrm{CE}$. 


\section{सสำ यर}

\section{CETONIA. Scarabaeus Linn.}

Geoff.

Os maxillis palpisque quatuor.

Palpi fubaequales.

anteriores filiformes, triarticulati : ar. ticulo vltimo cylindrico adhaeren. tes maxillae.

pofteriores triarticulati: articulo vltimo longiori, fubcrafliori bafi internae labii inferti.

Mandibula porrecta, cornea, recta, acu. ta, inermis.

Maxilla ad infertionem palporum dilatata, vnidentata, fetofa.

Labium elongatum, coriaceum, cylindricum, apice fiffum, aut emarginatum palpos pofteriores fere totos tegens.

Antennae breues, clauato lamellatae; lamellis tribus ouatis, articulo primo porrecto, cralfiori.

Lamu hexapoda, annulata, pilofa, abdomine apice veficulofo, capite paruo corneo.

Puppa quiefcens intra glebam, abdomine apice obtufo.

Vićus laruae e ligno putrefcente, fubaci. dulo, imaginis ex arborum foliis \& flo. ribus.
A 5
7. $\mathrm{HI}$ 
7. HISTER. Linn. Attelabus

\section{Geoff.}

를

Os maxillis palpis que quatuor.

Palpi aequales, fubfiliformes: articulis oblongis, aequalibus.

anteriores quadri articulati: arriculo vltimo obtufo, truncato fub a pice maxillae inferti.

pofteriores triarticulati apici labii adhaerentes.

Mandibula porrecta, cornea, arcuata, acu. ta, vnidentata.

Maxilla membranacea, fubcyindrica, vnidentata, apice obtufa.

Labium corneum, porrectum, cylindricum, apice membranaceum, rotunda. tum, integerrimum.

Antennac breues, vndecim articulati: articulo primo longiori, reliquis fubglobofis vitimo clauato, ouato.

Metasnorploofis \& victus latent. 


\section{A PATE. Dermeftes Linn. Ligni. perda Pall.}

Os maxillis palpisque.

Palpi quatuor aequales, filiformes.

anteriores quadriarticulati: articulo vltimo breuiori, cylindrico, obtufo adhaerentes maxillae dorfo.

pofteriores triarticulati: articulo vltimo breuiori, craffiori, obtúfiffimo labii medio inferti.

Mandibula cornea, recta, acuta, bafi dentata.

Maxilla membranacea, ad infertionem palpi vnidentata, apice rotundata.

Labium breue, cylindricum, membrandceum, depreffum, obtufiffimum \& fere truncatum, ciliatum, integerrimum.

Antennae clauatae: claua articulis tribus diftantibus, perfoliatis.

Metamorphofis ignota.

Victus imaginis e ligno putrefcente. 
8. DERMESTES. Linn. Geoff. Clerus. Geoff.

Os maxillis palpisque.

Palpi quatuor inaequales, filiformes.

anteriores longiores, quadriarticulati: articulis aequalibus adherentes maxillae dorfo.

pofieriores triarticulati articulo vltimo maiori fub labii apice interiori inferti.

Mandibula cornea, arcuata, acuta, inermis.

Maxilla cylindrica apice rotundata, obtufifima, bifida longitudine palporum anteriorum: laciniis fubaequalibus; exteriore paullo maiore.

Labium fubcylindricum, corneum, elongatum, obtufum, integerrimum palpos inferiores fere tegens.

Antennae articulo primo maiori, crafiori, vltimis tribus clauato perfoliatis.

Larua hexapoda, fafciculato pilofa cauda faepius fetofa.

Puppa quiefcens, immobilis, hifpida cauda obrufa.

Victus laruae \& imaginis e pinguedine, pellibus \&̊c. 


\section{6.}

ro. MELYRIS.

Os maxillis palpisque.

Pulpi quatuor aequales, filiformes.

anteriores quadriarticulati : articulis fubaequalibus; vltimo ouato adhaeren. tes maxillae dorfo.

Pofteriores triarticulati : articulo vltimo ouato labii medio laterali inferti.

Mandibula breuis, cornea, incurua, edentula.

Maxilla breuis, fubcornea, inmedio vni dentata, apice acutiffima.

Labium porre\&tum, cylindricum, corneum, annulatum, apice membranaceum, clauatum, emarginatum.

Antcnuac fecundum totam longitudinem perfoliatae : articulis breuibus, vtrinque pilofis, vltimo ouato, obtufo.

Metamorpbofis \& victus latent.

1. $\mathrm{BQ}$. 
Ir. BOSTRICHVS. Geoff. Dermeltes. Linn. Scolytus Geoff.

Os maxillis palpisque.

- Palpi quatuor aequales.

anteriores in medio craffiores, triarticulati: articulis fubaequalibus adhaerentes maxillae.

poferiores triarticulati : articulis aequalibus labii apici inferti.

Mandibula breuis, cornea, craffa, forni. cata, acuta, inermis.

Maxilla cornea, brenis, craffa, recta, rigida, cylindrica, acutiufcula, integra.

Labium porrectum, membranaceum, te. nue, cylindricum, integrum.

Antennac vndecim articulatae: articulo primo paullo longiori, fequentibus breuiffimis, rotundatis, vlrimis tribus elongatis incrafiatis, ouatis vltimo acuto.

Metamorpbofis mihi haud rite nota.

Victus \& laruae \& imaginis e ligno ra- morum emortuorum.

Obf. B. Scolytus antennis apice obtufis differt. 
12. BYRRHVS Linn.

Os maxillis palpisque.

Palpi quatuor aequales, fubclauati: articulis aequalibus; vltimo fubrotundo, crafliori.

anteriores quadriarticulati maxillae dor. fo adhaerentes.

pofteriores triarticulati labii medio ad-
haerentes.

Mandibula breuis, craffa, cornea, recta, dentata, apice fiffa.

Maxilla membranacea, bifida: lacinia exteriore maiore rotundata.

Labium membranaceum, porrectum, rotundatum apice bifidum: laciniis aequalibus, conniuentibus.

Antennae primo articulo longiori, reliquis breuiffimis perfoliatis fenfim craffio. ribus.

Metamorphofis \& Victus adhuc omninolatent. 
13. ANTHRENUS. Geoff. Byrrhus Linn.

Os maxillis palpisque.

Palpi quatuor inaequales, filiformes.

anteriores longiores, quadriarticulati: atticulis aequalibus, cylindricis adhaerentes maxillae dorfo.

pofteriores cylindrici, breuifimi, obtufi, triarticulati: articulis aequalibus fub labii apice interiori inferti.

Mandibula cornea, arcuata, acuta, inermis.

Maxilla membranacea, linearis, obtufa, bifida: lacinia exteriori fub longiori.

Labium breue, corneum, rotundatum, integrum palporum pofteriorum bafin tegens.

Antennae cylindrico clauatae: articulis bre. uiffimis, vltimis tribus incraflatis, connatis clauam ouatam, folidam conftituentibus.

Larua hexapoda, villora.

Puppa immobilis cauda obtufa.

- Victus laruae e plantis emortuis, imaginis efloribus. 
I4. A NOBIV M. Ptinus Linn. Dermeftes Linn. Byrrhus Geoff.

Os maxillis palpisque.

Palpi quatuor, fubaequales, clauati.

anterioves parum longiores, quadriarticulati: articulo fecundo longiori adhaerentes maxillae dorfo.

pofteriores triarticulati: articulis fubaequalibus labii apici inferti.

Maráibula breuis, cornea, arcuata, acuta, inermis.

Maxilla breuis, cylindrica, craffa, cornea, reeta, integra, apice obtufa, dentata.

Labium breue, cylindricum, membranaceum apice truncatum, integerrimum.

Antennae fliformes: articulis anterioribus orbiculatis, vitimis tribus ouatis bafi attentatis.

Larua hexapoda, nuda, mollis capite callofo.

Puppa immobilis.

Victus laruac e ligno duriori, incorrupto. 
15. PTINVS Linn. Bruchus Geoff. Bupreftis Scop.

Os maxillis palpisque.

Palpi quatuor, aequales, filiformes.

anteriores quadriarticulati : articulis aequalibus vltimo fetaceo adhaerentes maxillae dorfo.

pofteriores triarticulati: articulis aequalibus adnati labii apici laterali.

Mandibula cornea, arcuata, compreffa.

Maxilla porrecta, membranacea, cylindrica, obtufa, bifida: laciniis cylindricis obtufis, aequalibus.

Labium porrectum, membranaceum, cylindricum, ad bafin bifidum: laciniis linearibus, cuius apicibus fummis palpi pofteriores infident.

Antennac longiores, filiformes: articulis obconicis; fecundo globofo.

Larua hexapoda, mollis, glabra.

Puppa folliculata, immobilis.

Viftus \& laruae \& imaginis e plantis \& animalibus exficcatis at haud putrefcentibus. 
16. BRV CHVS Linn. Mylabris Geoff.

Os maxillis palpisque.

Palpi quatuor, fubaequales, filiformes.

anteriores vix longiores, quinque articulati : articulis aequalibus; vltimo cy. lindrico adhaerentes maxillae dorfo.

pofteriores quadriarticulati: articulis aequalibus; vltimo globoro labii medio laterali inferti.

Mandibula vix arcuata, cornea, inermis.

Maxilla porrecta longitudine palporum, membranacea, cylindrica, bifida: laciniis conniuentibus, aequalibus.

Labium membranaceum, breue, inter pal. pos acuminatum, integerrimum.

Antennac elongatae, fubfiliformes: articulis introrfum apice prominulis.

Metamorphofis omnino adhuc latet.

Victus imaginis e feminibus plantarum. 
17. ELOPHORVS. Silpha Linn. Dermeftes. Geoff.

Os maxillis palpisque.

Palpi quatuor, fubaequales.

anteriores quadriarticulati: articulo fecundo longiffimo, vltimo fubcraffiori adhaerentes maxillae.

pofeciores triarticulati articulo vltimo fubcrafiori labii apici inferti.

Mandibula cornea, arcuata, acuta, edentula. Maxilla cornea, cylindrica, adinfertionem palporum vnidentata, apice membranacea, fetora aut potius fifa.

Labium porrefum, corneum, quadratum, truncatum, integrum.

Antenna breues, clanatae: claua folida articulis tribus craffioribus.

Metamorpbofis ignota.

Vičtus imaginis e foliis plantarum aquaticarum. 


\section{SPHAERIDIVM.}

Dermeftes Linn. Geoff. Silpha Linn. An. thribus Geoff.

Os maxillis palpisque.

Palpi quatuor inaequales, filiformes.

anteriores longiores, quadriarticulati: articulo fecundo maiori adhaerentes

- maxillae.

pofferiores breuiffimi, triarticulati fub. labii apice inferti.

Mandibula cornea, arcuata, acutiffima; inermis.

Maxilla porrecta, fubarcuata, apice membranacea, rotundata, bifida: laciniis fubaequalibus, obtufis.

Labium elongatum, corneum, quadra. tum, apice emarginatum, ciliatum.

Antennac claulata : claua perfoliata e articulis tribus incraffatis conftans.

Metamorphofis ignota.

Victus imaginis e ftercore animalium. 


\section{TRITOMA. Geoff.}

Os maxillis palpisque.

Palpi quatuor, inaequales.

anteriores multo longiores, fecuriformes, triarticulati: articulo fecundo breuiffimo, vltimo claua dilatata, acuminata adhaerentes maxillae dorfo,

pofteriores breues, incurui, biarticulăti: articulo vltimo fubcraffiori, obtufo fub labii apice inferti.

Mandibula cornea, arcuata, inermis, apice fiffa.

Maxills breuis, membranacea, cylindrica, bifida: laciniis aequalibus, filiformibus.

Labium porrectum, cylindricum, bafi corneum, apice membranaceum, fube. marginatum.

Antennae clauatae: claua perfoliata articulis tribus craffioribus conftans.

Metamorpbofis ignota.

Victus imaginis e fungis inprimis Boletis arborum.

19. * IPS. 


\section{*สำ}

19. * IPS. Silpha Linn. Dermeftes Geoff.

Os maxillis palpisque.

Palpi quatuor, breuifimi, aequales, filiformes.

anteriores triarticulati vix maxillae longiores: articulo vltimo obtufo, truncato adhaerentes maxillae.

pofteriores triarticulati, breues: articulo vltimo obtufo, truncato labii medio laterali inferti.

Mandibula breuis, cornea, vix arcuata, inermis.

Maxilla breuis, membranacea, bifida: la ciniis fubaequalibus, linearibus; interiore paullo breuiore.

Labium breuiffimum, corneum, truncatum, emarginatum.

Antennae porrectae, clauatae: articulis rotundatis, aequalibus; vltimis tribus craffioribus, perfoliatis.

Metamorphofis ignota.

Vičtus imaginis e cádaueribus animaliım.

6f. Genus affine Sphaeridio.

$$
\text { B } 4 \text { 20. HI. }
$$


20. HISP A. Linn. Dermeftes Linn.

\section{Prinus Linn.}

Os maxillis palpisque.

Palpi quatuor, breues, aequales, fubfil:formes.

anteriorcs quadriarticulati: articulis futaequalibus adhaerentes maxillae.

pofteriores triarticulati: articulis aequali bus labii bafi laterali inferti.

Mandibula cornea, arcuata, acuta, inermis.

Maxilla breuis, cylindrica, membranacea, bifida: laciniis aequalibus, filiformibus.

Labium porrectum, membranaceum, cy lindricum, apice truncatum, integrum

Antennac cylindricae: articulis breuibus bafi apiceque planis.

Larua hexapoda, nuda.

Puppa immobilis, obtufa.

Victus Laruae e ligno arborum putrefcente

0bf. I. Antennae cylindricae, plerisque fpe ciebus pectinatae, in quibusdam $\mathrm{fim}$ plices, interdum extrorfum crafliores

obf. II. Genus Anobio affine. 
2I. NICROPHORVS.

Silpha Linn. Dermeftes Geoff.

Os maxillis palpisque.

Palpi quatuor, aequales, filiformes.

anteriores quadriarticulati: articulis ae: qualibus; vltimo cylindrico adhaerentes maxillae dorfo.

pofteriores quadriarticulati: articulo primo longiffimo, vltimo globofo la. bii bafi exteriori inferti.

Mandibula cornea, arcuata, acuta, inermis. Maxilla recta, bafi vnidentata, apice ouata, rotundata, integra longitudine palporum.

Labium fub palpis elongatum, membranaceum, cordatum, apice emarginatum, crenatum.

Antenuac clauatae: articulo primo longiffmo, fequentibus breuibus, penultimis tribus craffioribus, perfoliatis, transverfis, vltimo ouato, acuminato.

Larua hexapoda, nuda, capite callofo.

Puppa fubpilofa, quiefcens, ano ftylis duobus, incuruis.

Victus e cadaueribus animalium.

$$
\text { B } 5 \text { 22. SIL: }
$$


22. SILPHA Linn. Peltis Geoff.

$O s$ maxillis palpisque.

Palpi quatuor, inaequales, filiformes.

anteriores quadriarticulati: articulo fecundo obconico, vltimo cylindrico adhaerentes maxillae dorfo.

pofteriores triarticulati: articulo vltimo obo. vato labii bafi exteriori inferti.

Mandibula breuis, cornea, compreffa, incurua, obtufa, inermis.

Maxilla ad infertionem palporum dente porrecto', corneo, valido, arcuato, acuto armata, apice membranacea, rotundata, ciliata.

Labium elongatum, membranaceum, obtufum, fiffum.

Antennae clauatae; articulo primo paulo longiori, fequentibus breuibus apicibus prominulis, quatuor penultimis craffioribus, perfoliatis, vltimo ouato.

Larua hexapoda, nuda, deprefra, duriufcula marginibus fegmentorum vtrinque prominulis fubfpinofis.

Puppa ouata, nuda, quiefcens.

Victus \& Laruae \& Imaginis e animalium cadaueribus. 
23. OPA TRUM. Silpha. Linn. Tenebrio Geoff.

Os maxillis palpisque.

Palpi quatųor, inaequales, clauati. .

Anteriores longiores, quadriarticulati: articulis aequalibus; vltimo craffiori, obtufo, truncato adhaerentes maxillae dorfo.

pofteriores triarticulati, extrorfum craffio. res labii lateribus inferti.

Mandibula cornea, arcuata, acuta, inermis.

Maxilla breuis, cylindrica, membranacea, bifida: laciniis inaequalibus, acutis; interiore breuiore.

Labium corneum, orbiculatum, porrectum, apice membranaceum, fubemarginatum.

Antennae moniliformes, extrorfum craffio. res: articulis fubaequalibus.

Metamorphofis \& victus \& laruae \& imaginis ignota. 
28 शำ

24. NITIDULA: Silpha Linn. Dermeftes Geoff.

Os maxillis palpisque.

Palpi quatuor, aequales; filiformes. anteriores quadriarticulati:articulis aequalibus adhaerentes maxillae dorfo.

poferiores triarticulati: articulis aequalibus labii medio laterali inferti.

Mandibula cornea, arcuata, acuta, inermis.

Maxilla longitudine palporum cylindrica, apice acuta, integra.

Labium elongatum, membranaceum, cylindricum, apice rotundatum, integerrimum.

Antennae clauatae: articulis breuibus, fubaequalibus; vltimo ouato, crafíori.

Metamorphofis \& victus ignota. 


\section{: \\ 25. COCCINELLA. Linn. Geoff.}

Os maxillis palpișque.

Palpi quatuor, inaequales.

anteriores paullo longiores, fecuriformes, triarticulati : claua dilatata acuta adhaerentes maxillae dorfo.

pofteriores filiformes, biarticulati : articulis aequalibus labii medio inferti.

Mandibula cornea, arcuata, acura, edentula.

Maxilla cylindrica, obtufa, recta, bifida: lacinis fubaequalibus, membranaceis.

Labium rectum, porrectum, cylindricum, ad infertionern palportum coarctatum, apice rotundatum, integrum.

Antennac clauatae : clauafolida, articulo primo longiori, vitimis quatuor incraffatis vltimo fubacuminato.

Larua hexapoda, fubuerrucofa, poftice attenuata.

Puppa gibbofa, fubrotunda, immobilis. Victus \& laruae \& imaginis e rapina A. phidum. 
26. CASSIDA. Linn. Geoff.

Os maxillis palpisque.

Palpi quatuor, inaequales.

anteriores longiores, quadriarticulati: articulo fecundo longiori, vltimo cla. uato maxillae dorfo adnati.

pofteriores breuiffimi, filiformes: articu. lis rotundatis, aequalibus labii baí inferti.

Mandibula cornea, arcuata, acuta, edentula.

Maxilla membranacea, cylindrica, obtufa, integerrima.

Labium elongatum longitudine palporum pofteriorum, cylindricum apice incrar. fatum, obtufum, integerrimum.

Antennac moniliformes, extrorfum craffiores: articulis fubaequalibus, vlrimo obouato.

Larua hexapoda, depreffa, fubrotunda, bicaudata, lateribus f pinofo ciliatis.

Puppa breuis, ouata, depreffa lateribus fpinofo ciliatis, quiefcens.

Victus \& laruae \& imaginis, e foliis plan. tarum in primis Carduorum. 


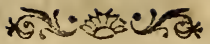 \\ 27. ALURNUS.}

Os maxillis palpisque.

Palpi fex, inaequales.

anteriores breuifimi, maxillae multo breuiores, biarticulati: articulo fecundo rotundato, ciliato adhaerentes maxillae dorfo.

intermedii longiores, filiformes, quadriarticulati: articulis fubaequalibus ad bafin anteriorum adnati.

pofteriores fubfiliformes, triarticulati: articulo primo breuiffimo, fecundo obconico, tertio rotundato parum craffiori fub labii inferióris apice inferti.

Mandibula craffa, cornea, arcuata, acuta, in medio vnidentata.

Maxilla porrecta palpis anticis mul to lon. gior, cornea, fornicata, apice rotun. data, ciliata.

Labium corneum, rotundatum, apice acuminatum, integerrimum.

Antennac filiformes: articulis cylindricis; fecundo longiori, reliquis aequalibus, vltimo acuminato.

Metamorphofis \& victus ignota.

28. CHRY- 
28. CHRYSOMELA. Linn. Geoft. Altica Syft. Ent. Geoff.

Os maxillis palpisque.

Palpi fex, inaequales.

anteriores longitudine maxillae filiformes, biarticulati : articulis aequalibus adhaerentes maxillae dorfo.

intermedii longiores: articulo primo breuiflimo, fecundo longiori, vlri. mo craffiori, truncato ad bafin ante. riorum adnati.

poferiores triarticulati : articulo fecun. do longiori, vltimo craffiori, truncato labii medio inferti.

Mandibula porrecta, cornea, arcuata, acuta, edentula.

Maxilla breuis, recta, membranacea, co. nica, acuta, integra.

Labium breue, corneum, rotundatum, fubcompreffum, integerrimum.

Antennae moniliformes: articulis vndecim fubaegualibus; vltimo ouato.

Larua hexapoda, mollis, nuda capite callofo.

Puppa breuis, ollata, quiefcens.

Victus \& laruae \& imaginis e foliis plantarum.

Obf. Altica f. Chryfomelae faltatoriae Linn. certe huius generis. 
29. CRYPTOCEPHALVS. Geoff. Chryfornela Linn. Melolontha Geoff. Buprertis Scop.

Os maxillis palpisque.

Palpi quatuor filiformes, aequales.

antcriores quadriarticulati:articulis aequa. libus adhaerentes maxillae, incumbentes.

poferiores triarticulati: articulis aequalibus apici labii inferti.

Mandibula breuis, craffa, cornea, diffor- mis, dentata.

Maxilla longitudine palporum, membranacea, filformis, bali dente elongato, rigido longitudine dimidiae maxillae armata.

Labium elongatum, corneum, cylindricum, apice rotundatum, integer rimum.

Antcnnae filiformes articulis vndecim, primo breuiori globofo, reliquis obconicis interne ferratis.

Larua hexapoda, mollis, nuda.

Puppa ouata, imnobilis.

Victus \& laruae \& imaginis e foliis plan. tarum.

Obf. Melolontha Geoff. antennis tantum ferratis differt.

$$
\text { C. 3I. CI. }
$$


3r. CISTELA. Geoff. Chryfomela Linn. Mordella Geoff.

Os maxillis palpisque.

Palpi quatuor, inaequales, filiformes.

anteriores longiores, quadriarticulati: articulo primo breuiflimo, fecundo longiori adhaerentes maxillae dorfo.

pofteriores quadriarticulati: articulis bre- uiffimis fubaequalibus labii medio larerali inferti.

Mandibula cornea, arcuata, fubintegra.

Maxilla porrecta, membranacea, cylindrica ad infertionem palporum vnidentata, apice obtufa.

Labium porreetum, membranaceum, cylindricum adinfertionem palporum coarctatum, apice bifidum: laciniis aequalibus, linearibus, diftantibus.

Antennas filiformes : articulis vndecim, obconicis apice fubprominulis.

Metamorpbofis ignota.

Victus imaginis e floribus \& foliis plantarum. 
32. CRIOCERIS. Geoff. Chryfomela Linn. Galeruca Geoff.

Os maxillis palpisque.

Pulpi quatuor, breues, aequales, fubfiliformes.

anteriores quadriarticulati: articulo vltimo parum maiori, craffiori apice acuminato adhaerentes maxillae bafi. pofteriores triarticulati, breues: articulis fubaequalibus, vltimo acuminato labii medio inferti.

Mandibula cornea, arcuata, acuta, inermis.

Maxilla porrecta, recta, obtufa, bifida: laciniis aequalibus longitudine palporum anteriorum.

Labium breuiffimum; membranaceum, gibbum, apice rotundatum, integrum. Antennac filiformes, articulis vndecim, obconicis, apice aequalibus; fecundo maiori.

Larua hexapoda; nuda, mollis, punctís eleuatis fcabra.

Puppa quief́cens, ouata, gibba, fcabra. Victus \& Jaruae \& imaginis e foliis plantarum.

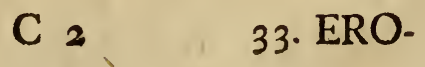


33. EROTYLVS. Chryfomela Linn.

Os maxillis palpisque.

Palpi quatuor, inaequales.

anteriores longiores, fecuriformes, quadriarticulati: articulo tertio breuiffimo, vltimo craffori, oblique truncato adhaerentes maxillae dorfo.

pofteriores breuiffimi, fubclauati, triarticulati: articulo fecundo breuiffimo, vltimo parum craffiori, truncato inferti labii medio laterali.

Mandibula cornea, concaua, acuta, edentula.

Maxilla cornea, bifida : lacinia éxteriore maiore, clauata, concaua, rotundata.

Labium breue, corneum, bafi cylindricum, apice dilatatum, truncatum, fube. . marginatum.

Antennae filiformes: articulis vndecim, fubaequalibus.

Metamorphofis \& Victus \& laruae \& imaginis incognita. 
34. LA GRIA. Chryfomela Linn. Meloe Linn.

Os maxillis palpisque.

- Aulpi quatuor, inaequales.

antcriores multo longiores, fecuriformes, quadriarticulati : articulis aequalibus, vltimo dilatato, acuminato adhaerentes maxillae dorfo.

poficriares breuifimi, extrorfum craffiores, triarticulati : articulo vltimo craffiori, truncato labii medio inferti.

Mandibula cornea, breuis, arcuata, vnidentata.

Maxilla cylindrica, membranacea, bifida: laciniis inaequalibus; exteriore maiore rotundata.

Labium breue, rotundatum, membrana. ceum, integrum.

Antennae filiformes: articulis vndecim obconicis ; primo clauato, longiori, fecundo breviffimo, globofo, vltimo ouato, obtufo.

Metamorphofis ignota.

Victus laruae ignotus, imaginis e foliis arborum.

$$
\mathrm{C}_{3} \quad 35 . \mathrm{ZY} \text { - }
$$




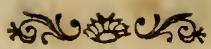

\section{Z Y GIA.}

Os maxillis palpisque.

Palpi quatuor, inaequales, filiformes.

anteriores longiores, quadriarticulati: articulo vltimo longiori, fetaceo adhaerentes maxillae dorfo.

poftcriores breuiores, triarticulati : articulo primo breuiffimo, reliquis cy. lindricis labii medio anteriori inferti.

Mandibula cornea, arcuata, acuta, integra.

Maxilla recta, membranacea, compreffa: bafi dente ouato, breui apice ouata rotundata.

Labium valde elongatum, membranaceum, cylindricum, ad infertionem palporum parum coarctatum, apice truncatum, vix emarginatum.

Antenuae moniliformes, extrorfum craffiores: articulis fubaequalibus primo paullo ${ }_{3}$ craffiori, reliquorumque apicibus prominulis.

Metamorphofis \& Victus \& laruae \& imaginis omnino ignota. 


\section{अन \\ 36. ZONITIS.}

Os maxillis palpisque.

Palpi quatuor, inaequales, filiformes.

anteriores longiores, quadriarticulati: articulo fecundo longiffimo, vltimo obtufo adhaerentes maxillae dorfo.

pofteriores breuiores, triarticulati: articu. lo fecundo longiffimo labii medio anteriori inferti.

Mandibula cornea, arcuata, compreffa, acuta, inermis.

Maxilla porrecta longitudine dupla palporum anteriorum, fetacea, fubmembranacea, ciliata, integra.

Labium porrectum, membranaceum, cylindricum, apice villofum, emargi. natum.

Antennae fetaceae, elongatae : articulis cylindricis, fubaequalibus.

Metamorphofis \& Victus \& laruae \& ima. ginis latent.

$\mathrm{C}_{4}$ 37. APA- 
40

\section{*ลง}

\section{APALVS. Meloe Linn.}

Os maxillis palpisque.

Palpi quacuor, aequales, filiformes.

anteriores quadriarticulati : articulis fubaequalibus adhaerentes maxillae dorfo.

pofferiores triarticulati: articulis longio. ribus, obconicis labii medio inferti.

Mandibula cornea, arcuata, acuta, inermis.

Maxilla cornea, recta, fubcylindrica ad infertionem palporum vnidentata, apice obtufa, rotundata.

Labium porrectum, fubmembranaceum, cylindricum, apice truncatum, obtufum, integrum.

Antennac filiformes: articulis vndecim, obconicis, fubaequalibus; vltimo otrato, obtufo.

Metamorphofis \& ViEtus \& laruae \& imaginis adhuc latent. 


\section{CVRCVLIO. Linn. Geoff.}

Os roitro elongato, corneo maxillis palpisque. Palpi quatuor, breuiffimi, aequales, filiformes.

anteriores quadriarticulati: articulis acqualibus, breuiffimis; vltimo acuto adhaerentes maxillae dorfo incum. bentes.

pofferiores triarticulati labii apice inftdentes.

Mandibula breuis, cornea, arcuata, acuta, inermis.

Maxilla breuis, cylindrica, bafi vnidentata, apice acuta longitudine palporum.

Labium porrectum, cylindricum, apice rotundatum, membranaceum, integerrimum.

Antcrnac infidentes roftro corneo plerum. que clauatae.

Larua hexapoda, mollis, annulata, albida capite pedibusque callofis.

Puppa immobilis.

Victus laruae e feminibus, difco \& folits plantarum, imaginis e foliis.

Obf. Antennae differunt \& forfitan meliores darent fpecierum fubdinifiones, quas vero nondum affequi valui.

a. Antennae clauatae : articulis aequalibus.

b. Antennae clatatae: articulo primo longiffimo.

c. Antennae moniliformes.

$$
\text { C } 5 \text { 39. AT. }
$$


39. A T TELABVS. Linn. Rhinomacer Geoff.

Os roftro elongato corneo maxillas palpos. que continente.

Palpi quatuor, inaequales, filiformes.

antcriores longiores, quadriarticulati: articulis aequalibus, rotundatis adhae. rentes maxillae dorfo.

poferiores breuiores, triarticulati : articu. lis rotundatis, aequalibus labii parieti interiori inferti.

Mandibula cornea, arcuata, acuta, fubinermis.

Maxilla porrecta, cylindrica, membranacea, bifida: laciniis aequalibus, acutis.

Labium breue, latum, corneum, truncatum, crenatum palpos inferiores totos tegens.

antennac moniliformes: articulo primo longiori, clauato, reliquis aequalibus breuiffimis, vltimo clauato, obtufo, ouato.

Larua hexapoda, mollis, annulata.

Puppa immobilis, ouata, laeuis.

Victus \& laruae \& imaginis e foliis plantarum.

40. CLE. 
40. CLER V S. Geoff. Attelabus Linn.

Os maxillis palpisque.

Palpi quatuor, aequales.

anteriores breuiores, filiformes, quadriarticulati: articulo vltimo obconico adhaerentes maxillae dorfo.

pofteriores longiores, clauati : claua dilatata, fecuriformi, articulis reliquis aequalibus labii medio inferti.

Mandibula cornea, arcuata, acuta, edentula. Maxilla cornea, recta ad infertionem palporum vnidentata apice rotundata.

Labium elongatum, membranaceum ad infertionem palporum coarctatum, apice dilatatum, emarginatum.

antennae moniliformes: articulo primo craffiori, longiori, reliquis moniliformibus, vltimis tribus annulatis, craf. fioribus.

- Larua hexapoda, mollis, annulata.

Puppa folliculata, quiefcens.

Victus laruae e rapina laruarum, imaginis e floribus praefertim vmbellatis. 
41. NOTOXVS. Geof. Attelabus I.inn. Meloe Linn. Clerus Geoff.

Os maxillis palpisque.

Palpi quatuor, inaequales, clauati: claua fecuriformi.

anteriores longiores, quadriarticulati : articulo vltimo fecuriformi, reliquis aequalibus adhaerentes maxillae.

pofteriores triarticulati: articulo vltimo, fecuriformi labii bafi exteriori inferti.

Mandibula cornea, arcuata, acuta, edentula. Maxilla recta, cylindrica, in medio vnidentata, apice rotundata, integra.

Labium elongatum, cylindricum, membranaceum, re ftum, apice bifidum: laciniis aequalibus, conniuentibus, obtufis.

Antenna filiformes: articulis fubcylindricis, aequalibus; exterioribus tribus breuioribus fubrotundis, vltimo ouato.

Metamorphofis ignota.

Victus laruae ignotus, imaginis e floribus plantarum vmbellatarum. 
42. SPONDYLIS. Attelabus

Linn.

Os maxillis palpisque.

Palpi quatuor, aequales, fubfiliformes.

anteriores filiformes, quinque articulati: articulis aequalibus adhaerentes maxillae dorfo.

poferiores fubclauati, triarticulati : articulis aequalibus, vltimo fubcraftiori la. bii bafi cxteriori inferti.

Mandibula porrecta, exferta, forcipata, cornea, acura denticulata.

Maxilla breuis, craffa, conica, acuta, recta, pilofa, integra.

Labium porrećtum, corneum, bifidum: laciniis aequalibus, diftantibus, obtufis cum mucrone, vel potius cordato emarginatum cum mucrone.

Antennae moniliformes: articulis fubaequalibus apice obtufiffimis \& fere truncatis.

Metamorphofis ignota.

Viftus laruae ignotus, imaginis e fungis arborum. 
43. PRIONUS. Geoff. Cerambyx Linn.

Os maxillis palpisque.

Palpi quatuor, fubaequales, filiformes. anteriores paullo longiores, quadriarticulati : articulo fecundo longiffimo, vltimo truncato adhaerentes maxillae dorfo.

pofferiores triarticulati : articulo fecundo longiffimo, vltimo truncato fublabii apice inferti.

Mandibula porrecta, cornea, exferta, arcuata, acuta, apice dentata.

Maxilla breuis, cornea, cylindrica, fub. incraffata, obtufa, integerrima, extrorfum ciliata.

Labium breuifimum, membranaceum, rotundatum, integrum.

Antennae elongatae, fetaceae: articulo fecundo breuiffimo, reliquis fubaequalibus, obconicis apice prominulis.

Laru hexapoda, mollis, annulata.

Puppa immobilis.

Victus \& laruae \& imaginis e ligno putrefcente. 44. CE- 
44. CERA MBYX. Linn. Geoff.

Os maxillis palpisque.

Palpi quatuor, aequales, filiformes.

anteriores quadriarticulati : articulis breuibus, vltimo longiori, fetaceo adhaerentes maxillae dorfo.

poffcriores triarticulati: articulis inaequa. libus labii medio exteriori inferti.

Mandibula exferta, cornea, arcuata, acuta, edentula.

Maxilla porrecta, membranacea, fubarcuata, bafi vnidentata, apice rotunda. ta, obtufa, integra.

Labium porrectum, membranaceum, vsque ad infertionem palporum bifidum: laciniis aequalibus, rotundatis.

Antennac elongatae, fetaceae : articulis vndecim cylindricis.

Larua hexapoda, mollis, annulata capite pedibusque callofis.

Puppa intra globum quiefcens, pone acuminata.

Victus \& laruae \& imaginis e ligno pu. trefcente, acidulo. 
48

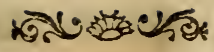

\section{L A M IA. Cerambyx Linn. Cerambyx Geoff.}

Os maxillis palpisque.

Palpi quatuor, fubaequales, filiformes.

anteriores paullo longiores, quadriarticulati, articulo vltimo fetaceo adhae. rentes maxillae.

poffcriores triarticulati, articulis aequali. bus, vltimo fetaceo labii bafi interiori inferti.

Mandibula cornea, fornicata, acuta, edentula.

Maxilla breuis, cornea, recta, bifida: laciniis inaequalibus; exteriore longiore, tenuiore, acuta, interiori cralliori, obtufa.

Antennac elongatae, fetaceae: articulis cylindricis; primo parum crafliori; vl. timo fubacuto.

Metamorphofis ignota.

Victus \& laruae \& imaginis e ligno arbo. rum putrefcente, acidulo. 


\section{STENOCORUS. Geoff:}

\section{Cerambyx Linn.}

Os maxillis palpisque quatuor.

Palpi quatuor, inaequales.

anteriores longiores, fubfiliformes, quà. driarticulati: articulo fecundo quartoque longioribus maxillae adhae: rentes.

pofteriores clauati, triarticulati: articulo vltimo claua obtufa, truncata labii bafi exteriori inferti.

Mandibula exferta, cornea, arcuata; acuta, edentula.

Maxilla recta, porrecta, cylindricà inme. dio vnidentata, apice obrufa, rorun. data.

Labium membranaceum, elongatum faepe longitudine fere palporum pofteriorum, rotundarum, bifidum: laciniis ae' qualibus, diftantibus, rotundatis; inte. gris.

Antennac elongatae, fetaceae, articulis cy: lindricis, fubaequalibus; primo incraf: fato.

Metamorphofis ignota.

Victus laruae ignotus, imaginis e floribtis plantarum. 


\section{CALOPVS. Cerambyx. Linn.}

Os maxillis palpisque.

Palpi quatuor, inaequales.

anteriores longiores, clauati, quadriarticulati : articulo fecundo longiori, vltimo craffiori, truncato adhaerentes maxillae.

pofferiores filiformes, triarticulati: articulis aequalibus labii bafi exteriori inferti.

Mandibula breuis, cornea, arcuata, acuta, inermis.

Maxilla porrecta, fubarcuata, bifida: laciniis obtufis; exteriore fublongiore, tenuiore.

Labium porrectum, membranaceum, ad medium bifidum: laciniis aequalibus, rotundatis, diftantibus.

Antennae filiformes: articulis compreffis apice altero latere prominulis; primo cralfiori, clauato.

Metamorphofis adhuc omnino latet.

Victus \& laruae \& imaginis ignotus. 


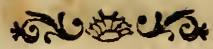

48. RHAGIVM. Cerambyx. Linn. Stenocorus Geoff.

$O s$ maxillis palpisque.

Palpi quatuor, inaequales, capitati.

anterioves longiores, quadriarticulati: articulis aequalibus, vltimo capitato, truncaro adhaerentes'maxillae.

pofteriores triarticulati : articulo vltimo clauato, truncato labii bafi inferti.

Mandibula breuis, cornea, arcuata, acuta, inermis.

Maxilla membranacea; obtufa, adinfertionem palporum vnidentata.

Labium breue, membranaceum, bifidum: laciniis aequalibus, diftantibus, rotunt: datis.

Antennae elongatae, fetaceae: arriculis cylindricis; primo craffiori clauato, vltimo fetaceo.

Larua hexapoda, annulata, fubpilofa.

Puppa intra globum quiefcens.

ViEtus \& laruae \& imaginis e truncis arbo. rum putrefcentibus.

$\mathrm{D} \approx$ 49. SA. 


\section{भกसบ}

49. SAPERDA. Cerambyx Linn. Leprura Geoff.

Os maxillis palpisque.

Palpi quatuor, fubaequales, filiformes.

anteriores quadriarticulati : articulis rotundatis; fecundo quartoque longioribus adhaerentes maxillae.

pofteriores triarticulati: articulis fubaequalibus, labii medio exteriori inferti.

Mandibulu arcuata, cornea, acuta, edentula.

Maxilla membranacea, cylindrica, bifida : laciniis inaequalibus; exteriore paullo breuiore craftiore.

Labium membranaceum, adinfertionem palporum paullo coarctatum, ápice rotundatum, dilatatum, truncatum.

Antennae elongatae, fetaceae: articulis cylindricis; primo clauato, craffiore.

Mctamorphofis ignota.

Victus laruae e trunco putrefcente arborum, imaginis e foliis. 


\section{सत्रुप}

50. CALLIDIVM. Cerambyx. Linn. Leprura Linn. Geoff.

Os maxillis palpisque.

Palpi quatwor, aequales, clauati: artiçulo vlrimo cralfiori, truncato.

anteriores quadriarticulati: articulis fubmoniliformibus adhaerentes maxillae dorfo.

pofteriores triarticulati: articulis vltimo excepto aequalibus, labii bafi exteriori inferti.

Mandibula breuis, cornea, arcuata, acuta, fubdenticulata.

Maxilla cylindrica, membranacea, recta, apice outata, acuta, bifida : laciniis oblique truncatis, fubaequalibus; exteriore paullo maiore.

Labium porrectum, membranaceum, bifidum : laciniis aequalibus, tenuiflimis, acutis, diftantibus.

Antennac elongatae, fetaceae: articulis cylindricis, fubaequalibus; primo craffio. re clauato.

Metamorplogis ignota.

Victus laruae e trunco arborum putrefcente, imaginis e foliis plantarum.

$$
\mathrm{D}_{3} 5 \text { I. DO. }
$$


54

\section{सक्षण}

51. DONACIA. Leptura Linn. Stenocorus Geoff.

Os maxillis palpisque.

Palpi quatuor, aequales, filiformes.

anteriores quadriarticulati : articulis aequalibus adhaerentes maxillae dorfo.

pofferiores triarticulati : articulis aequalibus labii medio laterali inferti.

Mandibula breuis, fornicata, cornea, den. tata, apice fiffa.

Maxilla cylindrica, recta, inmedio vnidentata.

Labium elongatum, membranaceum, cylindricum, apice truncatum, integrum.

Antennae porrectae, fetaceae: articulis cylindricis, fubaequalibus; primo craffiore, fecundo breuiffimo.

Mctamorphofis ignota, larua forfitan aquatica.

Victus laruae ignotus, imaginis e foliis plantarum. 
52. LEPTVRA. Linn. Stenocorus Geoff. Necydalis Linn.

Os maxillis palpisque.

Palpi quatuor, inaequales, filiformes.

anteriores quadriarticulati: articulis aequalibus; vltimo truncato adhaerentes maxillae dorfo.

pofteriores triarticulati : articulis aequa. libus labii bafi inferti.

Mandibula cornea, fubarcuata, acuta, edentula.

Maxilla recta, cylindrica, membranacea, inmedio vnidentata, apice fetofa.

Labium elongatum, membranaceum, fubcylindricum, porrectum, bifidum: laciniis aequalibus, diftantibus, rotundatis.

Antcunac elongatae, fetaceae: articulis cylindricis, aequalibus; primo craf. fiore, clauato.

Metamorpbofis ignota.

Viffus laruae forte e ligno putrefcente, imaginis e foliis plantarum.

Obf. Leptura $\mathbf{8} 8-2 \mathbf{r}$. elytris abbreuiatis differunt, attamen certe huius generis.

$$
\mathrm{D}_{4} 53 . \mathrm{LAM} \text { - }
$$


56

\section{มลบ}

53. LAMPYRIS. Linn. Geoff,

Os maxillis palpisque.

Palpi quatuor, inaequales.

antcriores longiores, fubclauati, quądriarticulati : articulo vltimo crafficri, fubulato, acuto adhaerentes maxillae dorfo.

pofferiores fubclauati, triarticulati: articulo vltimo, craffiori, fubulato, acuto, labii apici inferti.

Mandibrsla cornea, arcuata, tenuifima, acuta, edentula.

Maxilla breuis, membranacea, cylindrica, bifida: laciniis inaequalibus; exteriore maiore, rotundata.

Labium breue, coineum, cylindricum, gibbum, integerrimum,

Anten?ate filiformes: articulis aequalibus, obconicis; vitimo cylindrico.

Metamorpiofis haud rite cognita.

ViEtus \& laruae \& imaginis adhuc latent.

Obf. I. Antennae interdum articulis breuio. ribus fere moniliformibus, interdum ferratis aut pectinatis.

Obf,II. Faemina in omnibus fpeciebus aptera. 
54. PYROCHROA. Geoff. Lampyris Linn. Geoff.

Os maxillis palpisque.

Palpi quatuor, inaequales, fubfiliformes. anteriorcs paullo longiores, quadriarticulati : articulis aequalibus; vltimo flexo fubcraffiori, adhaerentes maxillae dorfo.

pofteriores bafi coeuntes, triarticulati : articulis aequalibus, labii apici inferti.

Mandibula breuis, cornea, arcuata, acuta, edentula.

Maxilla membranacea, fubcylindrica, in tegra, pilofa, apice acuta.

Labium porrectum, corneum, lineare, integerrimum, bafi compreffum.

Antennac filiformes, articulis breuibus apice interiori porrectis, acuminatis; primo longiori crafliori.

Metamorpisofis mihi later.

Victus \& laruae \& imaginis omnino latet.

Dif. Pyrocbroa 5 - 8. habitu a reliquis differunt \& forte nouum genus ore porrefto, cylindrico conftitune mihi haud pire examiriatae.

D 5

$55 \cdot L Y$. 
55. LYMEXYLON. Cantharis Linn.

Os maxillis palpisque.

Palpi quatuor, inaequales, extrorfum craffiores.

anteriores longiores, exferti, dependentes, fenfim craffiores, quadriarticulati : articulo vltimo longiore cylindrico adhaerentes maxiliae dorfo.

pofteriores breues, triarticulati, obtufiffimi labii medio laterali inferti.

Mandibula breuis, cornea, fubrecta, inermis.

Maxilla breuiffima, membranacea, cralfa, bifida: laciniis inaequalibus; exteriore paullo longiore, rotundata.

- Labium porrectum, membranaceum, lineare, tenuiffimum, apice rotundatum, concauum, fubemarginatum.

Antennac breues, incuruae, moniliformes: articulis breuibus; apicibus vtrinque prominulis.

Metamorphofis latet.

Victus \& laruae \& imaginis e ligno recenti. 


\section{+⿵人一 \\ 56. CVCVIVS.}

Os maxillis palpisque.

Palpi quatuor, breues, aequales.

anteriores triarticulati: articulo primo obconico, fecundo tertioque bre. uioribus, obtufis, truncatis adhaerentes maxillae dorfo.

pofteriores biarticulati: articulo primo obconico, vltimo craffiori, obtufo, truncato labii bafi anteriori inferti.

Mandibula cornea, arcuata, bafi incraffa. ta, apice acuminata, edentula.

Maxilla breuis, membranacea, bifida: la. ciniis inaequalibus; exteriore maiore, rotundata, interiore acuta.

Labium breue, membranaceum, bifidum: laciniis linearibus, obtufis, diftantibus, palpis pofterioribus tectis.

Antennae moniliformes: articulis vndecim, breuibus, pilofis; vltimo acuto.

Metamorpbofis \& Victus omnino adhuc latent.

Obf. Palatum vtrinque unidentatum. 
57. CANTHARIS. Linn. Cicindela Geoff. Necydalis Geoff.

Os maxillis palpisque.

Palpi quatuor, inacquales, fecuriformes.

anteriores longiores, quadriarticulati: articulis aẹqualibus; vltimo claua dila. tata, acuminata adhaerentes maxillae.

Pofteriores triarticulati: articulis aequalibus; vltimo claua dilatata, acuminata labii apici inferti.

Mandibula porrecta, exferta, cornea; arcuata, acuitifima, edentula.

Maxilla breuis, cylindrica, oblique truncata, bifida: laciniis aequalibus, fliformibus, obtufis.

Labium breue, membranaceum, cylindricum, truncatum, integerrimum.

Antennac filiformes: articulis cylindricis, aequalibus; fecundo breuifimo.

Metamorphofis ignota.

Victus laruae latet, imaginis e rapina alio- rum infectorum. 
58. MAL A CHIV S. Cantharis Linn.

\section{Cicindela Geoff.}

os maxillis palpisque.

Palpi quatuor, inaequales, filiformes.

anteriores paullo longiores, quadriarticulati : articulis aequalibus; vltimo feraceo adhaerentes maxillae dorfo.

pefteriores triarticulati : articulis aequalibus; vltimo fetaceo labii medio inferti.

Mandibula cornea, arcuata, acuta, integra, edentula.

Maxilla cylindrica, fubincurua, obtufa, membranacea, in medio acute dentata.

Lalium porrectum, cylindricum, mem. branaceum, apice rotundatum, integrum.

Antennae filiformes: articulis aequalibus, cylindricis; primo fubcraffiori, vltimo ouato.

Metamorpbofis ignota.

Victus laruae later, imaginis e rapina infectorum.

Obf. ad bafin abdominis \& thoracis vtrinque tentacula duo exferta bafi connata gerunt. 
59. NECY DALIS. Linn. Cantharis

Linn. Geoff. Cicindela Geoff.

Leptura Geoff.

Os maxillis palpisque.

$P$ alpi quatuor, inaequales, fubfiliformes.

anteriores quadriarticulati: articulis ae. qualibus; vltimo fubcraffiori adhaerentes maxillae dorfo.

pofteriores triarticulati: articulis aequalibus; vltimo fubcraffiori, truncato labii medio inferti.

Mandibula cornea, arcuata, acuta, edentula. Maxilla porrecta, cylindrica, membranacea, ad infertionem palporum vniden. tata, acutiufcula.

Labium porrectum, membranaceum, cylindricum, ad infertionem palporum coarctatum, apice late emarginatum.

Antenna filiformes: articulis aequalibus, cylindricis; primo cralfiori.

Metamorplogis \& Victus adhuc omnino la. tent. 
60. ELATER. Linn. Geoff.

Os maxillis palpisque.

Palpi quatuor, inaequales, fecuriformes.

anteriores quadriarticulati: articulis fub. aequalibus; vlrimo claua dilatata,acu. minata adhaerentes maxillae dorfo.

pofteriores breuiores, triarticulati : articulis aequalibus; vltimo claua dilatata, acurs labii medio inferti.

Mundibula cornea, arcuata, inermis, apice fiffa.

Maxilla cylindrica, membranacea, in medio vnidentata, apice obtufa, fetofa.

Labium porręum, membranaceum, apice fubdilatatum, bifidum, laciniis aequalibus, truncatis.

Antennue filiformes: articulis breuibus, fae. pius ferratis; primo crafliori.

Metamorphofis \& Victus omnino adhuc la. tent. 
6i. PVPRES TIS. Linn. Cucujus Geoff.

Os maxillis palpisque.

$P_{a l p i}$ quatuor, inaequales, filiformes arti. culo vltimo obtufo truncato.

anieviores longiores, quadriarticulati: articulis fubaequalibus adhaerentes ma. xillae dorfo.

pofferiores triarticulati, labii apici laterali inferti.

Mandibula breuis, cornea, arcuata, acil. ta, edentula.

Maxilla breuis, cylindrica, membraria. cea, medio vnidentata, apice rotunda. ta, obtufiffima.

Labiwm porrectum, membranaceum, cylindricum, inter palpos pofteriores acuminatum, integrum.

Antennac breues, filiformes, ferratae: articulis aequalibus, primo craffiori, vliimo outo, obtufo.

Metamorphofis \& Viclus \& laruae \& imag:nis latent. 
62. CICINDELA. Linn. Bupreftis. Geoff.

Os mexillis palpisque.

Palpi fex fubaequales, filiformes.

anteriores paullo breuiores, biarticulati : articulis aequalibus, longiffimis adhaerentes maxillae dorfo.

medii quadriarticulati : articulo primo tertioque breviffimis adnati anteriorum baí.

poferiores multiarticulati articulis breuiffimis, rotundatis, pilofis, vltimo longiori, obconico, nudo labii me. dio interiori inferti.

Mandibula elongata, exferta, cornea, arcuata, acuta, multidentata.

Maxilla recta, cornea, rigida, ciliata, apice incurua, acuta.

Labium breue, corneum, apice tridenta. tum, dentibus elongatis, rigidis, acutis.

Antcnuac elongatae, fetaceae: articulis cylindricis fubaequalibus excepto fecundo breuiffimo.

Metamorphofis latet.

Victus laruae ignotus, imaginis e rapina laruarum. 
63. ELA PHR VS. Cicindela. Linn. Bupreftis Geoff.

Os maxillis palpisque.

Palpi fex fubaequales, filiformes.

antcriores paullo breuiores, biarticulati: articulis aegualibus maxillae dorfo incumbentes.

medii longiores, quadriarticulati : articulo primo tertiogue breuiffimis anteriorum bafi adnati.

poferiores triarticulati : articulis aequalibus labii bafi laterali inferti.

Moindibula breuis, craffa, cornea, acuta in medio vnidentata.

Muxilla cornea, arcuata, intus ciliata, acuta, integra.

Labium breue, membranaceum, cylindricum, apice acuminatum.

Antcnnae fubfetaceae: articulis breuibus, aequalibus, fubcylindricis primo craffiori.

Mctumorphofis latet.

Victus laruae ignotus, imaginis e rapina infectorum.

06\%. Differt manifefte a Cicindelis ipfa anten. narum itructura omnino alia. 
64: HYDRO PHILVS. Geoff. Dytifcus Linn.

os maxillis palpisque.

Palpi quatuor, inaequales, filiformes.

anteriores longiores, quadriarticulati: articulo primo breuifimo adhaerentes maxillae dorfo.

pofferiores triarticulati: articulis aequalibus labii apici inferti.

Mandibula cornea, arcuata, inermis, acu. minata.

Maxilla breuis, nembranacea, bifida: la. ciniis inaequalibus; exteriore maiore rotundata.

Labium elongatum, corneum, rotundatum, fubemarginatum.

Antenniae breues, perfoliatae: articulo primo craffiori longiori, fequentibus breuiffrmis vix diftinctis, penultimis duobus craffioribus perfoliatis latere interiori acuminatis, vltimo ouato obrufo.

Larua hexapod:, natatoriis vtrinque feptem, cauda biappendiculata.

Puppa quiefcens, ouata, pilora, cauda fermilunari.

Victus \& laruae \& imaginis e rapina pifcium, infectorum.

$$
E_{2} \text { 6g. DY. }
$$


68

65. DYTISCVS. Linn. Geoff:

Os maxillis palpisque.

Palpi fex inaequales, filiformes.

anteriores breuiores, biarticulati : articu: lis aequalibus, vltimo acuto maxillae dorfo incumbentes.

medii longiores, quadriarticulati: articu: lis aequalibus bafi anteriorum adhaerentes.

pofteriores triarticulati, labii medio in. ferti.

Mandibula exierta, cornea, arcuata, acuta, edentula.

Maxilla cornea, ciliata, integra, acutiffima.

Labium elongatum, corneum, latum, truncatum, integerrimum.

Antennae porrectae, fetaceae: articulis fubaequalibus, cylindricis, vltimis tenuioribus.

Larus hexapoda, vltimo abdominis articulo conico faepius bicaudato maxillis porrectis, arcuatis, inermibus.

Puppa quiefcens, mollis, ouata intra glebam.

Victus \& laruae \& imaginis e rapina infectorum, laruarum pifciumque. 


\section{66. GYRIN VS. Linn. Geoff.}

Os maxillis palpisque.

Palpi quatuor, aequales, filiformes.

anteriores vix longiores, quadriarticu. lati : articulis breuibus rotundatis, vltimis duobus fubcraflioribus adhaerentes maxillae bafi.

poferiores cylindrici, triarticulati : articulis aequalibus labii medio interiori inferti.

Mundibula cornea, craffa, arcuata, apice bidentata.

Maxilla porrecta, cornea, arcuata medio vnidentata, apice acutiffima.

Labium porrectum, corneum, røtundatum profunde emarginatum: laciniis rotundatis.

Antenna breuiffimae, cylindricae, filiformes, rigidae: articulis breuiffimis vix diftinctis.

Larua hexapoda, filiformis: natatoriis $\mathrm{v}$ trinque nouem, cauda quadrifida.

Puppa ignota.

Viftus \& laruae \& imaginis e rapina reliquorum infećtorum.

$$
\mathrm{E}_{3} \quad 67 . \mathrm{CA} \text {. }
$$


67. CARA B VS. Linn. Bupreltis Geoff. $O$ s maxillis palpisque.

Palpi fex, inaequales: articulo vltimo obrufo, truncato.

anteriores breuiores, filiformes, biarticulali, obtufi, truncati adhaerentes ma. xillae dorfo.

medii longiores, quadriarticulati : articulo primo breuiftimo, reliquis obconicis bafi anteriorum adnati.

poferiores triarticulati, bafi connati: articulo primo breuiffimo, fecundo cy. lindrico longiori, tertio obconico fub labii apice inferti.

Mandibula cornea, arcuata, acuta, integra. Maxilla integerrima, cornea, cylindrica, intus ciliata apice arcuata, acutiffima.

Labium porrectum, membranaceum, cylindricum, truncatum, integerrimum. Antennae filiformes: articulis elongatis, aequalibus, obconicis vltimo cylindri. co obtufo.

Larua hexapoda, depreffa, coriacea, maxillis exfertis, arcuatis.

Puppa ignota.

Victus laruae e quisquiliis, ligno putre. fcente, imaginis e rapina reliquorum infectorum, in primis laruarum.

Obf. I. In Carabis maioribus palatum elongatum tridentatum, labium tegens. D6f: II. C. fpinibarbis mandibula bafi dilatata, maxillaeque dorfo fpinis ciliato. 68 . 
68. SCARITES. Tenebrio. Linn.

Os maxillis palpisque.

Palpi fex, fubaequales, filiformes.

anteriores breuiores, biarticulati: articulis aequalibus, cylindricis adhaerentes maxillae dorfo.

medii longiores, triarticulati: articulo lon. giori, fetaceo, acuto bafi anteriorum adnati.

pofferiores triarticulati: articulis aequalibus labii medio laterali inferti.

Manáibula cornea, arcuata valida, acuta, intus dentata.

Maxilla cornea, arcuata, intus ciliata, acu. minata.

Labium corneum, porrectum, cylindricum, apice tridentatum, dentibus aequalibus acutis.

Antennas moniliformes, articulo primo longiori fecundoque obconicis, reliquis breuioribus orbicularis.

Metamerphofis \& vißtus \& laruae \& imaginis omnino adhuc latent.

Obf. S. clauicornis antennas extrorfum craffiores habet, actamen huius generis.

$$
\text { E } 4 \text { 69. SE. }
$$




\section{SEPIDIVM.}

Os maxillis palpisque.

- Palpi quatuor, inaequales, filiformes.

anteriores longiores, quadriarticulati: articulis cylindricis, fecundo longiori, vltimo obtufo adhaerentes maxillae dorfo.

pofteriores breuiores, triarticulati : articulis aequalibus, labii bafi laterali inferti.

Mandibula breuis, cornea, valida, arcuata, apice fiffa.

Maxilla breuis, cylindrica, membranacea, apice obtufa, rotundata, ciliata, medio vnidentata.

Labium breue, corneum, cylindricum, latum vsque adbafin fere emarg!natum.

Antennac filiformes: articulo fecundo longiori, reliquis breuibus cylindricis, vltimo ouato, acuto.

Metamorphofis \& victus \& laruae \& imaginis omnino adhuc latent.

Obf. Genus Pimeliis affine, at habitu \& charactere omnino diftinctum. 


\section{PIMELIA. Tenebrio Linn. Geoff.}

Os maxillis palpisque.

Palpi quatuor, inaequales, filiformes.

anteriores multo longiores, quadriarticulati : articulo fecundo longiori, vltimo fubglobofo, obtufo adhaeren. tes maxillae dorfo.

pofferiores breuiores, triarticulati: articulis aequalibus labii bafi laterali inferti.

Mandibula magna, cornea, gibba, crafra, compreffa, denticulata.

Maxilla cylindrica, membranacea, me. dio vnidentata apice obtufa, rotundata.

Labium porrectum, corneum, rotundatum, apice truncatum, fubemargina. tum, pilofum.

Antennae filiformes, apice moniliformes: articulo fecundo longiffimo, vltimis quatuor breuioribus, moniliformibus. Metamorphofis \& Victus omnino adhuc la. rent. 


\section{7r. SCAVRVS.}

Os maxillis palpisque.

Palpi quatuor inaequales, filiformes.

anteriores longiores, quadriarticulati : articulis cylindricis, fecundo longiori adhaerentes maxillae dorfo.

pofteriores breuiores, triarticulati: articulis cylindricis, breuiffimis labii bafi laterali inferti.

Mandibula breuis, cornea, arcuata, acu. ta, inermis.

Maxilla recta, membranacea, medio vnịdentata, apice dilatata, rotundata.

Labium corneum, rotundatum, latum, truncatum, integerrimum.

Antennac moniliformes: articulis inferiori. bus longioribus (inprimis fecundo) obconicis, reliquis aequalibus, breuibus, moniliformibus.

Mctamorphojis \& Victus \& laruac \& imaginis omnino adhuc latent. 
72 BLAPS. Tenebrio Linn. Geoff.

Os maxillis palpisque.

Palpi quatuor, inaequales, clauati: claua truncata, obtufa.

anteriores longiores, quadriarticulati: articulo fecundo longiori, tertio orbiculato adhaerentes maxillae dorfo.

pofferiores triarticulati: articulis aequalibus labii bafi laterali inferti.

Mandibula cornea, arcuata, integra, acuta. Maxilla recta, porrecta, bifida: laciniis inaequalibus; exteriore maiori, obtufa, rotundata.

Labium breue, membranaceum, rotundatum apice fiffum.

Antennue filiformes apice moniliformes: articulo fecundo longiori obconico, vlrimis quatuor orbiculatis moniliformibus.

Metamorphofis \& Victus omnino latent. 
73. TENEBR IO. Linn. Geoff. Platycerus Geoff.

Os maxillis palpisque.

Palpi quatuor, inaequales.

anteriores longiores, quadriarticulati: articulis fubaequalibus, vltimo obtufo, truncato craffiori adhaerentes maxillae dorfo.

pofteriores triarticulati, filiformes: articulis aequalibus labii medio laterali inferti.

Mandibula cornea, arcuata, acuta, insegerrima.

Maxilla recta, cylindrica, membranacea, bifida: laciniis inaequalibus; exteriori maiori obtufa, interiori acuta.

Labium porrectum, coineum, cylindri. cum, medio parum coaretatum apice truncatum, integerrimum.

Antennae moniliformes : articulis fubaequalibus excepto primo longiori obco. nico.

Laiua hexapoda, annulata, mollis, cauda ftylis duobus breuibus, incuruis.

Puppa quiefcens, ouata, pilofa, cauda ftylis duobus, breuibus, filiformibus.

Victus \& laruae \& imaginis e quisquiliis, farina, aliisque. 
74. HEL OPS. Tenebrio Linn. Geoff.

Os maxillis palpisque. .

Palpi quatuor, inaequales.

anteriores porrecti, longiores, fecuriformes, quadriarticulati: articulis aequalibus, vltimo clauato fecuriformi adhaerentes maxillae dorfo.

pofferiores breuiores, clauati : claua capitata, obtufa, triarticulati labii medio laterali inferti.

Mandibula cornea; arcuata, acuta, in medio vnidentata.

Maxilla cylindrica, membranacea, in medio vnidentata, apice rotundata, obtufa.

Labium corneum, breue, rotundatum, in medio gibbum, apice truncatum, in tegrum.

Antennae fubmoniliformes: articulis prioribus obconicis, fecundo longiori, vltimo ouato, obtufo.

Metamorpbofis \& Victus \& laruae \& imagi. nis latent.

Obf. Helops ferratus palpis maioribus, reflexis, ferratis differt, attamen huius generis. 


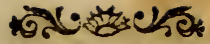

\section{ERODIVS.}

Os maxillis palpisque.

Palpi quatuor, aequales, filiformes.

anteriorcs vix longiores, quadriarticula* ti: articulis aequalibus adhaerentes maxillae dorfo.

pofteriores triarticulati : articulo vltimo globofo fubcraffiori labii bafi laterali inferti.

Mandibula cornea, arcuata, acuta, edentula. Maxilla cornea, recta, rigida, bifida: laciniis aequalibus, truncatis, obtufis, ciliatis.

Labium corneum, rotundatum, truncatum, emarginatum, ciliatum.

Antennae breues, moniliformes: articulis fubaequalibus, fecundo longiori, cylincirico.

Metamorphofis \& Victus \& laruae \& imaginis ignoratur. 
76. MELOE. Linn. Geoff.

Os maxillis palpisque.

Palpi quatuor, iraequales, extrorfum fubcralfiores.

anteriores longiores: articulis aequalibus, vltimo fubcraffiori, obtufo, truncato, adhaerentes maxillae dorfo.

pofteriores quadriarticulati : articulis minoribus, rotundatis labii medio inferti.

Mandibula exferta, cornea, arcuata, acuta, edentula.

Maxilla recta, membranacea, bifida: laciniis fubaequalibus, rotundatis, obtufis; exteriore paullo maiore.

Labium porrectum, corneum ad infertionem palporum coarctatum, apice ro. tundatum, emarginatum.

Antennac moniliformes: articulis breuibus,

fubaequalibus, fecundo paullo longiori, vltimo fetaceo.

Larua hexapoda, filiformis lareribus fubpilofis.

Puppa quiefcens, mollis.

Victus \& laruae \& imaginis e foliis plantarum.

Obf. Antennarum articulus intermedius interdum dimidiatus an Varieras fexus? 


\section{LYTTA. Meloe Linn. Cantharis Geoff,}

Os maxillis palpisque.

Palpi quatuor, inaequales.

anteriores longiores, triarticulati : articulis aequalibus, vltimo fetaceo adhaerentes maxillae dorfo.

pofteriores triarticulati: articulis aequalibus, vltimo obtufo, truncato, clauato labii medio inferti.

Mandibula craffa, cornea, acuta, inermis.

Maxilla recta, porrecta, merrbranacea, apice dilatata, rotundata, bifida: laciniis conniuentibus inaequalibus; exteriore maiore.

Labium elongatum, fubcorneum, cylindricum ad infertionem palporum coarctatum, apice truncatum, integrum.

Antennuc filiformes: articulis aequalibus, fubcylindricis; primo craffiori, fecundo breuiffimo vltimo, feraceo.

Mciamorphofis \& Victus omnino ignotus. 


\section{MYLABRIS. Meloe Linn.}

Os maxillis palpisque.

Palpi quatuor, inaequales, filiformes.

anteriores longiores, quadriarticulati : articulis fubaequalibus adhaerentes maxillae dorfo.

poferiores triarticulati : articulis aequalibus labii medio laterali inferti.

Mandibula craffa, breuis, cornea, acuta, inermis.

Maxilla recta, porrecta, cornea, compreffa, apice oblique truncata, obtufa, bifida: laciniis aequalibus, conniuentibus.

Labium porrectum, membranaceum, cylindricum ad palporum infertionem coarctarum, apice emarginatum.

Antennae moniliformes, extrorfum craffiores: articulis fibaequalibus fecundo breuiori.

Metamorpbofis \& Vidfus omnino latent. 


\section{CER O COMA. Geoff. Meloe Linn.}

Os maxillis palpisque.

Palpi quatuor, aequales, filiformes.

antcriores quadriarticulati: articulis cy. lindricis aequalibus adhaerentes maxillae dorfo.

pofteriores vix breuiores, triarticulati: articulis cylindricis, aequalibus labii medio laterali inferti.

Mandibula cornea, porrecta, arcuata apice acuminata, edentula latere interiori dilatata, membranacea.

Maxilla cylindrica, linearis, membranacea, apice acuminata, fetofa, integerrima.

Labium cylindricum, memb:anaceum, elongatim ad palporum infertionem coarctatum apice bifidum: laciniis aequalibus rotundatis.

Antennae moniliformes: articulis aequalibus, breuibus; vltimo maiori, clauato, compreffo.

obf. In altero fexu tertius palporum anteriorum articulus incraffatus, veficulofus.

$06 \%$ In altero fexu articuli antennarum. 3.4 . s.6. dilatati, foliacei, perfoliati. 


\section{MORDELLA. Linn. Geoff.}

Os maxillis palpisque.

Palpi quatuor, inaequales.

anteriores longiores, porrecti, quadriarticulati: articulis aequalibus; vltimo craffiori adhaerentes maxillae dorfo.

pofteriores breuiores, filiformes, triarticulati: articulis aequalibus labii medio laterali inferti.

Mandibula cornea, arcuata, acuta, inermis. Maxilla membranacea, linearis, bifida: lacinis obtufis, inaequalibus; exteriore maiore.

Labium elongatum, membranaceum, lineare, inier palpos porrectum, dilatatum, rotundatum, bifidumi : laciniis aequalibus, rotundatis.

Antennac fub moniliformes: articulo primo longiori, fecundo breuiffimo glo. bofo, vltimo ouato, acutiufculo. Metomorpbofis ignota.

Victus laruae ignotus, imaginis e floribus plantarum, inprimis vmbellatarum. 
84 सत्र

8r. STAPHYLIN VS. Linn. Geoff.

Os maxillis palpisque.

Palpi quatuor, aequales, filiformes.

anteriores quadriarticulati: articulis ae: qualibus adhaerentes maxillae dorfo. pofteriores vix breuiores, triarticulati: articulis aequalibus labii bafi exteriori inferti.

Mandibula porrecta, exferta, cornea, arcuata, acuta in medio dentibus validis armata.

Maxilla membranacea, recta, cylindrica, in medio obtufe dentata.

Labium membranaceum, fub palpis elongatum, trifidum: laciniis fubaequalibus; intermedia latiore apice rotundata, fubemarginata, lateralibus paullo longioribus, diftantibus, acutis.

Antennae moniliformes: articulis fubaequalibus, breuibus, apice truncatis, vltimo ouato, obtufo.

Mctamorpbojis ignota.

Victus \& laruae \& imaginis e cadaueribus $\&$ rapina animalium. 
82. OXYPORVS. Staphylinus Linn.

Geoff.

Os maxillis palpisque.

Palpi quarnor, fubaequales.

anteriores quadriarticulati: articulis aequalibus, filiformibus adhaerentes maxillae bafi.

poftcriores vix longiores, quadriarticulati: articulis aequalibus; vlrimo clauato, fecuriformi labii bafi laterali inferti.

Mawdibula exferta, cornea, arcuata, acuta, inermis.

Maxilla membranacea, cylindrica, medio vnicientata, apice ouata, obtufa.

Labium elongatum, membranaceum, cylindricum, emarginatum cum mucrane. Antennae moniliformes extrorfum fubcraffiores, articulis fubaequalibus fubpilofis apice truncatis, vitimo ouato, acuto. Larua hexapoda, mollis, laeuis poftice attenuata.

Puppa ignota.

Victus \& laruae \& imaginis e Boletis, Agaricis aliisque fungis.

$$
F_{3} \text { 83. PAE. }
$$


86

\section{W0}

83. PAEDERVS. Staphylinus Linn. Geoff.

Os maxillis palpisque.

Palpi quatuor, inaequales.

axteriores porrecti, multo longiores, capitati, quadriarticulati : articulis aequalibus adhaerentes maxillae dorfo.

pofteriores breues, triarticulati : articulis aequalibus, filiformibus labii apice laterali inferti.

Mandibula cornea, arcuata, acuta, inermis. Maxilla membranacea, cylindrica, fubarcuata, medio vnidentata.

Labium porrectum, membranaceum, cy. lindricum, apice truncatum, obtufum, integrum.

Antennae moniliformes: articulo primo longiori, craffiori, reliquis aequalibus, orbiculatis, vltimo acutiufculo.

Metamorphofis \& victus \& laruac \& imaginis omnino adhuc latent. 


\section{เพื \\ Clajis II. \\ VLO NATA.}

$O$ s maxillis palpisque.

Palpi quatuor, veficulofi, porrecti, filiformes, obtufi: anteriores infidentes maxillae dorfo, pofteriores labio.

Clypeus horizontalis, membranaceus, ro. tundatus, os fuperne tegens.

Mandibulac duae, transuerfales, corneae, mobiles, dentatae, latera oris fuperne includentes.

Maxillac duae, liberae, transuerfales, acutae \& faepius dentatae aut fiffae 12tera oris inferne includentes.

Galea maxillam tegens, cylindrica, inarticulata, veficulofa, obtufa maxillae dorfo inferta.

Labium porrectum, liberum, membrana. ceum, femper apice fiffum.

Antchuac inter oculos infertae. 


\section{GENERA Claffis II.}

84. FORFICVLA.

85. BLATTA.

86. MANTIS.

87. ACRYDIVM.

88. TRVXALIS.

89. ACHETA.

90. LOCVSTA.

91. GKYLLVS. 


\section{FORFICVIA. Linn. Geoff.}

Os maxillis palpisque.

Palpi quatuor, inaequales, filiformes.

anteriores longiores, quadriarticulati: articulo primo, breuiffimo, reliquis aequalibus adhaerentes maxillae dorfo.

pofteriores multo breuiores, triarticulati: articulo primo breuifimo labii bafi inferti.

\section{Mandibula cornea, arcuata, acuta.}

Maxilla cornea, arcuata, acuta, apice fiffa.

Galea maxillam tegens, cylindrica, obtura longitudine maxillae.

Labium elongatum, porrectum, trifidum: laciniis inaequalibus, lateralibus, paul. lo longioribus, tenuioribus, cylindricis, obtufis; intermedia latiori, rotun. data, integra.

Antennac fetaceae: articulo primo longiori, craffiori, reliquis aequalibus, cylindricis.

Larua hexapoda, agilis, imagini fimillima, aptera.

Puppa hexapoda, agilis, imagini fimillima alarum rudimentis.

Victus \& laruae \& imaginis e fructibus plantisque fucculentis.

$$
\text { F5 85.BLAT. }
$$


90

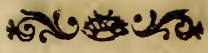

\section{BLATT A. Linn. Geoff.}

Os maxillis palpisque.

Palpi quatuor, inaequales, filiformes.

axteriores longiores, quinquearticulati: articulo primo fecundoque breuiffimis, tertio longillimo adhaerentes maxillae dorfo.

pofteriores triarticulati : articulis aequalibus labii medio inferti.

Mandibula cornea, arcuata, acuta, inermis. Maxilla cornea, arcuata, acuta, apíce fiffa. Galea maxillam tegens, cylindrica, obtufa, truncata, maxilla longior.

Labium elongatum, rotundatum, bifidum: laciniis aequalibus, rorundatis, apice fiflis; pinna exteriore maiore rotundata. Antenna porrectae, fetaceae: articulis innumeris, breuiffimis, primo craffiori, ouato.

Larua hexapoda, agilis, currens, imagini fimillima, aprera.

Puppa hexapoda, agilis, imagini fimillima alarum rudimentis.

Victus \& laruae \& imaginis e farina, radicibus plantarum, faccharo aliisque rebus culinaribus. 


\section{MANTIS. Linn. Geoff.}

Os maxillis palpisque.

Palpi quatuor, fubaequales, filiformes.

anteriores vix longiores, quinquearticulati: articulo primo fecundoque breuioribus adhaerentes maxillae dorfo.

pofteriores triarticulati: articulo vltimo fubulato labii medio laterali inferti.

Mandibula fubcornea, breuis, recta, acuminata, medio bidentata.

Maxilla cornea, compreffa, ciliata, apice acutifima, integra.

Galca cylindrica, maxillis longior, apice rotundata, maxillam tegens.

Labium porrectum, membranaceum, bifidum: laciniis aequalibus, vsque ad medium fiffis; pinnis aegrialibus.

Antennae fetaceae: articulis breuibus, primo longiori, reliquis aequalibus.

Larua hexapoda, currens, agilis, imagini fimillima, aptera.

Puppa hexapoda, agilis, currens, rudimentis alarum.

Victus \& laruae \& imaginis e rapina In. feetorum. 
87. A CRYDIV M. Geoff. Gryllus Linn.

Os maxillis palpisque.

Palpi quatuor, fubaequales, filiformes.

anteriores quadriarticulati: articulis aequalibus adhaerentes maxillae dorfo.

poferiores triarticulati : articulis aequalibus labio medio laterali inferti.

Mandibula breuis, cornea, arcuata, acu. ta, apice dentata.

Maxilla cornea, arcuata, acuta, apice fiffa. Galea maxillarn tegeìs, cylindrica, obtufa longitudine maxillae.

Labium membranaceum, cylindricum, elongatum adinfertionem palporum coarctarum, apice fiffum.

Antennac filiformes, articulo primo longiori, cralliori; reliquis breuibus, aequalibus, vltimo fetaceo.

Larua hexapoda, aptera, agilis, currens, imagini fimillima.

Puppa hexapoda, agilis, imagini frmillima, folis alarum rudimentis. 
88. TR VXA L.IS. Gryllus. Linn.

Os maxillis palpisque.

Palpi quatuor, inaequales, filiformes.

anteriores longiores, quinquearticulati: articulis aequalibus; cylindricis ad. haerentes maxillae dorfo.

poferiores triarticulati : articulis aequalibus, cylindricis labii bafi laterali inferti.

Mandibula breuis, cornea, arcuata, acuta, edentula.

Maxilla cornea, fubarcuata, apice tridentata.

Galea maxillam tegens, lata, fornicata, longitudine maxillae.

Labium porreçum, membranaceum, ro. tundatum, bifidum:- laciniis eequalibus, rotundatis, integris.

Antennac enfiformes, fubulatae: articulis breuibus bafeos trigonoprismaticis, apice cylindricis.

Larua hexapoda, currens, agilis imagini fimillima, aptera.

Puppa hexapoda, agilis, currens, imagini fimillima rudimentis tantum alarum. Victus e rapina infectorum, inprimis dipterorum. 
89. A C HE T A. Gryilus Linn. Geoff.

Os maxillis palpisque.

Palpi quatuor, inaequales, filiformes.

anteriores longiores, quinquearticulati: articulo vltimo breuifimo, veficu. lofo, reliquis aequalibus adhaerentes maxillae dorfo.

pofteriores quadriarticulati: articulo vltimo breuiori labii bafi inferti.

Mandibula cornea, porrecta, incurua, apice transuerfe truncata, dentata.

Maxilla cornea, arcuata, acuminata, apice filfa.

Galea maxillam tegens, cylindrica, obtufa longitudine maxillae.

Labium elongatum, fubcylindricum, quadrifidum: laciniis aequalibus; exterioribus membranaceis, cylindricis, obtufis; interioribus corneis, cylindricis apice fubulatis, acutis.

Antennae fetaceae: articulis innumeris, breuiffimis, aequalibus; primo craffiori.

Larua hexapoda, agilis, aptera, imagini fimillima.

Puppa hexapoda, agilis, imagini fimilli. ma alarum rudimentis.

Victus e radicibus piantarum plantisque ipfis. 
90. LOCVSTA. Geoff. Gryllus Linn. Os maxillis palpisque.

Palpi quatuor inaequales: articulo vltimo, obtufo, truncato.

anteriores guadriarticulati : articulis fubaequalibus adbaerentes maxillae dorfo.

pofferiores triarticulati: articulis aequalibus labii medio inferti.

Mundibula cornea, arcuata, acuta, inermis. Maxilla cornea, arcuata, acuta, tridentata.

Galea maxillam tegers, cylindrica, obtufa maxillae longitudine.

Labium membranaceum, bafi cylindricum, apice rotundatum, bifidum: laciniis aequalibus; latere interiore fetafubulata inftructis.

Antennae fetaceae, porrectae: articulis innumeris, breuiffimis, aequalibus primo craffiori longiori.

Larua hexapoda, aptera, agilis, imagini fimillima.

Puppa hexapoda, agilis, imagini fimillima at rudimentis tantum alarum.

Victus e foliis plantarum.

9. GRYL. 
96

91. GR Y LL VS. Linn. Acrydium Geoff.

Os maxillis palpisque.

Palpi quatuor, fubaequales, filiformes. anteriores paullo longiores, quinquearticulati: articulis aequalibus adhaerentes maxillae dorfo.

poferiores quadriarticulati: articulis aequalibus labii medio inferti.

Mandibula craffa, cornea, recta, obtufa, dentata.

Maxilla breuis, cornea, fubarcuata, acuta, apice tridentata.

Galca maxillam tegens, cylindrica, fornicata, obtura, vix maxilla longior.

Labium elongatum, membranaceum, ad infertionem palporum coarctatum, apice incraffatum, rotundatum, bifidum: laciniis aequalibus, rotundatis, conni. uentibus, fornicatis.

Antennae filiformes: articulis vndecin cy. lindricis, aequalibus; primo craffiori breuiori.

Larua hexapoda, aptera, agilis, imagini fimillima.

Puppa hexapoda, agilis, imagini fimilli. ma, rudimentis tantum alarum. Viftus \& laruae \& imaginis e foliis plantarum. 


\section{मूल \\ Claffis. III. \\ S Y NIS T A T A.}

$O$, maxillis palpisque.

Palpi quatuor, porrecti, cornei: anterioribus infidencibus maxillae, pofterioribus labio.

Clypeus corneus, rotundatus, horizontalis, os fuperne tegens.

Mandibulac duae, transuerfales, corneae, mobiles, acutae, faepius dentatae, latera oris fuperne includentes.

Mandibulas nullae Ephemeris proprium.

Maxillac duae, transuerfales, membranaceae, cum labio bafi connatae, latera oris inferne includentes.

Maxillae faepius porrectae, elongatae, inflexae, lacinıas exteriores linguae conftiruentes.

Labium porrectum, membranaceum, interdum inflexum, in lacinias linguae interiores elongatum.

Antenuse inter oculos infertae. 
98

GENERA Claffis III.

92. MONOCVLVS. 1O7.ICHNEVMON. 93. ONISCVS. IO8. EVANIA: 94. LEPISMA. 109. SPHEX. 95. PODVRA. IIO. TIPHIA. 96. EPHEMERA. II I. SCOLIA. 97. SEMBLIS. II2. CHRYSIS. 98. PHRYGANEA. II3. THYNNVS. 99. HEMEROBIVS. I 1 4. LEVCOSPIS. 100. MYRMELEON II5. BEMBEX. 101. ASCALA- I 6. VESPA. PHVS. II7. CRABRO. 102. PANORPA. II8. ANDRENA. 103. RAPHIDIA. I 9. APIS. 104. CYNIPS. 120. NOMADA. 105. TENTHRE- 121. TERMES. DO. 122. FORMICA. 106. SIREX. 123. MVTILLA. 


\section{*ब.}

92. MONOCVL, VS, Linn. Geoff. Binoculus Geoff.

Os maxillis palpisque.

Palpi quatuor, inaequales.

antcriores extrorfum crafliores, triarticulati : articulo primo breuiffimo, reliquis aequalibus, fubtus capitis tefta adhaerentes.

poferiores triarticulati: articulo vltimo conculo, auriformi maxillae inferti.

Mandibula cornea, craffa, gibba, fubglobofa, altero latere truncata, denticu- lata.

Maxilla fubmembranacea, bifida: laciniis inaequalibus, exreriore breuiore.

Labium membranaceum, rotundatum, inteģrum, cum maxilla vltra medium connatum.

Antennae ramofae: ramis fetaceis; articulis innumeris, breuiffimis, aequalibus, primo longiori.

Larua \& Puppa imagini fimillimae,pedatae, currentes, agiles exuuias tantum deponunt.

Victus e plantis aquaticis.

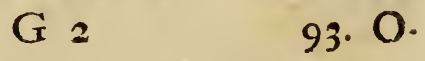


100

93. ONISC V S. Linn. Geoff. Afellus Geoff.

Os maxillis palpisque.

Palpi quatuor, inaequales, filiformeś.

antcriores breuiffimi, vix maxillae longiores, cuius dorfo adhaerent.

poferiores porrecti, longiores, quadriarticulati: articulis aequalibus, cy.

lindricis, vltimo fubulato labio inferti.

Mandibula breuis, craffa, apice acuta, dentata.

Maxilla recta, porrecta, membranacea, apice truncata, denticulata, connata cum labio.

Labium porrectum, membranaceum, rotundatum, bifidum: laciniis aequalibus, ouatis, obtufis.

Antennac interdum quatuor inaequales; anteriores breuiores, fubulatae, multiarticulatae, pofteriores longiores feta. ceae, articulis duobus anterioribus longioribus, cylindricis, reliquis breuiffimis, innumeris, interdum duae filiformes, quinquearticulatae: articulo primo fecundoque breuioribus, tertio quartoque cylindricis, vltimo fetaceo, acuto.

Larua \& Puppa agiles, currentes, pedatae exuuias tantum deponunt.

Victus \& laruae \& imaginis e foliis plantarum, quisquiliis. 
94. LEPISMA. Linn. Forbicina Geoff.

Os maxillis palpisque.

Palpi quatuor, inaequales, filiformes.

anteriores porreeti, multo longiores, quinquearticulati : articulis cylindricis, fubaequalibus; vltimo acuminato adhaerentes maxillae dorfo.

poftriores breuiores, triarticulati: articulo vltimo, ouato, fubcraffiori labii medio inferti.

Mandibula breuis, cornea, arcuata, acuta, inermis.

Maxilla porrecta, membranacea, cylindrica, fubueficulofa, apice truncata, cum labio connata.

Labium membranaceum, porrectum, rotundatum, apice emarginatum.

Antenssae fetaceae, porrectae: articulis innumeris, breuiffimis, aequalibus; primo parum craltiori.

Larua \& Puppa hexapodae, agiles, currentes exuuias tantum deponunt.

Victus \& laruac \& imaginis e faccharo, ligno purrido, quisquiliis.

$$
\mathrm{G}_{3} \quad 95 . \mathrm{PO}
$$


95. PODVRA. Linn. Geoff.

Os maxillis palpisque.

Palpi quatuor, inaequales, fubclauari.

anteriores longiores, quinquearticulati: articulis fubaequalibus; exterioribus fenfim paullo craflioribus; fecundo breuitimo adhaerentes maxillae dorfo.

pofferiores breues, triarticulati: articulis fubaequalibus; exterioribus renfim craffioribus labii apici adnati.

Mandibula breuis, cornea, arcuata, acu. ta, inermis.

Maxilla porrecta, connata, membranacea, linearis, apice truncata, obtufa, integra.

Labium breue, membranaceum, rotunda. tum, bifidum: laciniis aequalibus, con. niuentibus.

Antennae filiformes, quadriarticulatae: arriculo primo breuiffimo, reliquis aequalibus, vltimo feraceo, acuto.

Larua \& Puppa hexapodae, agiles, cur. - rentes, imagini fimilimae exuuias tantum deponunt.

Victus \& laruae \& puppae \& imaginis e foliis plantarum. 


\section{EPHEMERA. Linn. Geoff.}

Os maxillis palpisque.

Palpi quatuor, breuilfimi, fubaequales, filiformes.

anteriores quadriarticulati: articulis fub. aequalibus, cylindricis; fecundo paullo longiore adhaerentes maxillae dorfo.

poferiores triarticulati : articulis aequali-

bus, breuibus adhacrentes labii apici. Mundibula omnino nulla.

Maxilla breuis, membranacea, cylindrica, obtufa, integra, cum labio arcte connata.

Labium breue, membranaceum, cylindri$\mathrm{cum}$, apice rotundatum, integerrimum. Anternae breuifimae, fubulatae: articulo primo maiori, reliquis breuiffimis, vltimo acuro.

Larua aquatica, hexapoda, agilis, caudata,

natatoriis lateralibus, fenis.

Puppa hexapoda, agilis, caudata, nata-

toriis extrorfum craffionbus, alarumque rudimentis.

Victus \& laruac \& puppae e foliis plantarum aquaticartum? imaginis omnino nullus.

Vita Imaginis vix viginti quatuor horas attingir ideoque cibo haud eget.

$$
\text { G } 4 \quad 97 . \text { SEM. }
$$


97. SEMBLIS. Phryganea. Linn. Perla Geoff.

Os maxillis palpisque.

Palpi quatuor, elongati, fubàequales, fili. formes.

anteriores vix longiores, quadriarticulati: articulo vltimo tenuiori, acuto adhaerentes maxillae lateri cxteriori.

pofteriores triarticulati : articulis fubaequalibus; vltimo acuto labii medio laterali inferti.

Mandibula breuiffima, cornea, arcuata, acuta, inermis.

Maxilla breuis, membranacea, connata, fubarcuata, bifida: laciniis aequalibus, tenuiffimis, acutis.

Labium porrectum, cylindricum, membranaceum, annulatum, integrum.

Antonnae fetaceae: articulis plurimis, breuibus, primo paullo maiori.

Larua aquatica, hexapoda, caudata, natatoriis feptenis, filiformibus.

Puppa quiefcens, hexapoda, maxillis corneis, prominulis.

Vifus laruae e rapina aquatilium minimorum, imaginis ignotus. 


\section{PHR Y GANEA. Linn. Geoff.}

Os maxillis palpisque.

Palpi quatuor, inaequales, approximati, porrecti, filiformes.

anteriores longiores, quinquearticulati: articulo fecundo tertioque longiffi-

- mis adhaerentes maxillae medio.

pofteriores breuiores, quadriarticulati: articulo primo plano, lateribus dilatatis, vltimo compreffo, latiore labii apici inferti.

Mandibula breuis, cornea, arcuata, acuta, inermis.

Maxilla recta, membranacea, acuta, integra, cum labio inferiori tota connata, vt vix appareat.

Labium porrectum, cylindricum, latum, membranaceum, apice emarginatum. Antennac fetaceae: articulis innumeris, breuibus; primo paullo naiori.

Larua aquatica, hexapoda, fubpilofa, vnguibus duobus caudalibus tentaculisque tribus erectis quarti fegmenti intra cucullum latitans.

Puppa quiefcens, folliculata, imagini fimillima, vnguiculis duobus caudalibus, breuibus.

Vičus laruae e rapina aquatilium minimorum, imaginis adhuc later.

$$
\text { G } 599 . \mathrm{HE} \text {. }
$$




\section{HEMER OBIV S. Linn. Geoff. Termes Linn.}

Os maxillis palpisque.

Palpi quatuor, porrecti, inaequales, filiformes.

anteriores longiores, quadriarticulati : articulo fecundo longiori, rellquis aequalibus maxillae adhaerentes.

poftcriores triarticulati: articulo vltimo cylindrico, longiori labii medio laterali inferti.

Mandibula breuis, cornea, craffa, apice acurninata.

Maxilla cylindrica, membranacea, recta, fifla: laciniis aequalibus, breuiffimis.

Labium corneum, porrectum, ad infertionem palporum coarctarum, apice rotundatum, fornicatum, integrum.

Antennae fetaceae: articulis plurimis, breuiffimis; primo maiore.

Larua hexapoda, ouata, pilofa.

Puppa folliculata, quiefcens.

Victus \& laruae \& imaginis e rapina Infecto. rum minimorum, inprimis Aphidum. 
100. MYRMELEON. Linn. For. micaleo Geoff.

Os maxillis palpisque.

Palpi fex, inaequales, porrecti.

antcriores breuiores, filiformes, triar-

tictlati: articulo fecundo longiffimo maxillae adhaerentes.

medii vix longiores, filiformes, quadriarticulati: articulo primo fecundo-

que longioribus anteriorum baii in. ferti.

pofteriores longiffimi, quadriarticulati: articulo primo fecundogue breuiffimis, tertio quartoque longifimis, clauatis labii bafi laterali inferti.

Mandibula exferta, cornea, arcuata, acura. Maxilla cornea, compreffa, bafi dilatata, vnidentata, apice acuta.

Labium porrectum, membranaceum, quadratum, truncatum, emarginatum. Antennac extrorfum crafilores: articulis plurimis, breuibus, primo maiori.

Larua hexapoda, ouata, pilofa, maxillis exfertis, dentatis.

Puppa incuruata, quiefcens intra glebam. Victus \& laruae \& imaginis e rapina formicarum aliorumque Infectorum. 
108

101. ASCALAPHVS. Myrmeleon: Linn.

Os maxillis palpisque.

Palpi fex, fubaequales, filiformes.

anteriores paullo breuiores, triarticulati: articulo fecundo longiffimo adhaerentes maxillae dorfo.

medii longiores, quadriarticulati : arti-* culo fecundo longiffimo anteriorum bafi inferti.

pofteriores quadriarticulati: articulo primo \& yuarto breuiffimis labii bafi laterali inferti.

Mandibula cornea, arcuata, acuta, dentata. Maxilla cornea, fubarcuata, acuta, ciliata, integra.

Labium porręum, corneum, rotundatum, integrum.

Antensac porrectae, clauatae: articulis plurimis, breuibus; primo maiori, vltimis tribus craffioribus.

Metamorpbofis \& Victus adhuc nobis latent. 


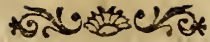

102. PANORPA. Linn. Geoff.

Os porrectum in roftrum cylindricum, corneum, maxillis palpisque.

Palpi quatuor, fubaequales, filiformes.

anteriores vix longiores, quadriarticu. lati: articulis fubaequalibus adhae. rentes maxillae dorfo.

poferiores breuiores, biarticulati: articulo primo craffiori, gibbo, labii apici inferti.

Mandibula porrecta, cornea, arcuata, acuta, edentula.

Maxilla cornea, porrecta, apice truncata, bifida: laciniis fubaequalibus, cylin. dricis; exteriore tenuiore integra, interiore apice bidentata.

Labium elongatum, porrectum, corneum; fornicàtum, rotundatum, integrum, totum os obtegens.

Antennae filiformes : articulis plurimis; breuifimis; primo maiori.

Metamorphofis ignota, larua forfan aquatica: Victus laruae ignotus, imaginis e rapina reliquorum Infectorum. 
I 10

I03. RAPHIDIA. Linn. Geoff.

Os maxillis palpisque.

Palpi quatuor, breuiffimi, fubaequales, filiformes.

anteriores paullo longiores, quadriarticulati: articulis aequalibus adhaerentes maxillae dorfo.

pofferiores triarticulati; articulis aequalibus labii apici inferti.

Mandibula cornea, compreffa, arcuata, acuta, dentata.

Maxilla breuis, cornea, cylindrica, ob. tura, vix vnidentata, integra.

Labium breue, corneum, rotundatum, integrum, apice palpigerum.

Antennae porrectae, filiformes: articulis fubaequalibus; primo paullo maiori.

Larua hexapoda, agilis imagini fimillima at aptera.

Puppa ignota.

Victus \& laruae \& imaginis e rapina reliquorum Infectorum. 


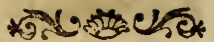

104. CYNIPS. Linn. Geoff. Diplolepis Geoff.

Os maxillis palpisque.

Palpi quatuor, brenes, inaequales, capitati.

anteriores longiores, quinquearticulati: articulis cylindricis, fubaequalibus; vltimo rotundato, cralliori adhaerentes maxillae dorfo.

poferiores quadriarticulati : articulis cy. linaricis, aegualibus; vltimo rotundato, cralliori labii apici inferti.

Mandibula cornea, arcuata, apice fiffa.

Maxilla breuis, membranacea, vnidenta-

ta, cum labio arcte connata.

Labium breue, corneum, cylindricum, integrum.

Antcinae porrectae, filiformes, multiarticulatae: articulis fubaequalibus; primo maiore.

Lavua apoda, mollis, cylindrica, incur. ua intra gallam plantarum.

Puppa quiefcens, imagini fimillima, rudimentis tantum alarum.

Victus e fucco plantarum e vulnere ftillan-

te in Gallam excrefiente. 
I05. TENTHREDO. Linn. Geoff. Crabro Geoff.

Os maxillis palpisque.

Palpi quaruor, inaequales, filiformes.

anterieres porrecti, multo longiores, fex articulati: articulis fubaequalibus adhaerentes maxillae dorfo.

pofteriores triarticulati: articulis aequa. libus labii medio inferti labium in. cludentes.

Mandibula exferta, cornea, arcuata, acuta, intus dentata.

Maxilla recta, porrecta, compreffa, ad infertionem palporum vnidentata, apice obtula.

Labium porrectum, cylindricum, membranaceum, ad infertionem palporum coarctarum, apice rotundatum, dilatatum, trifidum: laciniis fubaequalibus; intermedia teruiore, obtufiore. Antennae clauatae, filiformes, fetaceae. Larua cylindrica, molis, pedibus fedecim vsque aduiginti.

Puppa quiefcens, imagini fimillima, ru dimentis tantum alarum.

Victus e' foliis plantarum.

Crabro Geoff. differt labio longiori magis porrecto, antennisque clauatis, artamen huius generis. 


\section{SIREX. Linn. Vroceros Geoff.}

Os maxillis palpisque.

Palpi quatuor, inaequales.

anteriores breuiffimi, filiformes, biarticulati: articulis aequalibus adhaerentes maxillae dorfo.

pofteriores porrecti, longiores, extrorfum craffiores, pilofi, quadriarticulati : articulis fubaequalibus labii apici inferti.

Mandibula breuis, craffa, cornea, apice truncata, denticulata.

Maxilla breuis, incurua, acuminata, membianacea, ciliata, cylindrica, integra.

Labium breue, membranaceum, integrum. Antennae filiformes: articulis plurimis, breuibus, aequalibus, primo vix longiori.

Larua hexapoda, mollis, cylindrica, capite rotundato.

Puppa folliculata, quiefcens, imagini fimillima, alarum tantum rudimentis.

Victus laruae ex arborum ligno; imaginis e florum nectare. 
107. ICHNEVMON. Linn. Geoff.

Murilla Linn.

Os maxillis palpisque.

Palpi quatuor, porrecti, inaequales, filiformes.

anteriores longiores, fexarticulati : articulo fecundo obconico, tertio fub. dilatato adhaerentes maxillae dorfo. pofteriores breuiores, quinquearticulati: articulo vltimo longiflimo, cylindrico labii medio laterali inferti.

Mandibula cornea, arcuata, acuta, inermis. Maxilla recta, membranacea, bifida, ad infertionem palporum vnidentata, apice rotundata, dilatata, ciliata.

Labium porrectum, corneum, cylindricum, gibbum, carinatum, apice membra. naceum, rotundatum, emarginatum. Antennae fetaceae: articulis plurimis, breuiffrmis, aequalibus; primo maiori. Larua apoda, mollis, cylincirica. Puppa mox nuda, mox folliculata, quie. fcens, imagini fimillima rudimentis fo. lis alarum.

Vietus laruae e fucco animalium, intra corpora eorum habitantis, imaginis e nectare florum.

Icb. luteus differt mandibula fornicata, inermi, apice fiffa. 
108. EVANIA. Sphex Linn.

Os maxillis palpisque.

Palpi quatuor, inaequales.

anteriores longiores, porrecti, filiformes, fexarticulati: articulo vltimo longiori adhaerentes maxillae dorfo.

pofterioves incurui, quadriarticulati : arriculo tertio craffiori, quadrato labii medio inferri.

Mandibula breuis, cornea, incurua, acuta, vnidentata.

Maxilla breuis, membranacea, compreffa, apice rotundata, integra.

Labium breue, corneum, conicum, apice membranaceum, acutum, integerrimum.

Antennae filiformes: articulis plurimis, cylindricis, aequalibus; primo maiori, vltimo acuto.

Metamorphofis \& Victus \& laruae \& imaginis omnino adhuc latent.

Obf. Genus Sphegibus affine, attamen charactere fatis diftinctum. 
ro9. SPHEX. Linn. Ichneumon. Geoff. Os maxillis, palpis linguaque inflexa, trifida. Palpi quatuor, porrecti, fubaequales, fili. formes.

anteriores paullo longiores, fexarticulati: articulis fubaequalibus, obconi. cis adhaerentes maxillae dorfo.

pofteriores quincuearticulari : articulis aequalibus, obconicis labii medio laterali in?erti.

Mastdibula cornea, crafla, arcuata, acuta, dentata.

Maxilla porredta, cornea, comprefra, la. tere interiori membranacea, in medio inflexa, apice obtufa, integra linguae laminam exteriorem conttituens.

Labium porrectum, corneum, cylindri. cum, apice elongatum, membrana. ceum, inflexum, emarginatum vtrinque fera membranacea, valida, longi. tudine dimidii labii interiorem linguae laminam conftituens.

Antennae breues, conuolutae, fetaceae, - I r articulatae: articulis aequalibus, cy. lindricis; primo paullo craffiori.

Larua apoda, mollis, veficulofa, intra corpora Infectorum latitans.

Puppa quiefcens imagini fimillima, folis alarum rudimentis.

Victus laruae e fucco infectorum, imaginis e floribus inprimis vmbellatis.

I I O. TI. 


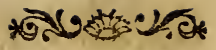 \\ I10. TIPHIA.}

Os maxillis palpisque absque lingua.

Palpi quatuor, inaequales, filiformes, porrecti.

anteriores paullo longiores, fex articulati : articulis aequalibus adhaerentes maxillae corro.

poferiores quinqucarticulati: articulis aequalibus labii medio inferti.

Mandiviula cornea, arcuata, acuta, integra.

Maxilla breuis, membranacé, apice rotundata, integra.

Labium breue, corneum, cylindricum, obtufum, ante apicem dentibus duobus erectis, obtufis, vel potius tridentatum dente interiore maiore, obtufiore.

Antennae arcuatae, fubpetiolatae: articulo primo longiori, reliquis vix diftinctis, breuiffimis, rotundatis.

Metamorphofis \& Victus \& laruac \& imagipis omnino adhuc nobis latent. 


\section{SCOLIA.}

Os maxillis, palpis, linguaque inflexa trifida, breuiflima.

Palpi quatuor, aequales, breues, filiformes. anteriores quadriarticulati: articulis aequalibus, cylindricis adhaerentes maxillae dorfo.

pofferiores triarticulati: articulis aequalibus, globofis labii medio laterali inferti.

Mandibula cornea, arcuata, acutiflima, intus crenata.

Maxills porrecta, cornea, compreffa, apice obtufiufcula, integerrima, lacinias linguae exteriores conftituens.

Labium porrectum longitudine maxillae, corneum, compreffum, apice membranaceum, cylindricum, integrum, linguae laciniam interiorem conftituens.

Anteinnac craffae, filiformes, fubpetiolatae: articulo primo longiori, reliquis vix diftinctis, cylindricis, breuibus.

Metamorphofis \& Victus omnino adhuc latent. 


\section{I 2. CHR Y SIS. Linn. Verpa Geoff.}

Os maxillis palpisque absque lingua.

Palpi quatuor, porrecti, inaequales, filiformes.

anteriores longiores, quinquearticulati: articulo vltimo tenuiori, filiformi adhaerentes maxillae dorfo.

poferiores quadriarticulati: articulis aequalibus labii medio inferti.

Mandibila exferta, cornea, arcuata, integra.

Maxilla porrecta, elongata, cornea, linearis, vnidentata, apice membrana. cea, acuta.

Labium porrectum, linguaeforme, corneum, lineare, maxillae muito longius, apice membranaceum, acuturn, emarginatum.

Antennac breues, filiformes: articulo primo longiori, reliquis breuibus aequalibus.

Metamorpbofis \& Victus adhuc latent. 


\section{3 . THYNNVS.}

Os maxillis, palpis linguaque breuiffima, inuoluta, haud exferta.

Palpi quatuor, filiformes, aequales.

anteriores quadriarticulati: articulis ae. qualibus adhaerentes maxillae dorfo.

pofteriores triarticulati: articulis fubaequalibus adnati labii medio.

Mandibula cornea, incurua, apice acuta, vnidentata.

Maxilla breuis, recta, cornea, concaua, apice rotundata, integra.

Labium maxillis longius, vsque ad infertionem palporum cylindricum, corneum, apice inflexum, membranaceum, compreffum, trifidum : laciniis aequalibus; intermedia emarginata.

Antennac cylindricae: articulo primo breui, cralfiori, reliquis aequalibus, ob. foletis.

Metamorphofis \& Victus \& laruae \& imaginis adhuc latent. 


\section{LEVCOSPIS.}

Os maxillis, palpisque absque lingua.

Palpi quatuor, breues, aequales, filiformes: articulo vltimo reliquis longiori, obconico.

anteriores quadriarticulati : articulis fub. cylindricis, aequalibus adhaerentes maxillae dorfo.

pofteriores triarticulati labii medio late. rali inferti.

Mandibula cornea, craffa, breuis, apice tridentata.

Maxilla labio breuior, cornea, compreffa, integra.

I. biume elongatum, cylindricum, corneum, apice membranaceum, emarginatum.

Antennac breues, rectae, cylindricae, extrorfum craffiores: articulis breuibus, cylindricis; primo paullo maiore.

Metamorplofis \& Victus \& laruae \& imaginis omnino adhuc latent. 
I 5. BEMBEX. Vefpa Linn. Apis Linn.

Os maxillis, palpis linguaque inflexa quinque fida, labio fuperiore porrecto, conico, corneo obtectum.

Palpi quatuor, breues, inaequales, filiformes.

anteriores longiores, fex articulati: articulis fubaequalibus; vltimo fubulato adhaerentes maxillae flexurae.

pofteriores. breuiores, triarticulati bafi laciniarum exteriarum labii inferti. Mandibula resta, cornea, concaua, apice fubdentata.

Maxilla porrecta, fubcylindirica, cornea, medio inflexa, compreffa, obtufa, laciniam exteriorem linguae conftituens. Labium porrectum, bafi corneum, gibbum, trifidum: laciniis exterioribus tenuio. ribus filiformibus; intermedia maiori, fornicata, laterales includente, lacinias linguae intermedias conftituens.

Antennac filiformes, inuolutae: articulo primo longiore, fylindrico, reliquis breuibus, fere obfoletis.

Lerua spoda, mollis, cylindrica.

Puppa quiefcens, imagini fimillima, rudimentis tantum alarum.

Victus \& laruae \& imaginis e nectare florum.

B. fgnata lacinia media labii emarginata.

II6. VE. 


\section{VESPA. Linn. Geoff.}

Os maxillis palpisque absque lingua. Palpi quatuor, inaequales, filiformes. anteriores porrecti, longiores, fexarticulati : articulis fubaequalibus, obconicis; vltimo fetaceo adhaerentes maxillae dorfo.

pofteriores breuiores, quinque articulati: articulis fubaequalibus, cylindricis labii medio inferti.

Mandibula breuis, recta, cornea, lata, conca. ua, apice oblique truncata, denticulata. Maxilla porrecta, cornea, cylindrica, ad infertionem palpi flexa, membranacea, compreffa, vnidentata, apice acuta, ciliata.

Labium compreffum, bafi corneum, gibbum, carinatum, apice concauum, membranaceum, late emarginatum, medio vtrinque feta tenuifima, filiformi, acuta inftructum.

Antennae filiformes, incuruae: articulo primo longifimo, cylindrico, fecun. do vix breuiori, reliquis breuibus, fe. re obfoletis.

Larua apoda, mollis : antice truncata, obtufa, poftice attenuata intra cellulas hexangulares.

- Puppa quiefcens, imagini fimillima, rudimentis tantum alarum.

Victus laruae e nectare florum, melle, imaginis e rapina A pium, Mufcarum. 117 . 
ri7. CRA BRO. Verpa Linn. Sphex Linn. Os maxillis palpisque absque lingua.

Palpi quatuor, porrećti, inaequales, filiformes.

anteriores longiores, fexarticulati: articulis compreffo thomboidalibus; vlti. mis duobus cylindricis adhaerentes maxillae dorfo.

pofteriores breues, gibbi, quinquearticulati: articulis cylindricis, aequalibus labii apici laterali inferti.

Mandibula cornea, arcuata, fornicata, dentata, apice truncata, fiffa.

Maxilla recta, porrecta labio paullo longior, cornea, comprefra, bifida: laciniis fubaequalibus, rotundatis.

Labium breue, corneum, obconicum, depreffum, marginibus parum eleuaris, apice rotundatum, integrum.

Antennate filiformes, incuruae: articulo primo longiffimo, cylindrico, reliquis breuiffimis fere obfoletis.

Larua apoda, mollis.

Puppa quiefcens, imagini fimillima, rudimentis tantum alarum.

Victus laruae e nectare florum, melle, ima. ginis e rapina Apium, Mufcarum. 
118. ANDRENA. Apis Linn. Geoff.

Os maxillis, palpis linguaque infexa trifida. Paloi quatuor, inaequales, filiformes.

anteriores porrecti, longiores, fexarticulati: articulis cylindricis, aeçua. libus adhaerentes flexurac maxillae.

pofteriores breuiffimi, biarticulati : articulis aequalibus, cylindricis fub apice ferarum labii inferti.

Mandibula recta, cornea, fornicata, inermis. Maxilla cornea, apice membranacea, compreffa, inflexa, labio multo breuiore linguae lacinias exteriores conftituens.

Labium porrectum, cylindricum, bafi corneum, apice membranaceum, in. flexum, vtrinque iuxta flexuram fetis duabus membranaceis, rectis, rigidis: exteriore longitudine dimidii labii, interiore breuilfima, compreffa, incurua. Antennac breues, filiformes, fubperiolatae: articulo primo paullo longiori, fecundo bafi attenuato, reliquis aequalibus, breuibus.

Larua apoda, mollis: antice gibba, obtufa, poftice attenuata.

$\boldsymbol{P} u p p a$ quiefcens, imagini fimillima. Victus \& laruae \& imaginis e nectare flo. rum.

IIg. A- 


\section{बत्र.}

119. APIS. Linn. Geoff.

Os maxillis, palpis linguaque inflexa quin. quefida.

Palpi quatuor, breuillimi, inaequales, filiformes.

anteriores paullo longiores, fexarticula.

ti: articulis aequalibus flexurae maxillae adhaerentes.

pofteriores quinquearticulati : articulis ae. qualibus, apici laciniarum exteriorum labii inferti.

Mandibula porrecta, cornea, recta, obcufa, dentata.

Maxilla porrecta, cornea: bafi cylindrica cum labio connata, apice compreffa, acuta, integra, marginibus membranaceis, in medio inflexa, laciniam lin. guae exteriorem conftituens.

Labium porrectum, corneum, bafi cylindricum, apice trifidum: laciniis lateralibus dilatatis, membranaceis, fub apice palpigeris, intermedia longiori retractili, tereti pilofa, lacinias inte. riores linguae confticuens.

Antenuae filiformes, breues: articulo primo 
mo longiffimo, incuruo, reliquis breuibus, aequalibus.

Larua apoda, mollis, gregaria intra cellulas hexangulares.

Puppa quiefcens imagini fimillima.

Victus \& laruae \& imaginis e nectare flo. rum, melle, fructibus dulcibus.

0bF. Ap. longicornis \& linguaria labio gaudent quinquefido laciniis exterioribus dilatatis palpigeris, fecundariis mino. ribus tenuiffimis, interiori tereti pilofo. 


\section{NOMADA. Apis Linn.}

Os maxillis, palpis linguaque inflexa, trifida. Paipi quatuor inaequales, porrecti, filiformes.

anteriores breuicres, fexarticulati : articu. lis acqualibus, cylindricis adhaerentes flexurae maxillae.

poferiores quadriarticulati: 'articulis cy. lindricis fecundo longifimo, lin. guae formi labii medio inferti.

Mandibula cornea, fornicata, arcuata, acuta, integra.

Maxilla bafi cornea, cylindrica, apice porrecta, compreffa, membranacea, acuta, integra linguae exteriorem laciniam conltituens.

Labium cylindricum, elongatum, bafi corneum, apice membranaceum, acutum, compreffum, integrum, linguae laciniam interiorem conitituens.

Antenual filiformes, breues, articulo primo paullo longiori, reliquis aequalibus, breuibus, rocundatis.

Metamorplofis \& Victus \& laruae \& ima. ginis latent.

Obf. Genus affine A pibus; differt tamen palpis pofterioribus linguae formibus, quaruin figura cylindrica \& articuli veros effe palpos indicant. 


\section{TERMES. Linn.}

Os maxilis palpisque absque lingua.

Palyi quatuor, aequales, filiformes.

anteriores vix longiores, quadriarticula-

ti: articulo primo breuiflimo, reliquis aequalibus, cylindricis maxillae medio laterali adhaerentes.

pofteriores triarticulati : articulo primo breuiori, reliquis aequalibus, cylindricis labii medio inferti.

Mandibula breuis, cornea, craffa, acuta, dentata.

Maxilla cornea, compreffa, incurua, bafi fquama maxilla breuiore, truncata, integra fuffulta, apice emarginata: denti. bus duobus validis, acutiffimis; po- fteriore longiore.

Labium porrećtum, corneum, bafi cylindricum, canaliculatum apice quadrifidum, laciniis linearibus, acutis.

Antennae moniliformes: articulo primo breui, cralfioni.

Larua apoda, mollis, gregaria, lucifuga intra tubum cylindricum.

Puppa quiefcens, immobilis.

Victus laruae \& imaginis e rebus cibariis,

culinariis, domefticis fere omnibus.

06). Neutra mandibulas gerunt exfertas; forcipatas, tenuiores. 
122. FOR MIC A. Linn. Geoff.

Os maxillis palpisque absque lingua. Palpi quatuor, porrecti, inaequales, filiformes.

anteriores longiores, fex articulati: articulis fubaequalibus, cylindricis ad. haerentes maxillae medio.

pofteriores quinquearticulati : articulis - aequalibus, breuiffimis labii apici inferti.

Mandibula recta, cornea, lata, fornicata, apice obtufa, denticulata.

Maxilla fubmembranacea, arcuata, fornicata, compreffa, obtufa, integra.

Labium porrectum longitudine maxillae, fubmembranaceum, cylindricum, truncatum, integrum.

Antennae filiformes: articulo primo longiori, cylindrico, reliquis breuibus, vltimo fetaceo.

Lavua apoda, mollis, alba, antice po. fticeque obtufa.

Puppa immobilis, quiefcens.

Vičus \& laruae \& imaginis e quisquiliis, rapina, faccharo, fructibus aliisque.

Maribus minoribus alatis, faeminis maioribus alatis \& fpadonibus apteris conftat Formicarum refpublica.

123. MV. 


\section{MVTILLA. Linn.}

Os maxillis palpisque absque lingua.

Palpi quatuor, porrecti, inaequales, filiformes.

antcriores longiores, fex articulati: articulo tertio longiffimo, reliquis aequalibus, obconicis: angulo interiori prominulo, vltimo feraceo maxillae apici adhaerentes.

pofteriores breuiores, quinquearticulati: articulo fecundo longiffimo, obco. nico, quarto breuiffimo, latiori la. bii a pici inferti.

Mandibula cornea, fubarcuata, acuta, integra.

Maxilla breuis, fubcylindrica, recta, cornea, apice membranacea, integra, obtufa.

Labium corneum, obconicum, gibbum, truncatum, integrum, longitudine maxillae.

Antennae filiformes: articulo primo longiori, incurue, reliquis breuibus aequalibus.

Metamorphofis \& Victus \& laruae \& imaginis omnino adhuc latent.

$$
\text { I } 2
$$




\section{*ลำ 250.}

\section{Clafis IIII.}

\section{A GONATA.}

$O$ s mandibulis palpisque absque maxillis.

Palpi fex inaequales, filiformes: anterioribus quatuor longioribus bafi bifidis, apice incuruis os obtegentibus, pofticis mandibulae dorfo infertis.

Clypeus breuis, corneus, rotundatus, vix fupra os exfertus.

Mandibulac duae transuerfae, corneae, craffae, dorfo palpigerae.

Maxillac omnino nullae.

Labium triplex, membranaceum, rotun: datum, diuifum.

Antennac quatuor, fub oculis infertae. 


\section{सक्षण}

\section{GENERA Claffis IIII.}

125. CANCER.

126. PAGVRVS.

I27. SCYLLARVS.

128. ASTACVS.

129. GAMMARVS.

$$
I_{3} 125 . \mathrm{CAN} \text {. }
$$


125. CANCER. Linn.

Os mandibulis palpisque absque maxillis.

Palpi fex inaequales: anterioribus quatuor, compreffis latis totum os obregentibus.

anteriores bifidi : laciniis longitudine aequalibus; interiori quadriarticulata : articulo primo longiori, fecundo fuborbiculato, vltimo acuminato, exteriori biarticulata: articulis aequalibus.

medii bifidi: laciniis inaequalibus; interiori latiori, breuiori, triarticulata: articulo fecundo longiori, ex. teriori longiori, tenuiori, biarticulato: articulis aequalibus; vltimo incuruo.

poferiores breues, incurui, triarticulati: articulis aequalibus adhaerentes mandibulae dorfo.

Mandibula breuis, craffa, cornea, apice rotundata, fornicata, obtufa.

Labium triplex: exterius octofidum, laciniis interioribus breuilfimis, cylindricis, fecundis tertiisque aequalibus, apice elongatis, fubulatis, quartis latiori- 
bus truncatis, apice exteriori feta fubulata, longiffima, tenui, acutiffima.

medium quadrifidum, laciniis intermediis latifimis, breuioribus truncatis, filfis; exterioribus tenuioribus dorfo fetigeris apice fubulatis porrectis.

interius paruum, quadrifidum: laciniis aequalibus; interioribus extrorfum craffioribus fornicatis, truncatis, exterioribus cylindricis.

Antonnae quatuor breuiffimae, aequales.

exteriores latae, petiolo lacui, vnidentato.

intermedii palpiformes, quadriarticulati, articulo fecundo longiori, vltimo acuminato, bifido.

Metamorphofis completa larua puppaque omnibus partibus completis agilibus.

Viffus e rapina infectorum, ranarum pifciumque. 
126. PAGVRVS, Cancer Linn,

Os mandibulis palpisque absque maxillis.

Palpi fex fubaequales: anterioribus qua. tuor totum os obregentibus.

anteriores porrecti multo longiores, bifidi: laciniis inaequalibus; exteriori breniori, quadriarticulata: articulo fecundo longiori comprello, vitimo acuto annulato, interiori longiori, fexarticulata: articulis fubaequalibus, pilofis; fecundo extrorfum ferrato fub ore inferti.

medii breuiores, bifidi: laciniis aequalibus; exteriori acutiffima, quadriarticulara : articulo fecundo longisfimo, interiori quing̣uearticulara: articulis compreffis, ciliatis.

poferisres parui, triarticulati: articula vltimo craffiori, compreffo mandibulae dorfo inferti.

Mandibula cornea, craffa, valida apice rotundata, obtufa, fornicata.

Labiwin triplex.

exterius quadrifidum: laciniis interioribus rotundatis, fornicatis, intus ciliatis, exterioribus rectis, fubco. nicis, 
nicis, apice bafique interiori feta fubulata, acuta palpiformi inftructis.

medium quadrifidum: laciniis fubaequalibus, fornicatis, interioribus bafi interiori incifis, ciliatis; exterioribus apice fubulatis bafi interiori feta rigida acutiffima inftructis.

interius quadrifidum: laciniis interioribus rocundatis, arcte mandibula adhaerentibus, exterioribus longioribus, extrorfum craffioribus, ciliatis dorfo feta valida inftructis.

Antenna quatuor, inaequales, pedunculatae. exteriores longiores, fubulatae, multiarticulatae: pedunculo craffiori triarticulato; articulo fecundo fpinofo.

interiores breues, palpiformes, triarticulari : articulo fecundo longiori, vltimo bifido, pedunculo vniarticu. laro, gibbo, fpinofo.

Mictamorpbogis completa, larua puppaque omribus partibus completis, agilibus.

Victus e rapina infectorum, ranarum pi. íciumgue. 


\section{SCYLLARVS. Cancer. Linn.}

Os mandibulis palpisque absque maxillis.

Palpi fex inaequales; anterioribus quatuor, porrectis obtegentibus.

anteriores longiores, quadriarticulati: articulis compreflis, inaequalibus; primo tertioque breuioribus, bafi exteriore fquamula breui cornea, arcuata, inarticulata, acuta armatis.

medii bifidi: laciniis fubaequalibus; interiore triarticulata: articulis compreffis, breuibus, vltimo incuruo, exteriore biarticulata, erecta, obtufa.

pofteriores breues, fetacei, triarticulati, incurui mandibulae dorfo inferti.

Mandibula porrecta, cornea, intus canaliculata bafi fubcylindrica apice incralfata, concaua fubemarginata.

Labium triplex.

exterius quadrifidum: laciniis rotundatis, fubaequalibus.

medium bifidum: laciniis fiffis, aequalibus. 
interius bifidum: laciniis extrorfum craffioribus, trifidis.

Antenrac quatuor, inaequales.

anteriores paullo longiores, filiformes, quadriarticulati: articulis fubaequalibus; vltimo breuiori bifido.

pofteriores breues, bifidi : lacinia interiori biarticulata; articulo primo rotundato breui, vltimo magno, compreffo, rotundato, crenato, la. cinia exteriori inarticulata, com. preffa, carinata, acuta margineque fpinofo.

Metamorphofis completa, larua puppaque omnibus partibus completis, agilibus.

Victus e rapina infectorum aquatilium pifciumque minimorum. 
I28. AST A CVS. Cancer Linn. Geoff.

Os mandibulis palpisque absque maxillis.

Palpi fex, inaequales: anterioribus quatuor porrectis, os obregentibus.

anteriores longiores, biffi: laciniis in. aequalibus; interiore longiore, qua. driarticulata: articulo fecundo tertioque longioribus, exteriori breni, acuriflima, triarticulata.

medii bifidi: laciniis aequalibus; interiore, craffiori, triarticulata : articulo fecundo breuifimo, vltimo crafliori, inflexo, exteriori fubula. ta, tenuiori, inarticulata.

pofteriores breues, fetacci, triarticulati mandibulae dorfo inferti.

Mandibula breuis, craffa, cornea, bifida: lacinia inceriore cylindrica, recta, apice dentata; exteriore fornicata, apice truncata, dentata.

Labium triplex.

exterius quadrifidum: laciniis fubaequalibus, interioribus inferne ferratis, exterioribus fifis, apice feta fubula. ta, porrecta, acuta. 
medium bifidum: laciniis rotundatis, tri. fidis; pinna media acutiore, bre. uiore.

interius bifidum : laciniis extrorfum craffioribus, quinquefidis ; pinna media longiore.

Antennae quatuor, inaequales, multarticulatae, pedunculatae.

anteriores longiores, fetaceae, multiarticulatae: pedunculo articulato, craf. fo, fpinofo.

pofteriores multiarticulatae, ad bafin firfae: pedunculo articulato, fpinofo.

Metamorpbofis completa, larua puppaque omnibus partibus completis, agilibus.

Victus e rapina infectorum aquatilium, ranarum: pifciumque. 
129. G A M MA R VS. Cancer. Linn. Geoff. Onifcus Pallas.

Os mandibulis palpisque absque maxillis.

Palpi fex, inaequales, filiformes: anterioribus quatuor porrectis, os obtegentibus.

anteriores longiores, compreffi, bifidi: lacinia interiori quadriarticulata; arriculo vltimo incuruo, exteriori breuiori, vix articulata.

medii paullo breuiores, bifidi : laciniis fubaequalibus; interiori triarticulata, exteriori fubulata, acuta.

pofteriores breues, filiformes, triarticu. lati mandibulae dorfo inferti.

Mandibula breuis, cornea, craffa, fornicata, obtufa, vix dentata, dorfo palpigera.

Labium triplex membranaceum.

exterius quadrifidum: laciniis fubae. qualibus, linearibus.

medium bifidum : laciniis rotundatis, diuifis, aequalibus. 
interius bifidum: laciniis aequalibus, rotundatis, extrorfum crallioribus, diuifis.

Antennac quatuor inaequales, peduncula. tae, fimpliciffimae.

- anteriores breuiores, fubulatae: pedunculo biarticulato.

pofteriores longiores, fetaceae : pedunculo triarticulato.

Metamorphofis completa larua puppaque omnibus partibus completis, agilibus.

Victus e rapina minimorum aquatilium plantisque aquaticis. 


\section{Clajpis $V$. \\ VNOGATA.}

Os maxillis palpisque.

Palpi duo, breues, faepius filiformes, interdum maxillae inferti, incumbentes, interdum palato inter mandibulas $\mathrm{ma}$ xillasque adhaerentes.

Clypeus horizontalis, corneus, rotundatus, os fuperne tegens.

Mandibulae duae transuerfales, corneae, mobiles, breues, gibbae, interdum concauae, vnguiculacae latera oris fu. perne includentes.

Maxillae duae, transuerfales, mobiles, membranaceae, faepius vnguiculatae, latera oris inferne includentes.

Labium porrectum, liberum, os inferne claudens.

Antennae breuiffimae, filiformes fub ocu. lis infertae. 


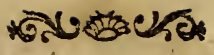

\section{GENERA Claffis V.}

330. LIBELLVLA.

331. AESHNA.

132. AGRION.

33. IVLVS.

134. SCOLOPENDRA.

135. TROMBIDIVM.

36. ARANEA.

124. SCORPIO.

137. PHALANGIVM。 
130. LIBEL L V L A. Linn. Geoff.

Os maxillis palpisque.

Palpi duo filiformes, multiarticulati: articulis obfoletis, vix diftinguendis maxillae dorfo inferti, cui fuperincumbunt.

Mandibula breuis; cornea, craffa, gibba, bafi dentata, apice acuminata.

Maxilla porrecta, cornea, compreffa, bafi dilatara, ciliata, apice vnguiculata, acutiffima, dentata.

Labium porreftum, exfertum, membranaceum, trifidum: laciniis lateralibus maioribus, fornicatis, rotundatis, ciliatis totum os obtegentibus, tertia dorfali, minutiffima, rotundata, vix emarginata.

Antennac breues, filiformes: articulis vix diftinguendis, breuiffimis.

Larua hexapoda, agilis: ore forcipe arti. culato, bifido, membranaceo tecto.

Puppa hexapoda, agilis, laruae fimillima at rudimentis alarum.

Victus \& laruae \& puppae e rapina infectorum aquatilium, imaginis e rapina Antliatorum. 
13I. A ESHNA. Libellula Linn. Geoff.

Os maxillis palpisque duobus.

salpi dio, porrecti, pilofi, fubcornei, incumbentes: articulis plurimis, breuiffimis, obfoletis longitudine maxillae, maxillae dorfo inferti.

Mandibula craffa, cornea, arcuata, denta. ta, exferta.

Maxilla cornea, valida, compreffa, ar. cuata, dentata, apice bifida: dente interiori mobili.

Labium porrectum, fornicatum, fubmem. branaceum, trifidum: lacinis interme. dia rotundata, canaliculata apice emar. ginata; lateralibus ouatis, oblique trun. catis, dentatis: dente fuperiori maiori, validiori, inflexo.

Antennae breues, filiformes: articulis ob. foletis vix diftinguendis, breuiffimis.

Larua hexapoda, agilis, currens: ore for. cipe articulato, vnguiculato, acuto, tecto.

Puppa hexapoda, agilis laruae fimillima at alarum rudimentis.

Vi ctorum aquatilium, imaginis e Antlia. torum. 
I32. A GRION. Libellula Linn. Geoff.

Os maxillis palpisque.

Palpi duo breues, filiformes, multiarticulati: articulis fubobfoletis, vix diftin. guendis maxillae corfo inferti, cui fuperincumbunt.

Mandibula breuis, craffa, cornea, gibba, apice acuminata, dentata.

Maxilla porrecta, cornea, comprefla, bafi dilatata, apice vnguiculata, acutiffima, dentata.

Labium porrectum, membranaceum, ro. tundatum, trifidum: laciniis exterio. ribus tenuiflimis, fublongioribus, apice bifidis, acutiffimis, intermedia maiori, latiore, apice emarginata.

Antennac breues, filiformes: articulis obfoletis, vix diftinguendis, breuifimis.

Larua hexapoda, agilis, currens: ore forcipe articulato, bifido; lacinia exterio. ri vnguiculis pluribus armato, recto.

Puppa hexapoda, currens, laruae fimillima at alarum rudimentis.

Victus \& laruae \& puppae e rapina infectorum aquatilium, imaginise Antliatorum. 


\section{IVLVS. Linn. Geoff.}

Os maxillis palpisque.

Palpi duo, breues, filiformes, compreffi, connati, quadriarticulati : articulo fecundo longiori, vltimo ouato obtufo, inter mandibulas maxillasque inferti.

Mandibula breuis, craffa, gibba margine interiori ferrata apice obrufa, bifida.

Maxilla breuis, membranacea, filiformis, integra.

Labium magnum, porrectum, membranaceum, rotundatum, apice crenatum, emarginatum.

Antexnac filiformes, fexarticulatae: articulis aequalibus, fubmoniliformibus, vltimo obtufo.

Metamorphofis completa.

Larua polypoda, agilis, currens matri fimillima.

Puppa polypoda, agilis, imagini fimillima.

Victus \& laruae, \& puppae \& imaginis $c$ rapina infectorum minimorum, Aca rorum, aliorumque.

$$
\mathrm{K}_{3}-\mathrm{I} 34 . \mathrm{SCO}
$$


I5O मำ

134. SCOLOPENDRA. Linn. Geoff. Os maxillis palpisque.

Palpi duo aequales, connati, compreffi, quadriarticulari: articulo fecundo longiffrmo, vltimo acutiffimo, fubulato palato inter mandibulas maxillasque inferti.

Mandibula breuis, fornicata, bafi anuulata, apice obtura, rotundata, fiffa.

Maxilla magna, porrecta, cornea, arcuata, acutiffima, bafi vnidentata.

Labium breue, corneum, rigidum, apice truncatum, dentatum, bifidum: laciniis aequalibus, obtufis.

Antennae porrectae, fetaceae, multiarticulatae: articulis aequalibus, brenibus; fecundo paullo maiore.

Metamorphofis completa.

Larua polypoda, agilis, currens, ima. gini fimillima.

Puppa polypoda, agilis, currens imagini fimillima.

Victus omnium e rapina infectorum minimorum. 
135. TROMBID I V M. Acarus Linn.

Geoff.

Os maxillis palpisque.

Palpi duo porrecti, incurui, maxillas ae. mulantes, filiformes quadriarticulati: articulis cylindricis; fecundo gibbo, craffiori, vltimo corneo, acutifimo, arcuato os obregentes.

Mandibula recta, porrecta, compreffa, bafi excauata, apice vnguiculo corneo, arcuato, acutifimo armata.

Maxilla breuifima, incurua, approximata.

Labium porrectum, conicum, membranaceum, concrum, inuolutum, pilo. fum, maxillas recipiens.

Antennae, quantum video, omnino nullae. Metamorphofis completa.

Larua octopoda agilis, currens, omnibus partibus completa, imagini fimillima.

Puppa octopoda, agilis, currens imagini fimillima.

Victus. \& laruae \& puppae \& imaginis e rapina aliorum infectorum, quisquiliis. 
136. AR ANE A. Linn. Geoff.

Os maxillis palpisque.

Palpi duo porrecti, aequales, incurui, quadriarticulati : articulo fecundo longitfimo, vltimo obtufo maxillae dorfo adhaerentes.

Mandibula breuis, craffa, cornea, approximata, caua, cylindrica, apice vnguiculata, acutiflima.

Maxilla breuis, craffa, cornea, cylindrica, apice vnguiculo arcuato, acutifimo armata.

Labium breue, membranaceum, apice rotundatum, integrum.

Antennae, quantum videre licet, omnino nullae.

Metamorphofis completa.

Larua octopoda, agilis, currens, omnibus partibus completa, imagini fimillima. Puppa octopoda, agilis, currens imagiri fimillima.

Viftus \& laruae \& puppae \& imaginis e rapina aliorum infectorum inprirnis Antliatorum.

Ob. I. Palpi maris articulo vltimo claunto, veficuloro apice acuminato funt genitalia.

O6. II. Situs oculorum in fpeciebus differt \& fubdiuifiones generis dittincillimas praebet. 
124. SCORPIO. Linn. Chelifer. Geoff.

$O s$ maxillis palpisque.

Palpi duo elongati, cheliferi, quadriarticulati: articulis cylindricis; primo breuiffimo, vltimo ad medium bifido: laciniis conniuentibus, aequalibus, exteriori articulato, mobili fub maxilis inferti.

Mandibula breuis, craffa, cylindrica, dorfo gibbo, apice vnguiculata: vnguibus duobus arcuatis, acutiffimis.

Maxilla breuis, cornea, fornicata, apice vnguiculo arcuato, acuto labium includens.

Labium ređtum, porrectum, coneum, bi. fidum: laciniis aequalibus, obtufis.

Anterrac, quantum video, omnino nullae.

Metamorphogis completa.

Larua octopoda, agilis, currens omnibus partibus completa, imagini fimillima.

Puppa octopoda, aglis, currens, imagini fimillima.

Victus \& laruse \& puppae \& imaginis e rapina infectorum vermiumque.

$$
\text { K } 5 \text { I37. PHA- }
$$


137. PHALANGIVM. Linn. Geoff.

Os maxillis palpisque.

Palpi duo aequales, incurui, elongati, fcabri, filiformes, quadriarticulati: articulo fecundo quartoque longioribus, tertio interne bidentato maxillae dorfo inferti.

Mandibula porrecta, cornea, arcuata, rigida, biarticulata: articulo fecundo dente mobili chelifero acutiffimo.

Maxilla breuis, cylindrica, membranacea, caua, apice truncata, obtula.

Labium breue, rotundatum, membranaceum \& fere veficulofum, bificum: laciniis rotundatis, aequalibus.

Antennac, quantum videre licet, omnino nullae.

Metamorphofis completa.

Lerua octopoda, omnibus partibus com. pleta imagini fimillima.

Puppa octopoda, agilis, currens, imagini fimillima.

Victus \& laruae \& puppae \& imaginis e 12.pina aliorum Infectorum, vermiumque.

ObF. Pbalangii cornuti articulus palporum pea nultimus digito mobili palpiformi in. ftructus. 


\section{WN \\ Clajis $V I$. \\ G L O S S A T A.}

155

$O$ s lingua fpirali palpisque absque maxillis, mandibulis labioque.

Clypeus breuiffimus, corneus, rugofus, integer, vix bafin linguae f piralis tegens.

Palpi duo, interdum quatuor, compreff, outi, pilofi, reflexi os obtegentes fub ore inferti.

Lingus spiralis porreeta, inuoluta, fetacea, mox cornea, mox membranacea, bifida: laciniis aequalibus, acutis, intus canaliculatis inter palpos inferta, latens.

Antsnnac elongatae.

06f. Characteres generum huius claffis mihi nondum fatis fecerunt. 
156 เล.

GENERA Clamis VI.

38. PAPILIO.

139. SPHINX.

140. SESIA.

141. ZYGAENA.

142. BOMBYX.

143. HEPIALVS.

144. NOCIVA.

145. PHALAENA.

146. PYRALIS.

147. TINEA.

148. ALVCITA.

I49. PTEROPHORVS. 


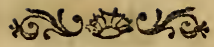

138. PAPILIO. Linn. Geoff.

Os lingua fpirali palpisque absque maxillis.

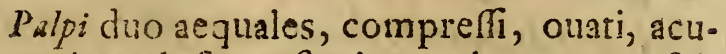
ti, pilofi, reflexi os obtegentes fub ore inferti.

Lingua fpiralis porreeta, elongata, cornea, involuta, fetacea, bifida: laciniis aequalibus, acutis, intus canalicu. latis inter palpos inferta, latens.-

Clypeus breuis, corneus, conicus, acutus, integer, rugofus, vix bafin lin. guae exteriorem tegens.

Antennac elongatae multiarticulatae, cla. uatae: claua capitata, ouata, obtufa.

Larua. XVI poda, agilis, currens, fpinis compofitis faepius armata, interdum nuda, tentaculata.

Puppa nuda, quiefcens, plerumque nodora interdum filis quibusdam apicis, interdum filis in medio alligatis adhaerens.

Vičtus laruae e foliis plantarum, imaginis e nectare florum fuccoque arborum exfudante.

Obf. Equitum plures fpecies antennas getunt filiformes absque omni claua.

339. SPHINX 
I39. SPHINX. Linn. Geoff.

Os palpis linguaque fpirali absque maxillis.

Palpi duo reflexi, compreffi, aequales, ouati, obtufi, hirfutifimi fub ore in. ferti os tegentes.

Lingua fpiralis, cornea, porrecta, exferta, inuoluta, filiformis, truncata, ob. tufa, bifida: laciniis intus canaliculatis fupra palporum bafin inferta.

Clypeus breuis, corneus, truncatus, fornicatus, integer linguae bafin fuperne tegens.

Antennae filiformes multiarticulatae : articulis aequalibus, fubrus fquamula parua, erecta, obtufa armatis.

Larua XVI poda, agilis poftice plerum. que cornti erecto rigido, acuto armata.

Puppa quiefcens, nuda, lacuis, glabra, poftice obtufiflima.

Vičus laruae e foliis plantarum, imaginis e nectare florum.

Obf. S. ocellatac lingua breuiffima, haud exSerta. 
140. SESIA. Sphinx Linn. Geoff.

Os palpis linguaque fpirali absque maxillis.

Palpi duo, compreffi, aequales, ouari, acuminati; pilofi fub ore inferti torum os tegentes.

Lingua Jpiralis cornea, exferta, porrecta, inuoluta, filiformis, obtufa, truncata, bifida: laciniis aequalibús, obtufis, intus canaliculatis fupra palporum balin inferti.

Clypeus breuis, corneus, rotundatus, apice acuminatus, vix bafin linguae tegens.

Antennae cylindricae, extrorfum craffo. res, multiarticulatae: articulis aequalibus.

Larua XVI poda, agilis, plerumque nu$\mathrm{da}$, inermis, antice attenuata.

Puppa quiefcens, nuda, laeuis, antice pofticeque acuminata.

Victus laruae e foliis plantarum, imaginis e nectare florum. 
14t. ZY GAENA. Sphinx Linn. Geoff.

Os palpis linguaque fpirali absque maxillis.

Palpi duo aequales, compreffi, reflexi, pilofi, ouati, acuminati fub ore inferti totum os tegentes.

Lingua fpiralis cornea, exferta, porrecta, inuoluta, fetacea, acuta, bifida: laciniis aequalibus, fetaceis, acutis, intus canaliculatis fupra palporum bafin inferti.

Clypezs breuis, corneus, rotundatus, integer vix linguae bafin tegens.

Antennae porrectae, multo articulatae, ante apicem faepius craffiores, apice acuminatae.

Larua XVI poda, agilis, craffa, obefa, pilis breuibus tecta.

Puppa quiefcens, folliculata, antice parum attenuata.

Victus laruae e foliis plantarum, imaginis e nectare florum.

Obf. Species quaedam antennas gerunt fili-, formes, pectinatas. 
142. BO MB YX. Phalaena Linn. Geoff.

Os palpis linguaque fpirali absque maxillis.

Palpi duo aequales, compreffi, pilofi, relexi, obtufi, fub ore inferti, totum os obtegentes.

Lingua fpiralis breuis, membranacea, vix exferta, filiformis, obtufa, bifida: laciniis aequalibus, filiformibus, fubcy. lindricis, intus canaliculatis fupra palporum bafin inferti.

Clypeus breuis, corneus, hirtus, apice acuminatus, linguae bafin fuperiorem regens.

Antennae filiformes, multiarticulatae, apice acutae.

Larua XVI poda, agilis, currens, faepius pilefe, fubcylindrica.

Puppa quiefcens, folliculata, cylindrica, apice acuminata.

Victus laruae e foliis plantarum, imaginis e nectare florum.

06\% Antennae femper filiformes, maris faepius pectinatae. 
143. HEPIA LVS. Phalaena Linn. Geoff.

os palpis, linguaque fpirali absque maxillis.

Palpi duo aequales, reflexi, obtufi, menıbranacei, compreffi, hirfuti, fub ore inferti, os obtegentes.

Linguae (piralis rudimentum breue, membranaceum, latum, depreffum, bifidum: laciniis aequalibus, obtufis, rotundatıs inter palpos infertum.

Clypeus breuis, corneus, rotundatus, integer, linguae bafin fuperne tegens.

Antennae breues, filiformes: articulis plurimis, diftinctis, aequalibus, rotundatis.

Larua XVI poda, agilis, currens, fubcy: lindrica, faepius giabra.

Pruppa quiefcens, folliculata, cylindrica; apice acuminata.

Victus laruae e radicibus plantarum, imaginis e ne£are florum. 
r44. NOCTVA. Phalaena. Linn. Geoff.

Os.palpis linguaque fpirali absque maxillis.

Palpi dno, aequales, reflexi, comprefli, pilofi, apice cylindrici, nudi, obtufi, membranacei, fub ore inferti, os obre.

- gentes.

Lingua fpiralis cornea, exferta, porrecta, inuoluta, fetacea, acuta, bifida: laciniis aequalibus fêtaceis, acutis, intus canaliculatis inter palpos inferta.

Clypeus breuis, corneus, rotundacus, inreger, vix linguae fpiralis bafin fuperiorem tegens.

Antemae fetaceae, articulis plurimis aequalibus, cylindricis, vix diftinguendis, vitino acuto.

Iarua XVI- pada, agilis, currens, fub. cylindrica, faepius glabra.

Puppa folliculata, cylindrica, apice acu. minata.

Jictus laruae e foliis plantarum, imaginis e nectare florum.

abf. Antennae plerumque fimplices, maris rarius pectinarae.

$$
\text { I. } \quad 45 . \mathrm{PHA} \text {. }
$$


164 क्तै

145. PHALAENA. Linn. Geoff.

os palpis linguaque fpirali absque maxillis.

Palpi duo aequales, reflexi, compreffi, membranacei, ftupofi, fubnudi, cylindrici, obtufi, fub ore inferti os tegentes.

Lingua (piralis membranacea, exferta, fetacea, inuoluta, bifida: laciniis aequalibus, fetaceis, intus canaliculatis fupra bafin palporum inferta.

Clypeus breuis, corneus, rotundatus, integer bafin linguae fuperne tegens.

Antennae filiformes: articulis plurimis, breuibus, aequalibus, obfoletis.

Larua VIII - X poda agilis, currens, cylindrica, glabra.

Puppa, folliculata, cylindrica, apice acuminata.

Victus laruae e foliis plantarum, imaginis e nectare florum.

06. Subdiuifio fpecierum in pectinicornes \& feticornes vix valet, quum mas faeminae feticornis faepius pectinicornis. 
146. PYR A L IS. Phalaena. Linn. Geoff.

Os palpis linguaque fpirali absque maxillis.

Palpi duo aequales, nudi; ftupofi, reflexi, bafi cylindrici, medio ouati, dilatati, apice fetacei fub ore inferti totum os obtegentes.

Lingua fpiralis porrecta, membranacea, inuoluta, fetacea, bifida: laciniis aequalibus, fetaceis, acutis fupra palporum bafin inferta.

Clypeus breuis, corneus, truncatus, latus, integer vix bafin linguae fuperne tegens.

Antennae filiformes, fimplices: articulis breuibus, aequalibus, obfoletis.

Larue XVI poda, agilis, currens, plerum. que intra cucullum e foliis plantarum contortis filis paucioribus connexis latens.

Puppa quiefcens, cylindrica, antice acuminata, poftice obtufa.

Victus laruae e foliis plantarum; imaginis e nectare forum.

$$
\text { L } 3 \text { I47. TI- }
$$


147. TINEA. Geoff. Phalaena Linn。

Os palpis linguaque fpirali absque maxillis. Palpi quatuor, inaequales.

anterieres longiores, porrecti, filiformes, cylindrici, membranacei, obtufi, bafi nudi, fubarticulati, apice fubhir futi, fub ore inferti os tegentes.

pofteriores multo breuiores, nudi, cylindrici, obtufi, bifidi: laciniis aequalibus vtrinque ad bafin linguae inferti.

Lingua fpiralis membranacea, exferta, fetacea, bifida: laciniis aequalibus, $\mathrm{fe}$ taceis, intus canaliculatis inter palpos inferiores inferta.

Clypeus breuis, cornets, rotundatus, integer, pilofus linguae bafin tegens.

Antcnnae fetaceae : articulis plurimis, aequalibus, breuiffimis, obfoletis.

iarua XVI-poda, agilis, currens, intra cucullum faepius latens.

Puppa quiefcens, fubcylindrica, antice acuminata.

Victus laruac e foliis plantarum, rebus culinariis, veftimentis, pellibus aliisque. 
148. A LVCITA. Phalaena Linn. Tinea. Geoff.

Os palpis linguaque fpirali absque maxillis.

Palpi duo reflexi, perrecti, cylindrici, nudi, aequales, membranacei, acuti, vsque ad medium bifidi: laciniis fubacqualibus lnearibus; interiori acutiffima, nuda, exteriori hirfuta, fub ore inferti os tegentes.

Lingus fpiralis membranacea, porrecta, fetacea, inuoluta, bifida: laciniis aequalibus, fetaceis, intus canaliculatis ad bafin palporum inferta.

Clypeus porrectus, corneus, rotundatus, hirtus, integer bafin linguae tegens.

Antennae fetaceae: articulis breuibus, plurimis, aequalibus vix diftinguendis.

Larus XVI- poda agilis, currens, faepius intra cucullum latens.

Puppa quiefcens, fubcylindrica, antice acuminata.

Victus laruae e foliis plantarum.

$$
\text { L } 4 \text { 149. PTE. }
$$


108

\section{หละ}

\section{PTEROPHORVS. Geoff. Phalaena Linn.}

Os palpis linguaque fpirali absque maxillis.

Palpi duo tenuiffini, cylindrici, filiformes, reflexi, nudi, apice fubulati, acuti, membranacei fub ore inferti toturn os tegentes.

Lingua ppiralis membranacea, porrecta, elongata, fetacea, acuta, bifida : laciniis aequalibus, intus canaliculatis; ${ }^{\prime}$ acutis fupra palporum bafin inferta.

Clypeus porrectus, membranaceus, truncatus, nudus, obtufus, integer linguae bafin tegens.

Antennac fetaceae: articulis plurimis bre. uiffimis, aequalibus vix diftinguendis.

Larua XVI- poda, agilis, currens, ouata, pilofa.

Puppa quiefcens, nuda, fubcylindrica apice fubulata.

Victus laruae e foliis plantarum, imaginis vix vllus. 


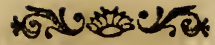 \\ Clafis VII. \\ R Y N G O T A.}

$O$ s roftro absque maxillis, mandibulis palpisque.

Roftrum inflexum, cylindricum: vagina vniualui, articulata, obtufa fetisque plerumque tribus, filiformibus, aequalibus, acutis.

Labium porrectum, corneum, acutum, rigidum, roftri bafin fuperne tegens.

Antennac breues, faepius filiformes, te. nuiffimae.

Pulex a reliquis generibus huius claffis differt vagina biualui, feta vnica, laminis duabus ad vaginae bafin infertis \& metamorphofi. 


\section{GENERA Clafis VII.}

\section{FVLGORA.}

$97 \rightarrow 5$ I. MEMBRACIS.

$298 \rightarrow$ 52. TETTIGONIA.

$298 \Rightarrow 153 . \mathrm{CICADA}$.

154. CERCOPIS.

I55. NOTONECTA.

I56. SIGARA.

157. NEPA.

158. NAVCORIS.

159. ACANTHIA:

I60. CIMEX.

I61. REDVVIVS.

162. PVLEX.

I63. APHIS.

164. CHERMES.

165. COCCVS.

I66. THRIPS. 


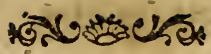

\section{FVLGORA. Linn.}

Os roftro absque maxillis palpisque.

Rofrum elongarum, inflexum, filiforme, obtufum.

Vagina vniualuis, cornea, cylindrica, fupra canaliculata, quinque articulata: articulo fecundo breuílimo, quarto longillimo, vltimo breuiori obtufo.

Sctae tres intra vaginam retractiles, filiformes, acutae; intermedia fublongiori.

Labium porrectum, corneum, rigidum acutum, carinatum, fuperne roftrum tegens.

Antennae breues, craffae, in fouea capitis recondendae, capitatae.

Stipes annulatus, retractilis, bafin capituli vaginans.

Cupinum oblongum, apice excauato retufum, feta filiformi acuta longitudine antennarum.

Larua hexapoda, agilis, currens, imagini fimillima at aptera.

Puppa hexapoda agilis, currens imagini fimillima at folis alarum rucimentis.

Victus e fucco plantarum, quem roftro haurit.

Iร T. MEM. 
172

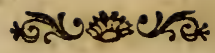

15 I. MEMBRACIS. Cicada Linn.

$O$ s roftro absque maxillis palpisque.

Roftrum inflexum, obtufum.

Vagina porrecta, vniualuis, cylindrica, obtufa, fuperne canaliculata, triarticulata: articulo primo breaiffimo, reliquis aequalibus fub feris inferta.

Setae tres aequales, conniuentes, arcte fibi inuicem adhaerentes, fubulatae, in vaginae canali recondend̦ae ad bafin vaginae infertae.

Labium elongatum, corneum, conicum, rigidum apice membranaceum, fubulatum, acutum, fetarum bafin regens.

Antennac tenuifimae, breues, fubulatae fronti infertae.

Larua hexapoda, currens, imagini fimil. lima, aptera.

Puppa hexapoda, currens, imagini fimillima at rudimentis tantum alarum.

Victus \& laruae \& puppae \& imaginis e fucco plantarum. 
I52. TETTIGONIA. Cicada Linn. roftro absque maxillis palpisque.

Rofirum porrectum, inflexum.

Vagina conuoluta, vniualuis, biarticulata: articulo primo craffiori, inaequali, fecundo longiori, cylindrico, fetas continens fub capitis apice inferta.

Setae tres, aequales, filiformes, apice fubulatae, tenues capitis apici in. fertae.

Labium breue, membranaceum, acutum, (integerrimum bafin fetarum tegens.

Antennae fetaceae: articulo primo craffiffimo, reliquis aequalibus fronti infertae.

Larua hexapoda, currens, aptera imagini fimillima.

Puppa hexapoda, currens imagini fimilli$\mathrm{ma}$ at folis alarum rudimentis.

icfus e fucco plantarum roftro hauriendo. 


\section{Q153. CICADA. Linn.}

Os roftro absque maxillis palpisque.

Roftrum breue, inflexum.

Vagina breuiffima, vniualtis, membra: nacea, cylindrica, obtufa, triarticulata : articulis fubaequalibus, $r e$ cundo fubcraffiori fub fetarum bafi inferta.

Setac tres porrectae, fubulatae acutae, vagina longiores, inaequales: intermedia longiori, acutioni fupra bafin vaginae infertae.

Labium porrectum, membranaceum, tenuiffimum, acutum bafin fetarum fuperne tegiens.

Antennae tenuiffimae, fubulatae : articulis vix diftinguendis fub oculis infertae.

Larua hexapoda currens imagini fimillima at aptera.

Pupp hexapoda, currens imagini fimillima at folis alarum rudimentis.

Victus omnium e fucco plantarun. 


\section{CER COPIS. Cicada Linn. Geoff.}

Os roltro absque maxillis palpisque.

Roftrum inflexum.

Vagina porrecta, vniualuis, obtufa, fuperne canaliculata, triarticulata: articulo fecundo maiori, tertio fub. conico, fub ferarum bafi inferta.

Setae tres, fubulatae, acutae in vaginae dorfo latentes, inaequales: intermedia longiori fub capitis apice infertae.

Labium abbreuiatum, membranaceum, truncatum, emarginatum bafin feta. rum tegens.

Aktennac fubulatae, tenuifimae: articulis vix diftinguendis fub oculis infertae.

Larua hexapoda, currens, agilis imagini fimillima at aptera.

Puppa hexapoda currens, agilis imagini fimillima ar folis alarum rudimentis.

Victus \& laruae \& puppae \& imaginis e fucco plantarum. 
155. NOTONECTA. Linn. Geoff.

Os roftro absque maxillis palpisque.

Roftrum arcuatum, inflexum.

Vagina porrecta, cornea, vniualuis, obtufiufcula, concaua, triarticulata: articulo fecundo longiffimo, craffiori, fetas continens.

Setae tres, fetaceae, fubulatae, acutae, inaequales: intermedia longiori adbafin vaginae infertae.

Labium rigidum, conicum, corneum, apice membranaceum, acuminatum bafi dilatatum roftri bafin tegens.

Antennae breues, triarticulatae: articulo primo \& fecundo cylindricis, vltimo breuiore fetaceo, fub oculis infertae.

Larua hexapoda, agilis, natans, imagini fimillima at aptera.

Puppa hexapoda agilis, natans imagini fimillima at folis alarum rudimentis. •

Victus omnium e fucco animalculorum aquaticorum. 
156. SIGARA. Notoneda Linn.

Corixa Geoff.

Os porrectum, corneum roftro, absque pal. pis maxillisque.

Rofirum breue, fubinflexum.

Vagina vniualuis, breuis, fubarcuata, conica, acuminata, cornea, concaua, lateribus fpinofa, transuerfe fulcata torum os obtegens.

Sctac tres fetaceae, fubulatae, acutae, diftantes, inaequales: intermedia longiori fub capitis apice infertae.

Labium nullum at yagina capiti adhaeret, os verinque tegit.

Antennae breuiffimae, filiformes, triarticu. latae: articulis aequalibus fub oculis infertae.

Larua hexapoda, agilis, natans, imagini fimillima, at aptera.

Puppa hexapoda, agilis, natans, imagini fimillima, at folis alarum rudimentis.

Victus e rapina animalculorum aquatico. rum. 
157. NEPA. Linn. Hepa Geoff.

Os roftro absque palpis maxillisque.

Rofrum breue, arcuatum, acutum, inflexum.

Vagina vniualuis, cornea, rotundata, fubulata, acutiufcula, triarticulata: articulo primo breuilfimo, fecundo longiffino, tertio tenuiori.

Setac tres fubulatae, acutae, inaeguales: intermedia longiore acutiore, lateralibus duplo breuioribus, intra vaginam latitantes.

Labium vix vllum, truncatum, haud exfertum.

Antennae brenes, palmato diuifae, fub oculis infertae, in forfula oculorum recondendae.

Larua hexapoda, agilis, natans, imagini fimillima, at aptera.

Puppa hexapoda, agilis, natans, imagini fimillima, at folis alarum rudimentis.

Victus e fucco animalium aquaticorum. 


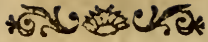

I58. NAVCORIS. Geoff. Nepa Linn.

Os roftro absque palpis maxillisque.

Roftrum breue, inflexum.

Vagina vniualuis, cornea, rotundata, fubulata, acutiufcula, triarticulata: articulo primo \& fecundo craflioriLus, terrio breuiori, fubulato.

Setue tres filiformes, vagina longiores, apice fubulatae, acutae, inaequales: intermedia longiore, acutiore, rigidiore fupra bafin vaginae infertae.

Labium corneum, porrectum, apice rotundatum, integrum, primum roftri articulum tegens.

Antennae breuilfimae, filiformes, fub oculis infertac.

Zarua hexapoda, agilis, natans, imagini fimillima, at aptera.

Puppa hexapoda, agilis, natans, imagini fimillima, at folis alarum rudimentis.

Victus \& laruae \& imaginis e fucco anima. lium aquaticorum. 
180

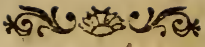

159. ACANTHIA. Cimex Linn. Geoff.

Os roftro absque palpis maxillisque.

Roftrum elongatum, inflexum.

Vagina vniualuis, recta, cylindrica, cor. nea, acuriufcula, triarticulata: articulis cylindricis, fubaequalibus; fecundo parum longiori fub capitis apice inferta.

Setae tres, filiformes, acutae, inaequales: intermedia parum longiore.

Labium nullum.

Antennae porrectae, filiformes, triarticulatae: articulis fubaequalibus, cylindricis ante oculos infertae.

Larua hexapoda, agilis, currens, imagini fimillima, at aptera.

Puppa hexapoda, agilis, currens imagini fimillima, at folis alarum rudimentis.

Victus \& laruae \& imaginis e fucco animalium plantarumque. 
160. CIMEX. Linn. Geoff.

Os roftro absque palpis maxillisque.

Rofrum elongatum, inflexum.

Vagina vniualuis, porrecta, cylindrica, cornea, obtufa, fupra canaliculata, fubtus rotundata, feras includens, guadriarticulata: articulis inaequalibus; primo craffiori, fecundo lon. giffimo.

Setac tres connimentes, fubulatae, 'acutae, fubaequales: intermedia pa. rum longiori.

Labium elongatum longitudine dimidiae ferae, validum, fibularum, annulatum, acutum, feras fuperne tegens.

Antennae porrectae, filiformes, quadriarticulatae: articulis cylindricis: primo longióri ante oculos ad latera roftri infertae.

Lavua hexapoda, agilis, currens, imagini fimillima, at aptera.

Puppa hexapoda, agilis, currens, imagini fimillima, at folis alarum rudimentis.

Victus e fucco animalium plantarumque. 
16r. REDVVIVS. Cimex Linn. Geoff.

Os roftro absque palpis maxillisque.

Rofrum breue, arcuatum, infiexum.

Vagina cylindrica, cornea, apice feta. cea, fetas continens, biarticulata:

- articulo primo breviori, crafliori, cylindrico, fecundo longiori, fubulato, acutiffimo.

Setae tres conniuentes, fubulatae, acutae, inaequales: intermedia longiore.

Labium vix vllum, truncatum, nec fupra bafin roftri porrectum.

Antennae porrectae, fetaceae, triarticulatae: articulis lcylindricis, vltimo bre. uiori fupra oculos infertae.

Larua hexapoda, agilis, currens, imagini fimillima, at aprera faepiusque quisquiliis obtecta.

Puppa hexapoda, agilis, currens, imagini fimillima, at folis alarum rudimentis. Tićtus e fucco animalium. 
162. PVLEX. I.inn. Geoff.

Os roftro absque palpis maxillisque.

Roftrum elongatum, inflexum.

Vagina cylindrica, biualuis: valuulis ae: qualibus, rotundatis, canaliculatis, quinquearticulatis: articulis fubaequalibus; vltimo obtufo.

Seta vnica filiformis, acuta, canaliculata, vagina fublongior.

Laminae duae, ouatae, acuriufculae, vagina multo breuiores ad bafin latera. lem vaginae infertae.

Labium abbreuiatum, rotundatum, aculeis reflexis ciliatum vix bafin roftri tegens. Antennae porrectae, extrorfum craffiores, quadriarticulatae: articulis obconicis; vltimo maiori ouato.

Larua apoda, cylindrica, agilis fpinis duobus, cylindricis, fubcaudalibus. Puppa quiefcens, immobilis, imagini fimillima.

Vicfus e fucco fanguineque animalium, quisquiliis.

Obf. Singulare fane infectum. Differt ab hac claffe vagina biualui, ab Antliatis defectu probofcidis palporumque vaginaque articulata. $\mathrm{Ab}$ ambabus vero metamorphofi, qua ad Vlonata accedit.

$$
\mathrm{M}_{4} \text { 163. A- }
$$


163. A PHIS. Linn. Geoff.

Os roftro absque palpis maxillisque.

Rofrum elongatum, inflexum.

Vagina porreeta, inuoluta, cylindrica, feram continens, quinquearticulata: articulo primo maiori, vltimo acumillato.

Sete vnica, tenuiftima, filiformis, apice acuminata, vagina longior, retractilis , intra vaginam latens fupra cius bafin inferta.

Labium breue, fornicatum, truncatum, integrum.

Antennac porrectae, fetaceae : articulo primo crafliori fronti infertae.

Larua hexapoda, agilis, currens, aptera, imagini fimillima.

Puppa hexapoda, agilis, currens, ima. gini fimillima.

Victus \& laruae \& imaginis e fucco plantarum.

Obf. A phides aeftate viluiparae, autumno ouiparae. Aliae apterae, aliae alatae abs. que fexus difcrimine in eadem fpecie.

164. CHER. 
164. CHERMES. Linn. Geoff.

Os roftro absque maxillis palpisque.

Rofrum elongatum, inflexum vagina pe. Etorali.

Vagina membranacea, cylindrica, ob. tufa, triarriculata: articulis fubae. qualibus pectori inter femora antica inferta.

Sitae tres fetaceae, acutae, inaequales: intermedia fiblongiori capitis apice incertae intra vaginam pectoralem latentes.

Labium conicum, acutum, compreffum, bafi dilatatum; corneum bafin fetarum fuperne tegens.

Antennac breues, cylindricae, apice feta antennis longiori armata.

Larua hexapoda, aptera, faepe villofa, imagini limillima.

Puppa hexapoda, agilis, imagini fimillima folis tamen alarum rudimentis.

Victus e fucco plantarum. 
165. COCCVS. Linn. Geoff.

$O s$ roftro abque maxillis palpisque.

Roftrum breue, inflexum vagina ferisque pectoralibus.

Vagina cylindrica, membranacea, ob. tufa, triarticulata: arriculis aequalibus pectori inter femora antica in. rerta.

Setae tres fubaequales: intermedia paullo longiore, acutae ad bafin vagi nae pectori infertae.

Labium nullum.

Antennae breues, filiformes, cylindricae, triarticulatae; articulis aequalibus; vltimo ouato.

Larua hexapoda, currens, imagini fimil. lima, aptera.

Puppa hexapoda, agilis, imagini fimillima. Victus e fucco plantarum.

Obf. Faeminae tardae, apterae, grauidae plan. tis adhaerent fere immobiles. Mares alis duabus erectis, compreflis. 


\section{Wล}

166. THR IPS. Linn. Geoff.

Os rima longitudinali absque palpis maxillisque.

Rofrum obfcurum, intra labia rimae re. conditum, haud diftinguendum.

Antcnnae porrectae, filiformes: articulis - feptem; primo maiori, reliquis aequalibus, vltımo acuto.

Larua hexapoda, agilis, currens, imagini fimillima, aptera.

Puppa hexapoda, agilis, currens, imagini fimillima folis alarum rudimentis.

Vicius omnium e polline florum.

Obf. Inftrumenta cibaria huius generis mihi haud rite nota. Ad Ryngota tamen pertinere ob metamorphofin videtur. 


\section{A N T L I A TA.}

$O$ s hauftello absque mandibulis maxillisque.

Hauftellum plerumque exfertum, vaginatum, cylindricum, intra rimam oris longitudinalem infertum.

Vagina mox vniualuis, mox biualuis fetas includens, acuta, inarticulata.

Sctae faepius, tres, fetaceae, acurae, inaequales: intermedia paullo longiore.

Probofcis quibusdam breuis, membrana. cea: ftipite cylindriço, retractili; dorfo canaliculato, capitulo bilabiato fub hauftello inferta.

Palpi interdum duo ad bafin probofcidis inferti.

Antennae breues, plerunque cylindricae, faepius feta armatae. 


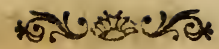

\section{GENERA Claffis VIII.}

167. OESTRVS.

168 TIPVLA.

169. BIBIO.

170. STRATIOMYS.

17 I. RHAGIO.

172. SYRPHVS.

173. MVSCA.

174. TABANVS.

I75. RHINGIA.

176. AsILVS.

177. CONOPS.

178. STOMOXYS.

179. MYOPA.

180. CVLEX.

I8r. EMPIS.

182. BOMBYLIVS.

183. HIPPOBOSCA.

184. PEDICVLVS.

185. ACARVS. 


\section{OESTRVS. Linn. Geoff.}

Os hauttello absque probofcide \& palpis.

Haufellum retractum intralabia veficulofa, tumida, connata, poro paruo, rotundo ad exferrionem hauftelli pertufa.

Vagina membranacea, cylindrica, obtufa, palato inferta fetas includens.

Sotal tres, membranaceae, flexiles, breues, reflexae, fubaequales labii apici infertae.

Palpi nulli.

Antennac breues, filiformes: articulo primo globofo, craffiori fronti infertae.

Larua apoda, breuis, craffa, mollis, annulata, intra animalium corpora latens.

Puppa ouata, apoda, immobilis, cute dura, craffa, brunnea tecta.

ViEtus laruae e fucco animalium, imaginis vix vllus. 
168. TIP VLA. Linn. Geoff.

Os probofcide, hauftello palpisque.

Probofcis breuiffima, vix exferta, membranacea: dorfo canaliculata fetam reci. piens; ftipite cylindrico retractili, capitulo bilabiato, aequali.

Hauftellum breue, nudum, absque vagina.

Scta vnica tenuis, longitudine probofcidis, rigida, fetacea, acuta in canali proborcidis recondenda.

$P$ alpi duo porrecti, aequales, incurui, filiformes, multiarticulati: articulis tribus anterioribus craffioribus, obconicis, reliquis breuioribus, cylindricis vtrinque ad bafin probo. fcidis inferti.

Antenna filiformes, multiarticulatae: arriculo primo craffiori, maiori.

Larua apoda, cylindrica, mollis: capite truncato, dentato.

Puppa immobilis, cylindrica: antice bicornis, poftice dentata.

Victus laruae e radicibus plantarum, imaginis e quisquiliis. 
192

169. B I B IO. Mufca Linn. Geoff.

Os probofcide, hauftello, palpisque.

- Probofcis membranacea, exferta : Atipite cylindrico, reflexo; dorfo canaliculato ad receptionem fetarum, capitulo bilabiaro labiis aequalibus.

Haufellum vagina vniualui, cornea, reflexa, dorfali, apice truncata, obtufa fetas fuperne tegente.

Setae tres fetaceae, fubaequales: intermedia rigidiore, lareralibus diftantibus, palpis breuioribus.

Palpi duo porrecti, filiformes, quadriarticulati : articulo fecundo longiffimo, quarto fuborbiculato ad bafin lateralem probofcidis inferti.

Antennae breves, cylindricae, approximatae.

Metamorphofis \& Victus adhuc omnino latent.

Musca illucens antennis longioribus clauatis. 


\section{I70. STRATIOMYS. Geoff. Murca Linn.}

Os probofcide, hauitello palpisque.

Probofcis breuis, exferta: ftipire fubccr. neo, cylindrico, recurwo; dorfo cs. naliculato ad receptionem fetae, capitulo membranaceo, incraffato, bilabjato: labiis aequalibus.

Har:fellum absque vaginà.

Seta vnica, valida, porrecta, longitudine probofcidis, cylindrica, caua, obtufa, medio dorfali probofcidis inferta in cuius canali dorfali recon. ditur.

Palpi duo breues, fubcapitati, triarticulati: articulis cylindricis; vltimo crarfiori, medio laterali probofcidis inferti.

sntennae porrectae, approximatae, cy. lindricae, acurae: articulo primo ma. iori, reliquis fubaequalibus.

Laru aquatica, apoda, annulata, fubcy. lindrica, poftice arrenuata, apice fpi. raculo pertufa, barbata.

Puppa immobilis, cylindrica, cute latuac indurata tecta.

Victus laruae e animalculis aqgitaticis, ima. ginis e quisquiliis. 
i.7. RHAGIO.

Os probofcide, hauftello palpisque.

Probufcis membranacea, exferta: dorfo canaliculato ad receprionem fetarum, ftipite breuiffimo, cylindrico, capituloque dilatato, adfcendente, bilabiato: labiis aequalibus; ciliatis.

Haffellum breue absque vagina.

Setae tres filiformes, cylindricae, apice acuminatae, probofcide parum breuiores, inaequales: intermedia parum longiori, validiori ad bafin dorfalem probofcidis infertae.

Palpi duo porrecti, longitudine probofcidis, filiformes, pilofi, quinquearticulati: articulo fecundo longiffimo, reliquis breuioribus, tenuioribus bafi laterali probofcidis inferti.

Antennae breues, approximatae, cylindricae, apice acuminatae, fetigerae.

Metamorpbofis \& Victus nobis adhuc latent. 
172. SYRPHVS. Mufca Linn. Geoff.

Os probofcide, hauftello atque palpis.

Probofcis porrecta, exferta, membranacea, dorfo ad receptionem fetarum canaliculata : ftipite elongato, cylindrico, capitulo bilabiato: labiis aequalibus, acuris.

Hauftellum porrectum absque vagina.

Setae quatuor inaequales: laterales paullo breuiores, fubulatae, intermediae inaequales: interiori minore, acutiore, fubulata, exteriori craffiori, fornicata, vaginante, obtufa, bafi dorfali probolicidis infertae.

Palpi duo fetis parum breuiores, filiformes: articulis aequalibus adhaerentes bafi fetarum exteriorum.

Antennae breues: articulo vltimo compreffo, ferigero.

Larua apoda, annulata, fubcylindrica, po. ftice attenuata.

Puppa immobilis, ouata cute dura, membranacea tecta.

Victus laruae \& imaginis e quisquiliis. 
173. MVSCA. Linn. Geoff.

Os probofcide, hatifello atgue palpis.

Probofcis exferta, bafi fraeta, dorfo canaliculato ad receptionem fetae: ftipite corneo, porrecto, cylindrico, capitulo ouato, veficulofo, bilabiato: labiis - aequalibus, acutis.

Haufellum breue absque vagina.

Seta vnica, probofcide multo breuior, cylindrica, apice acuminata ipfae - fracturae probofcidis inferta.

Palpi duo comprefli, porrecti extrorfum craffiores: articulis aequalibus, obfoletis, bafi laterali probofcidis inferti.

Anternac breucs, incuruae: articulo vltimo comprefio, fetigero.

Larua apoda, annulata, mollis, fubcylindrica, poftice attenuata.

Puppa immobilis, ouata, cute dura, coriacea, tecta.

Victus larnae e cadaueribus, animalculis, ftercore, inaginis e quisquiliis. 
174. TABANVS. Linn. Geoff.

Os probofcide, hauftello atque palpis.

Probofeis recta, exferta, membranacea, dorfo canaliculata ad receprionem hauftelli : ftipite breui, craffo, cylindrico, capitulo ouato, bilabiato; labiis aequalibus.

Hatffllum porrectum, exfertum, longi. tudine probofcidis.

Vagina triualuis, concana, acuminata, longitudine fetarum canalem probofidis fuperne \& ad larera claudens.

Setae tres aequales, compreffae, acutae, bafi probofcidis dorfali infertae.

Palpi duo aequales, triarticulati: articulo vitimo crafliori, ncuruo, frupofo; ob. tulo ad latera fetarum probofcidi inferti, reliquis breuioribatus, pilofis.

Antenuac breues, approximatae, cylindri. cae, acutae, feptem articulatae: arti. culo tertio faepius maiori denteque la. terali armato. .

Mctamorplofes ignota.

Victus imaginis e fanguine animalium haufto. 
175. RHINGIA. Scop. Conops Linn. Os probofcide, hauftello atque palpis.

Probofcis recta, porrecta, membranacea, dorfo canaliculato ad ferarum receptionem: ftipite cylindrico, retractili, capituloque ouato, bilabiato: labiis aequalibus.

Hauffllim rectum, porrectum, vagina vniualui, cornea, fornicata, cultrata, conuoluta, apice acuminata fetas probofcidemque continente totumque os obtegente.

Setac quatuor fubulatae, acutae, corneae, fubaequales, lateralibus paullo breuioribus acutioribus, intermedia interiori longiori, validiori vaginante exteriorem acutiffimam.

Palpi duo breues, filiformes, triarticulati: articulis aegualibus fub apice fetarum lateralium inferti.

Antennae breues, approximatae, compreffae, extrorfum craffiores, fetigerae.

Metamorpónis ignota.

- Victus imaginis e rapina Antliatorum, Gloffatorum. 


\section{A SILVS. Linn. Geoff. Erax Scop.}

Os hauftello palpisque absque probofcide.

Hauftcllum rectum, porrectum.

Vagina biualuis valuulis inaequalibus: inferiori longiori, cornea, cylindrica, bafi gibba, apice obrufa, fiffa fetas continente, fuperion multo breuiore, concaua, acutiffima batin fetarum tegente.

Setac tres porrectae, filiformes, acutae, inaequales: intermedia longiore, validiori, acutiori.

Palpi duo breues, filiformes, pilofi, triarticulati: articulis aequalibus, cylindricis ad bafin lateralem hauftelli inferti.

Antennae breues, approximatae, filiformes: articulis anterioribus longioribus, vltimo fubcraffiori fetaceo acuto.

Metamorphofis ignota.

Victus Imaginis e rapina inprimis antliato. rum, gloffatorum. 


\section{CONOPS. Iinn. Afilus Geoff.}

Os probofcide, hauftello atque palpis.

Probafcis porrecta, elongata: fipite corneo, cylindrico vltra bafin geniculato, dorfo canaliculato ad receptionem fetae, capitula ouato bilabiato: labiis aequalibus, rotundaris.

Hauftellum vagina vniualui valuula abbre. niata, concaua, acuminata canalem dorfalem probofcidis claudente.

Seta vnica cylindrica, rigida, acura longitudine probofcidis, cuius genicu. lo inferta eit.

Pelpi duo breuiffimi, filiformes, triarticu. lati: articulis aequalibus adhaerentes lateribus geniculi probofcidis.

Antennae approximatae, clauatae: claua acuminata, quadriarticulatae: articula. fecundo longiori.

Metamorploofis ignota.

Victus Imaginis e fucco anirralium haufo. 
178. ST OMOXYS. Geoff. Conops Linn. Empis Scop.

Os hauftello palpisque absque probofcide.

Hauffellum porrectum, elongatum vitra bafin geniculazum.

Vagina vniualuis, cornea, conuoluta, bafi compreffa, apice cylindrica, obtufa, fiffa fetas continens.

Setae duae aequales, filiformes, acutiffimae: fuperiori crafliori inferio. rem tenuiorem vaginante.

Palpi duo breues, filiformes, rriarticulati: articulis fubaequalibus, cylindricis, bati haufelli inferti.

Antennac breues, approximatae, inflexae, a pice craffiores, obtufae, fetariae.

Mctamorphofis latet.

Victus Imaginis e fanguine animalium haufto. 
179. MYOPA. Conops Linn. Afilus Geoff. Sicus Scop.

Os hauftello palpisque absque probofcide.

Hauftllum porrełum, elongatum, bafi medioque genicularum.

Vagina biualuis:valuulis inaequalibus; inferiori elongata, cylindrica, geniculata, apice obtufa filla, fuperiori breuiori, concaua, acuminata.

Seta vnica, rigida, fubulata, tenuis, acuta longitudine valuulae inferioris geniculo vaginae inferra.

Palpi duo breues, pilofi, extrorfum craffiores, triarriculati: arriculis fubaequa. libus, hauftelli bafi laterali inferti.

Antennae incuruae, clauatae, fetigerae. Metamorplofis omnino adhuc latet. Victus Imaginis e fucco animalium haufto. 


\section{C V LEX. Linn. Geoff.}

Os hauftello palpisque absque probofcide.

Hauffellum rectum, porrectum.

Vagina vniualuis, elongata, cylindrica, flexilis, inuoluta, apice acuminata, perforata, fetas continens.

Setae quinque fubaequales longitudine vaginae, fubclauatae, apice mucronatae, acutae.

Palpi duo aequales, filiformes, pilofi, triarticulati: articulis cylindricis; primo longiori, ad latera hauftelli inferti.

Antennae filiformes: articulis plurimis, globofis, breuibus, faepius pectinatis.

Larua aquatica, apoda, thorace incraffa. to, abdomine cylindrico, refpiratorio cylindrico ani.

Puppa quiefcens, incuruata, ouata refpiratoriis duobus corniformibus dorfi.

Vifus laruae e infectis aquaticis minutiffimis, imaginis e fanguine Mammalium haufto.

Obf. Maris palpi porrecti longitudine 10 fri, faeminae vero abbreuiati. 
207

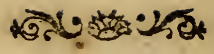

18r. EMPiS. Linn. Aflus Scop.

Os probofcide, hauftello palpisque.

Probofcis elongata, exferta, inflexa, hau.

ftelliformis: ftipite cylindrico, tenui,

dorfo canaliculato ad receptionem hau-

ftelli, capirulo elongaro, oblongo, bi-

labiato: labiis aequalibus, ciliatis, acutis.

Hituffellum probofcide breuius, infexum.

Vagina vniualuis, cornea, cylindrica, apice acuminata, firfa, fetas continens.

Setae tres rigidae, filiformes, apice acu. minatae, inaequales intermedia longiori, validiori, lateralibus breuir. fimis tenuioribus.

Palpi duo brenes, pilof, refexi, filiformes triarticulati: articulis fubaequalibus ad probofcidis bafin inferti.

Antennae approximatae brenes, filiformes, triarticulatae; articulo primo craltioni pilofo, vltimo acuto.

Metamorpbofis ominino adhuc latet.

vitus imaginis e fucco animalium, e rapina inprimis antliatorum.

06\%. In quibusdam rpeciebus proborcidis capirulum obfoletum.

182. BOM- 
I82. BOMB Y LIV S Linn. Afilus. Geoff.

Os hauftello palpisque absque probofcide.

Haufclitum elongatum, rectum, fetaceum.

Vagina biualuis, valuulis inaequalibus: inferiore longiore fetacea, inuoluta, fetas continente, apice acuminata, fifla, fuperiori porrecta, filiformi,acutiffima.

Sctac tres, fubulatae, inaequales, intermedia longitudine vaginae, lateralibus breuioribus, acutis, rigidis.

Palpi duo breues, pilofi, triarticulati: articulis aequalibus, cylindricis bafi la. terali hauftelli inferti.

Antennae breues, approximatae, filiformes, apice acuminatae.

Metamorphofis omnino adhuc latet.

Victus imaginis e nectare florum. 
183. HIP РОВОSCA. Linn. Geoff.

Os hauftello absque probofcide \& palpis.

Hauftllum breue, rectum, porrectum, cylindricum, rigidum.

Vagina biualuis, valuulis aequalibus, fimicylindricis, ciliatis, obtufis, emarginatis fetam continentibus.

Seta vnica, fubulata, rigida longitudine vaginae.

Antennac approximatae, breuiffimae, filiformes, biarticulatae articulo primo breuiffimo, fecundo tenuiffimo.

Metamorphofis latet.

Victus imaginis e fanguine animalium haufto. 
184. PEDICVLVS. Linn. Geoff.

Os hauftello absque probofcide \& palpis.

Hauftellum breve, cylindricum, retracti. le, rectum, rigidum.

Vagina biualuis, cylindrica: valuulis aequalibus femicylindricis, annulatis, truncatis, obtufis, fetam continentibus.

Seta vnica, recurua, fubulata, rigida, acutiffima longitudine vaginae.

Antennac breues, faepius moniliformes: articulis aequalibus.

Larua hexapoda, agilis, currens, imagini fimillima.

Puppa hexapoda, agilis, currens, imagini fimillima.

Victus \& laruac \& imaginis e fucco animalium haufto. 


\section{- 185. A CARVS. Linn. Geoff.}

Os hairftello palpisque absque probofcide.

Hauftllum breue, porrectum, rectum, cylindricum, rigidum.

Vagina biualuis valuulis aequalibus, femi. cylindricis, obtufis, horizontalibus: fuperiore ad bafin fiffa: laciniis aegualibus, cylindricis, inferiore planiore.

Scta . * - =

Palpi duo conpreffi, aequales, porrecti, longitudine hauftelli, obtufi, rigidi, triarticulati: articulis aequalibus, ad bafin lateralem hauftelli inferti.

Antennae filiformes, compreffi: articulis fubaequalibus, pedes aemulantes.

Larua hexapoda, agilis, currens, inagini fimillima.

Puppa hexapoda, agilis, currens, imagini fimillima.

Victus \& laruae \& imaginis e fucco animalium haufto.

06\%. I. Acarus Ricinus antennas ciauatas gerit. Obf. II. Pediculus \& Acarus metamorphofi ad Ryngora accedunt. 


\section{均}

\section{$M A N T I S S A$}

\section{Specierum nuper detectarum}

IOI - 2. SCARAB AEVS exfcutellatus, tho- Vitt-

race quadridentato, occipité cornubus lus duobus erectis breuibus, corpore atro.

Habitat in Aufria Dr. Schulz.

Magnitudo \& ftatura S. Vaccae. Clypeus rotundatus ater medio linea transuerfa ele. uata, poftice corniculis duobus eleuatis breuibus. Thorax antice quadridentatus denticulis aequalibus breuibus, poftice rotundatus absque fcutello. Elytra breuia, atra. Pedes atri.

104:-5 SCARABAEVS exfcutellatus, tho-fabre.

race inermi rugolo, capitis cornu erecto fus

breuiffimo, elytris teftaceis nigro-fcabris.

Habitat Surinami Dr. Schulz.

Statura omnino S. nuchicornis at paullo maior. Caput cupreo aeneum clypeo antice truncato pofice cornu breui, erecto. Thorax obfcurus, variolofus margine pallidiore. Elytra teftacea punctis nigris eleua. tis per ftrias difpofitis, ficabra. Corpùs ni. gricans. Pedes pallide teftacei femoribus bafi ribiisque apice nigris.

6.7. MELOLONTHA oblonğa glabra ni-oblon: gra, elytris obfolete friatis.

Scarabacus oblongizs Scop. cain. ig.

$$
\text { O Habi. }
$$


Habirat in Germania.

Minor M. vulgari tota nigra, glabra. Oculi teftacei. Elytra ftriis per paria approximatis, fubpunctatis, obfoleris.

varia $35 \cdots 36$. MELOLONTHA atra, elytris aubilis ro nitentibus, antennis pedibusque te. ftaceis.

Habitat in America boreali.

Antennae trilamellatae pallide teftaceae. Caput \& thorax atra, immaculata. Elytra Atriata, atra tomento aureo fere obfoleto fplendentia. Pedes teftacei.

Eandem magna in copia in horto Kilonienfi fub terra e ligno putrido nata degentem vidimus, at elytra haud auro nitentia fed tomento cinereo recta.

Variat interdum colore rufo.

Lynx $39 \therefore 40$. MELOLONTHA nigra, hirta, elytrorum margine aureo.

Habitat ad Cap. B. Spei. Dom. Lee.

Statura \& magnitudo M. Vrfus, cuius forte mera varietas. Differt tantum elytro. rum margine exteriori aureo, nitido.

crinita $39 \div$ 40. MEL.OLON'THA hirta fupra viridis fubtus nigra.

Habitat ad Cap. B. fpei. Dom. Lee.

Affinis praecedenti tota pilis longioribus nigris hirta at fupra viriais, nitens. 
20-2r. CETONIA nigra, thorace lineis trilitribus, elytris fafcia flexuofa fcurelloque neata albis.

Habitat ad Cap. B. Spei. Dom. Lee.

Media. Caput nigrum linea longitudinali flaua. Clypeus emarginatus. Thorax niger linea dorfali lareralibusque flauis. Punctum nigrum vtrinque in margine. Scutellum triangulum flaum. Elytra fubftriata, nigra fatcia flexuofa, abbreuiara, flaua. Abdomen nigrum ano fafcia flexuofa flaua. Pe. des nigri Hauo variegati.

I - 2. BOSTRICHVS piceus, elytris apice fauifpinofo dentatis, antennis luteis. cornis Habitat in America boreali.

Médius totus cylindricus. Caput nigricans antennis flauis claua compreffa. Thorax cylindricus. Elytra fubftriata apice vix rerufa, denticulata denticulo poftico elongato in fpinam validam, acutilfimam. Pedes vti corpus fubtus brunnei.

$3-4$ BOSTRICHVS nigricans, elytris glau- policis obtufiufculis. "graDermeftes poligraphus Linn. Syft. Nat. 2. phus 562. 10. Fn. Sv. 420.

Habirat in Europa boreali fubarborum corticibus.

7. BOSTRICHVS elytris integris glaber mimu. ater immacularus.

$$
\mathrm{O}_{2} \text { Habi: }
$$


Habitat Kiloniae in Boleto verficolore.

Corpus minimum, atrum, glabrum, immaculatum. Antennae clata folida, obtufa. Elytra laeuia, glabra, integra. Pedes nigri. fani- 3-4. ANOBIVM villofum nigrum, antenpes nis pedibusque teftaceis.

Habitat Hamburgi Dr. Schulz.

Magnitudo \& ftatura A. pertinacis. An: tennae filiformes, teftaceae. Caput inflexum. Thorax minus quam in reliquis fpeciebus rotundatus, villofus, niger. Elytra villofa, nigra. Pedes omnes teltacei.

gibbo. $2 \cdot 3$. BRVCHVS thorace gibbofo cupreus, jus

elytris nigris tuberculato-fpinofis. Habitat in America boreali.

Caput reconditum fubcupreum, antennis filiformibus flauis. Thorax cupreus, tuberculatus, in medio gibbofus gibbere canaliculato. Elytra nigra tuberculis plurimis eleuatis, obtufis, fubfpinofis; pontice retu. fa. Pedes nigricantes.

margi-5 -6. BRVCHVS niger, elytris cinereis mas nalis culis tribus nigris margine connexis. Habitat in Germania de Hattorf.

Antennae porrętae, nigrae. Caput \& thorax atra puncto paruo cinereo ad bafin thoracis. Elytra laeuia, cinerea, macula ad balin, altera maiori in medio marginis exte: 
exterioris, tertiaque in apice elytri nigris. Difcus elytrorum immacularus. Anus pro. minens, cinereus. 'Pedes nigri.

I-2. ELOPHORVS grifeus, thorace ely-mbilus trisque fulcato rugofis.

Habitat in Holfatiae aquofis Dr. Schulz.

Statura omnino E. aquatici at paulla minor: Antennae clauatae. Thorax grifeus fulcis quinque exaratus. Elytra fulcata ob. fcure grifea. Pedes concolores.

3. TRITOMA? nigra elytris pedibusque dubia teftaceis.

HabitatKiloniaeHolfatorumDom.Lund.

Parua huius generis videtur, quum antennae omnino perfoliatae. Caput \& thorax nigra cinereo tomentola. Elytra poftice acuta toftacea.

r. IPS. atra, elytris fafciis duabus rufis:fafcia. anteriore nigro maculata. ta

Habitat in America boreali.

Magna, obronga. Antennae porrełtae, atrac articulis tribus vltimis perfoliatis. $\mathrm{Ca}$ put \& thorax atra, nitida, immaculata. Coleoptra atra falciis duabus dentatis, rufis, anteriore bafeos maculis tribus atris; intermedia maiore, communi. Pedes atri.

2. IPS nigra, elytris punctis duabus ferru- 4 pagineis. 
Tritoma \& puftulata Syft. Ent. 69. 3. Habitat in Europac ligno humido.

Varietatem quadruplo maiorem vix tamen diftinctam ex America boreali habui.

picea 3. IPS picea, elytris nigris: bafi fafciaque pottica ferrugineis.

Habitat in Germania de Hattorf.

Minor i. quadripuftulata. Caput nigricans, ore antennisque piceis. Thorax vtrinque puncto bafeos impreffus. Elytra lacuia, nigra bafi fafciaque poftica lunata ferrugineis. Corpus \& pedes picei.

4 gut-4. IPS atra nitida; elytris maculis duabus rata albis: anteriore finuata.

Habitat Kiloniae Holfatorum. Dom. de Seheltedt.

Statura praecedentium, at multo minor. - Capur \& thorax atra, nitida, immaculata. Elytra lacuia, atra maculis duabus transuer. fis maroines haud attingentibus albis; ante. riore bilinuata. Pedes nigri.

vena. 5. IPS nigra, thorace rugofo, elytris fria. ta tis: maculis duabus rubris.

Tritoma crerata Sylt. Ent. 69. 4.

Habitat in Sveciae lignis.

ruf. 6. IPS glabra arra, fronte pedibus maculis. froms que duabus elytrorum ferrugineis.

Tritoma rufifrons Syftem. Ent. 69. 5. Habitat in Anglia. 
3-4. IISPA antennis pectinatis, thorace ely-bicortrisque viridiaeneis, capite bicorni.

Habitat in America boreali Dom. Yeats.

Corpus paruum, piceum. Antennae bre. ues fecundum totam longitudinem pectinatae fulcae bafi ferrugineae. Caput viridiaeneum corniculis duobus breuibus, erectis, acutis. Pedes ferruginei.

7-8. SILPHA atra, thoracis margine palli. margido, elytris fufcis.

Habitat in America boreali Dom. Lee.

Magnitudo S. rugofae. Caput atrum, rugofum. Thorax ater margine finuato, pallido. Scutellum atrum. Elytra fufca ftriis tribus eleuatis laenibus. Peces nigri.

9-10. SILPHA atra, elytris punctatis: li-lunat neis eleuatis tribus laeuibus, thorace transuerfo emarginato.

Habitat in Auftria Dr. Schulz.

Maior S. atrata. Caput atrum. Thorax latirudine elytrorum, transuerfus, antice valde emarginatus arer punctis duobus paruis, dorfalibus, nitidulis. Elytra valde punctara ftriisque tribus eleuatis. Pedes atri. I - 2. NITIDVLA ouata nigra obfcura, pe obfcr.

dibus piceis.

Habitat in Germania de Hattorf.

Starura omnino N. 2 puftulatae at paullo minor. Corpus fupra obfcure nigrum mi. O 4 nime 
nime nitidum. Elytra laeuia, immaculata. Pedes picei.

bicoler 3-4. NITIDVLA ferruginea, elytris nigris: fafcia bafeos pundtogue apicis ferrugineis. Habitat in aruis Kilonienfibus Dom. Lund.

Magnitudo $N$. ferrugineae. Anrennae rufae claua folida. ' Caput \& thorax ferru. ginẹa, immaculata. Filytra glabra, nigra fafcia lata bafeos punctoque verfus apicem ferrugineis. Abdomen fufcum. Pedes ferruginei.

basa 4-5. NITIDVLA nigra, elytris apice fer: mory. rugineis.

boida-

lis.

Habitat Hamburegi Dr. Schulz.

Statura N. Colon.at duplo minor. Tho. rax marginatus niger margine ferrugineo. Elytra laeuia, nigra apice late ferruginea. Pedes nigivi.

enifa- 5.6 COCCINELLA coleoptris rubris: fafriata fcia media atra.

Habitat Hamburgi Dr. Schulz.

Media. Caput \& thorax atra, immaculata. Elytra rubra faf́cia media lata, atra, quae futuram tamen haud attingit $\&$ ad mar. ginem punctis duobus paruis terminatur, Lineola parua obliqua nigra adfcutellum. Corpus arrum. 
7.8. COCCINELLA coleoptris luteis fa-fexuo fcia flexuofa punctisque duobus nigris. fa Habitat Hamburgi Dr. Schulz.

Corpus atrum, immaculatum. Thorax ater macula laterali apicis albida. Elytra lutea puncto bafeos orbiculato, fafcia in me. dio Aexuofa \& macula apicis rransuerfa, clauata nigris.

13-14. COCCINELLA oblonga, coleoptris $7 \mathrm{ma}$ rubris: punctis nigris feprem; communi culat trilobo.

Habitat in Germaniae plantis Dr. Schulz.

Magnitudo \& ftatura oblonga C. I3 punctarae. Caput atrum. Thorax laeuis, are: margine antico \& laterali albo. Elytra rubra punetis nigris tribus primo bafeos ro. rundazo, fecundo in medio transuerfo, tertio verfus apicem rotundato. Punctum denique commune trilobum. Corpus nigrum.

38-39. COCCINELLA coleoptris luteis: is gutspunctis quindecim albis; communi in tata medio obfoleto.

Coccinella coleoptris rubris punctis quatuordecim limboque albis. Geoff. Inf.

I. $327 \cdot 14$.

Habitat in Germania.

Corpus maiufculum, rotundatum. Tho: rax luteus margine latcrali albo puncto me- 
dio luteo. Macula obfoleta albida ad bafin thoracis. Elytra lutea punctis feptem rotundatis albis 2. 2. 2. I. Punctum commu. ne fere obfoletum in medio dorfi.

bae. 43-44. COCCINELLA coleoptris atris apimorr. ce rubris: fafcia nigra.

hoida. lis Habitat Hamburgi Dr. Schulz.

Corpus rotandatum. Caput obfcure rufum. Thorax rufus interdum bafi, inter$\therefore$ ․m punctis tribus bafeos nigris. Elytra arra apice rufa fafcia nigra, quae tamen futuram haud atringit.

Variat frequens puncto in medio dorfi communi, fanguineo.

vavia. 45-46 COCCINEL.LA oblonga, coleoptris bilis nigris: punctis duobus rubris orbiculatis fubmarginalibus.

Habitat Hamburgi Dr. Schulz.

Differt manifefte a C. bipuftulata. Corpus oblongam, immarginarum. Caput album. Thorax ater margine albo. Elytra laeuia atra puncto rubro.

Variar iunior elytris lureis puncto flauefcente, at aetate elytra nigra \& puncta rubra euadunt.

12 pu- $49 \cdot 50$. COCCINELLA coleoptris nigris: fitulata punftis duodecim albis; exterioribus margine connexis. 
Habitat Hamburgi Dr. Schulz.

Media. Caput albidum puncto frontali nigro. Thorax ater margine antico \& laterali pallido. Elytra atra punctis fex albis 2. 3. x. tribus exterioribus margine connatis. Punfum vltimum lunatum. 7 8. CASSIDA brunnea, elytris flauis: fu- fitura.
turis brunneis.

Habirat ad Cap. B. Spei. Dom. Lee.

Magna. Antennae brunneae. Clypeus porrectus, integer; brunneus. Elytra lata, flaua futura dorfali \& bafeos brunneis. Corpus brunneum.

I I-I 2. CASSIDA reftacea, elytris angulo perfo. antico fpinofo bafique perforatis.

Ciafida perforata Pall. Spicil. fafc. IX. p. 3 . tab. I. fig. I.

Habitat in America meridionali.

6..7. CHRYSOMELA atra, thoracis mar- 3 lineagine flauo puncto nigro, elytris flauis: ta

iutura vittaque nigris.

Habitat in Auftria Dr. Schulz.

Afinis C. futurali. Caput nigrum fronte flaua. Thorax ater margine laterali flauo punkto medio nigro. Scutellum atrum. Elytra fiaua futura nigra, quae tamen f́cutelium haud attingit. Vitta lata nigra in 


\section{0}

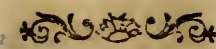

medio elytrorum, quae nec ad bafin nec ad apicem excurrit. Corpus \& pedes atra plantis fifcis.

dorfa. 6.. 7. CHRYSOMELA atra, thoracis marbis gine teltaceo puncto nigro, elytris tefta. ceis: futura abbreniata atra.

Habitat in Auftria Dr. Schulz.

Affinis videtur praecedenti at minor. Elytra teftacea fola fucura arra, quae bafin haud attingit. Antennae \& pecies nigri. Scurellum arrum.

4 ma-\$9-60. CHRYSOMELA oblonga, thoraculata ce teftaceo immaculato, elytris teftaceis. maculis duabus nigris.

Habirat in nemoribus Kilonienfibus Dom. Iund.

Magnitudo \& ftatura C. Aini. Caput tefaceum bafi inter oculos nigrum. Thorax rotundatus, teftaceus, immaculatus. Elytra laeuia, nitida, teitacea maculis duabus magnis nigris, altera baf́cos rotundata, aitera pone medium transuerfoli fere fafciam conftituente. Abdomen atrum. Pedes teftacei.

pube- I - I2. CRYPTOCEPHALVS thorace elyfens trisque obficure aeneis pulefcentibus. Habitat in America boreali.

Pauilo minor C. longrimano. Antennae porrectae, filiformes, cinereae. Caput, thorax 
thorax \& elytra obfcure acnea tomento cinereo breui denfo pubefcentia. Scurellum nigrum. Corpus fubtus \& pedes cinera. fcentia.

17-18. CRYPTOCENHALVS capite tho-nigri. raceque rufis, elytris pallidis, pedibus ${ }^{\text {pes }}$ apice nigris.

\section{Habitat in America.}

Magnitudo \& ftarura C. Coryli. Caput rufum, immaculatum antennis nigris bafi rufis. Thorax rufus, nitidus, immaculatus. Scurellum nigrum. Elytra pallida futura margineque nigricantibus. Abdomen pallidum ano teftaceo. Pedes teftacei apice nigri.

23-24. CRYPTOCEPHALVS ater, elytris qua-

flauis: vitta abbreuiata media atra.

Habitat in Germania. de Hattorf.

Magnitudo C. Moraei. Corpus totum atrum, nitidum. Elytra lacuia, flaua, virta media lata, atra, quae apicem tamen haud attingit, fed ante apicem reflectitur ad futuram.

32-33. CRYPTOCEPHALVS thorace ful-pufillus

uo, elytris teftaceis Inigro-maculatis.

Habitat Hamburgi Dr. Schulz.

Paruus duplo minor C. Pini. Caput fuluum antennis pallidis oculisque nigris. Thorax 
Thorax fuluus, immaculatus: Elytra fub. ftriata, reftacea punctis duobus bafeos fa. fciaque poftica nigris. Corpus nigrum. Pedes pallidi.

Variant interdum maculae elytrorum, mox confluunt, mox omnino defunt.

¿4 pun- I I - I 2. CRIOCERIS thorace cylindrico fulEtata uo pundis quinque nigris, elytris flauis punctis feptem.

Attclabus 1 punctatus Scop. Ent. I 16.

Habitat in Germania.

Magnitudo \& ftatura C. I 2 punctarae. Caput fuluum, ore, antennis punctoque ver. ticali nigris. Thorax fuluus punctis quin. que nigris. 4. I. Elytra pallidiora punctis 1. 2. 2. I. I., quorum fextum maius, rotundatum, feptimum iterminale. Abdomen \& femora fulua.

dilata- 5-6. EROTYLVS ater, thorace elytrisque tus

ferrugineis.

Habirat ad Cap. Bon. Sp. Lee.

Magnus. Antennae fufcae bafi ferrugineae. Thorax ferrugineus, immacklatus. Elytra corpore multo latiora, laevia, ferruginea, immaculata. Corpus \& pedes atra.

qufus 9. EROTYLVS oblongus niger, pedibus piceis.

Habitat Kiliae Holfatorum. Dom. Lund. Praede* 
Praecedentibus minor. Antennae filifor. mes, nigrae primo articulo ferrugineo. Capur \& thorax nigra, obfcura. Elytra ftria. ta, nigra, immaculata. Pedes picei geniculis nigris.

5.6 LAGRIA cyanea capite thoraceque ruffrufis. frons

Habitat in America boreali.

Antennae longitudine fere corporis fufcae apice rufefcentes. Caput rufum oculis ma. gnis nigris. Palpi antici exferti, fecuriformes, fufci claua rufa. Thorax cylindricus, rufus. Elyrra ftriata, cyanea. Pedes cyanei femoribus anticis rufis.

6-7. CVRCVLIO longiroftris rufo nigro varius

que varius, roftro apice nigro.

Habitat ad Cap. B. S. Dom. Lee.

Antennae fractae, capitatae. Roftrum elongatum, cylindricum, ferrugineum apice nigrum. Thorax ferrugineus lineis tribus nigris: lateralibus abbreuiatis. Pectus nigrum lineis tribus ferrugineis. Elytra ftriata, nigra lineolis aliquot ferrugineis. Pedes nigri femoribus ferrugineis annulo nigro.

22-23. CVRCVLIO longiroftris ater, an- Prunz tennis ferrugineis, thorace bituberculato.

Gurculio Pruni Linn. Syft. Nat. 2. 507. I 2. Habi- 


\section{4}

Habitat in Cerafi foliis.

Vaide diftinctus tuberculo vtrinque ele. uato thoracis. Elytra ftriata.

Cam- 22-23. CVRCVLIO longiroftris niger ouapanula tus, elytris ftriatis obtufis.

Curculio Campanulae Linn. Syft. Nat. 2. 506. 7 .

Habitat in Campanulae rotundifoliae pericarplis.

Magnirudo \& Atatura C. acriduli. Corpus torum nigrum poftice valde obrufum.

varia. 24-25. CVRCVLIO longiroftris fubtefta. bilis ceus, thorace viridi-lineato, roftro apice fufco.

Habitat Hamburgi Dr. Schulz.

Medius. Caput pallide teftaceum roftro apice fufco. Antennae rufefcentes claua cinerea. Thorax obfcurus lineis tribus diftinctis viridibus. Elytra pallide rufefcentia polline virefcenti adfperfa. Pedes rufi.

Sifym-26-27. CVRCVLIO longirottris albo fubrii fcoque varius, elytris puncto bafeos ele. uato atro, roftro nigro.

Habitat Kiliae in Sifymbrio amphibio lectus d. xx. Maj.

Paruus. Roftrum elongatum, nigitum. Antennae fufcae, clauatae. Thorax albus macula 
macula furca, in qua linea dorfalis alba. Elytra albo fufcoque varia \& ad bafin pundo paruo oblongo atro. Corpus fubtus albi. dum. Pedes mutici.

3I -32. CVRCVLIO longiroftris niger, ely $2 f a$ -

tris fafciis duabus cinereis: bafeos maio-friatus

re vidata.

Habitat Kiliae Dom. Lund. Noruagus.

Paruus, Roftrum elongatum, cylindricum, atrum. Antennae clauatae claua folida, cinerafcente. Thorax rotundatus ater, li. nea dorfali paullo pallidiori. Scurellum cinereum. Elyrra ftriata fafciis duabus vndatis cinereis vix marginem exteriorem attingentibus, quarum anterior in primis ad fururam maior, altera in medio multo angufior. Pedes nigri, fimplices.

$36-37$. CVRCVLIO ater, thoracis punctis Crux

duobus bafeos, elytrorum futura punctis. gue ragis aibis.

Habitat Hamburgi.

Statura \& magnitudo C. futuralis. Ca. put atrum, immaculatum roftro incuruo. Thorax rotundatus, ater vtrinque puncto oblongo bafeos aibo. Scutellum album. Elytra ftriata nigra, futura bafeos punctisque plurimis vagis albis. Pedes nigri. Cor. pus fubtus albidum.

49-50. CVRCVLIO longiroftris ater, tho-Atrirace nitido, elytris ftriatis obtufis. 
Habirat in Atriplice littorali Florae Kilonienfis Dom. Lund. Norwegienfis. Statura \& magnitudo C. linearis, cui valde affinis. Differt tamen antennis apice haud ferrugineis, roftro tenui bafi haud attenuato, thoraceque minus punctato, nitido.

raucus ro8-9. CVRCVLIO breuirofiris nigricans, elytris grifeis cinereo-punctatis.

Habitat in Germania Dom. de Hattorf.

Medius. Antennae medio fractae apice clauatae. Roftrum breue, craftum, fubpla. num. Thorax nigricans punctis eleuaris paruis fcaber. Elytra ftriata ftriis crenatis, grifea punctis plurimis cinereis fparfis irrorata. Pedes picei femoribus muticis.

bifpi- II2-13. CVRCVLIO breuiroftris fuccus, tharace cinereo lineato, elytris hifpidis punctis obfcurioribus firiatis.

Habiear Kiliae in plantis aquaticis Dom. Lund.

Paruus ftatura C. lineati. Antennae clauatae articulo primo longiori. Thorax punctatus, furcus lineis tribus longitudinalibus cinereis :- media tenuiore. Punctum vtrinque laterale cinereum. Elytra furca pilis albis erectis hifpida punctisque obfcurioribus ftriata, interiectis pilis albis, qui quafi lineas e maculis nigris albisque conftituunt. $\mathrm{Pe}$ des nigricantes. 


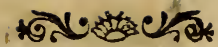

122-23. CVRCVLIO breuiroftris, thora-pizti. ce elytrisque variolofis nigris albo-pun-cus.. ctatis.

Habitat ad Cap. B. Spei.

Paruus. Caput nigrum, immaculatum. Thorax variolofus, ater, albo punctatus. Elytra variolofa, atra, albo punctata $\&$ verfus apicem fafcia alba. Pedes \& corpus atra. 123-24. CVRCVLIO breuiroftris ater, fuccinelytris margine lineolisque duabus albis. Etus Habitat ad Cap. Bon. Spei. Dom. Lee.

Corpus magnum, oblongum. Caput fulcarum, atrum, immaculatum. Thorax rotundatus, punctatus, ater linea laterali alba. Elyrra poftice gibba, punctata, atra margi. ne lineolisque duabus albis, altera a bafi ad medium, altera a medio marginis verfus apicem ducta, reflexa. Pedes arri, fimplices. I 25-26. CVRCVLIO breuiroftris grifeus, hiftrio. thorace lineis lateralibus fuluis, elytris nicus albis: maculis atris fuluisque.

Habitat ad Cap. Bon. Spei. Dom. Lee. Corpus magnum. Capur grifeum roftro craffiufulo thorace breuiore. Antennae medio fractae. Thorax dorfo grifeo linea laterali lata fulua margineque albido. Elytra alba maculis plurimis eleuatis nigris duabusque oblongis fuluis. Abdomen albidum vrrinque linea longitudinali punctorum ni. grorum. Pedes einerei, inermes.

$$
\mathbf{P}_{2} \quad \mathbf{1 3}_{35}-36 .
$$


foala. $135-3$ 6. CVRCVLIO breuiroftris, tho: ris race fpinoto inaequali ater, elytris ftriis rufis denticulatis.

Habitat ad Cap. Bon. Spei. Dr.Schulz.

Magnitudo \& ftatura C. barbari. Roftrum crafum, breus, obtufum, planum. Antennae obtufae \& fere truncatae. Thorax acute fpinofus fulcis tribus punctisque quatuor. bafeos profundis impreffus. Elytra connata, laevia, atra ftriis octo fecundum toram longitudinem denticulatis rufis. $\mathrm{Pe}$ des atri femoribus fimplicibus.

4 Spi- I39-40. CVRCVLIO breuiroftris albidus, nofus elytris 4 fpinofis, roftro fufco. Habitat ad Cap. B. Spei.

Minor. Roftrum breuiifimum, canaliculatum, fufcum. Thorax rotundatus, albidus, immaculatus dorfo plano. Elytra albida fpinis quatuor ereetis, validis, folita. ria verfus bafin, duabus in medio \& quarta verfus apicem folitaria. Pedes albi, fimplices. mbilus $145-46$. CVRCVLIO breuiroftris, femoribus dentatis grifeus, elytris punctis ob: feurioribus numerofis.

Habitat Hamburgi Dr. Schulz.

Corpus magnitudine \& ftatura C. Liguftici. Antennae clauatae claua acuminata, nigrae. Caput \& thorax grifea, immaculata. Elytra punctis ftriata punctisque plurimis vagis diftinctis obfcurioribus. Femora poftica annulo albo. $146-47$. 
146 - 47. CVRCVLIO breuiroftris, femo. gem. ribus dentatis ater, elytris punctis viri-matus dibus.

Curculio gemmatus Scop. Ent. 90.

Curculio gemmatus Naturforfcher Sect. 6. tab. 4 .

Habitat in Europa.

146-47. CVRCVLIO breuiroftris, femo-picipes.

ribus dentatis grifeas, elytris nebulofis, femoribus poficis rufis.

Habitat Kiliae Dom. Lund.

Minor C. nebulofo. f:ntennae fractae, clauatae, claua obtıfiufcula. Roftrum craffum, breue, obtufum, apice nigrum. Tho. rax grifeus punctis eleuatis globofis minutiffimis. Elytra nebulofa punctis eleuatis ftriata. Pedes itidem grifei femoribus inprimis pofticis rufis.

2-3. ATTELABVS arer, elyeris macula spufzubáleos rufa.

latus

Habitar in America boreali Dom. Yeats.

Statura \& magnitudo A. curculionoidis. Corpurs atrum, nitidum, elycris macula magna bafeos rufa. Pedes atri femoribus anticis intus vnidentatis.

I -2. CLERVS rufus, elytris nigris fafcia dubius duplici alba bafique rufis.

Habitat in America boreali Dom. Yeats.

Nimis affinis C. formicario. Antennae $P_{3}$ breues, 


\section{0}

\section{*⿻一𠃋十}

breues, moniliformes. Caput rufum. Thorax poftice anguftatus, rufus. Elytrn nigra bafi rufa fafciisque duabus. vndatis albis.

ichneu. I-2. CL.ERVS capire thoraceque rufis, moneus elytris nigris: fafcia media rufa frigaque apicis alba.

Habitat in America feptentrionali Dom. Yeats.

Statura omnino C. formicarii. Caput rufum ánteunis fulcis. Thorax gibbus, rufus, immaculatus, poftice anguftatus. Elytra bafi fubferruginea, tunc nigra, in medio falcia lata, rufa apice nigra ftriga poftica alba. Pectus nigrum. 4bdomen rufum. Pedes fufci.

pun. 2 I -22. LAMIA thorace fpinofo ater, ely. Etator tris albo punctatis, antennis longis.

Habitat in China Mul. Dr. Fothergill. Antennae corpore longiores, nigrae articulis bafi pallidis. Thorax rotundarus, fpinofus, ater. Elytra atra, àlbo-punitata, bafi fcabra. Pedes atri.

erispa 2 I -22. LAMIA thorace fpinofo, elytris lineis tribus eleuatis ferrulatis, antennis mediocribus, corpore cinereo.

Habitat àd Cap. Bon. Spei Dom. Lee.

Corpus magnitudine L. triftis totum cinereum. Antennae corpore breuiores. Tho. rax inaequalis, acute fpinofus. Elytra ci- 


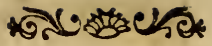

nerea lineis tribus eleutatis, acute ferrulatis. Pedes cinerei.

$29-30$. L. thorace fpinofo tuberculato ci. Spengnerea, elytris fcabris: maculis duabusleri lateralibus atris.

Habitat in America meridionali. Spengler.

Duplo minor L. Rubo. Antennae corpore longiores, cinereae articulorum apicibus fufcis. Thorax rotundatus, cinereus, verinque obtufe fpinofus tuberculisque tribus dorfalibus. Elytra punctis eleuatis fcabra, cinerea maculis duabus marginalibus atris, quorum pofterior ftrigam emitrit. E. lytra apice acuminata. Pedes nebuloli.

7-8. SAPERDA grifea, vittis tribus den-vittatatis albis, antennis longis. ta Mabitat in India Dr. Fothergill.

Antennae cinereae corpore duplo longio. res. Caput grifeum linea laterali alba, dorfali ferruginea. Thorax rotundatus, muticus lineis tribus albis. Coleoptra grifea, lineis lateralibus futuralique dentatis albis. Corpus grifeum.

4-5. CALLIDIVM thorace verrucofo nigricante, elytris acuminatis viridibus actmi futura cyanea.

Mabitat ad Cap. B. Spei Dom. Lee.

Minor C. violaceo. Caput fufcum. An$\mathrm{P}_{4}$ tennæ 
tennae longitudine corporis, fufcae articulis apice fpinofis. Thorax rotundatus, niger tuberculis plurimis eleuatis. Elytra viridia, nitida fircura cyaner, apice acuminata. Pedes nigri femoribus clauacis claua rubra.

m/ji- 4-5. CALLIDIVM thorace verrucofo, nicum grum, elytris teflaceis macula média apiceque nigris.

Habitat in Rutria Dom. Lee.

Statura C. Bajuli at triplo minus. Capue nigrum, immacularum antennis longitudine fere corporis. Thorax niger verucofus. Elytra laeuia, teftacea macula media apiceque nigris. Pedes nigri, mutici.

mofpes is - I6. CALLIDIVin thorace Jaeui nitido, elytris violaceis, tibiis rufis, antennis breuibus.

Habirat in Germaria Dom. de Hattorf. Corpus parum. Antennae breues, flifcae bafi ferrugineae. Caput \& thorax lae. uia, nitida, violacea. Elytra lacuia, vio. lacea, immaculata. Abdomen aeneum, nitidum. Pedes violacei tibiis rufis. Femo. ra poftica clauata bafi ferruginea.

varimas $2 \mathrm{I}-22$. CALLIDIVA thorace rotundato rufo, elytris nigris bafi rufis: falciis dua. bus albis.

Habirat in America boreali Dom. Yeats. Corpus C. vndato minus. Antennae ni- 
grae longitudine corporis. Caput rufum. Thorax rotundatus, inermis, rufus. Elytra lacuia, nigra bafi rufa fafciis duabus albis. Pedes nigri femoribus clauatis, rufis. $\mathrm{Ab}$ domen atrum.

I-2. LEPTVRA nigra, elytris teftaceisliuids immaculatis, pedibus nigris.

Habitat in floribus Chilonii Dom. Lund.

Statura \& fumma affinitas L. melanurae. Caput, Antennae, Thorax, Corpus nigra, immaculata. Elytra teftacea apice rotundata nec eniarginata. Pedes nigri.

2. CVCVIVS ruber, thorace fulcato, fe-clani. moribus clauatis rufis.

Habitat in America boreali Dom. Yeats.

Corpus depreffum. Antennae breues, niğrae articulis vndecim. Caput glabrum, rufum, poftice vtrinque rotundatum. Os pallefcens. Thorax rufus, bifulcatus. Scurellum paruum, rotundatum. Elytra rufa margine nigricante. Abdomen nigricans. Pedes nigri femoribus clauatis rufis.

3. CVCVIYS? thorace denticulato rufo, dubius elytris nigris, antennis filiformibus lon. gitudine corporis.

Habitat in America boreali.

Statura depreffa praecedentium at mihi haud rite examinatus ideoque de genere hae. reo. Antennae filiformes, flexuofae artiPs culo pes 
culo vltimo acuto. Caput rufum. Thorax denticulatus rufus. Elytra ftriata, nigra, obtufa. Corpus cum pedibus rufum.

pulina- 3-4. MALACHIVS niger, thoracis marginibus elytrorumgue apicibus rubris.

Habitat Chilonii Dom. Lund.

Affinis M. pediculario, cuius forte mera varietas at thoracis latera rubra.

soecus 2-3. ELATER ater, thorace maculis duabus ocellaribus, elytris ftrigis duabus arcuatis punctoque poítico ferrugineis.

Habitat in Africa Dom. Lee.

Corpus maiufculum. Caput laeue, nitidum, atrum, immaculatum. Thorax ater verinque ocello coeco fiue annulo magno, oblongo, ferrugineo. Elytra laeuia, atra ftrigis duabus anteriore antrorfum, pofteriore retrorfum arcuats. Poftice punctum oblongum obfcurius.

filca- 8-9. ELATER villofo-albidus, elytris ftriis tribus eleuatis glabris atris.

Habitat in America boreali Dom. Spengler.

Magnitudo \& fumma affinitas E. porcati, cuius forte iunior varietas. Caput atrum, obfcurum antennis breuibus ferratis. Thorax villofo albidus antice nigricans. Pectoris futura atra, glabra. Elyrra villofo albida ftriis tribus eleuatis, atris, nitidis. Abdomen fubtus vti \& pedes villoro albida. 
28-29. ELATER niger, thorace pube-baema. foente fuluo, elytris fanguineis.

tlater antennis pectinatis fecundus

Schaeff. Icon. I. tab. 2. fig. 6. potius:

hic pertinere videtur, quamuis tho:

rax niger.

Habitat in Germania.

Paullo maior E. fanguineo. Antennae ferratae, nigrae. Thorax pubefcens, fuluus. Scutellum nigrum. Elytra fubltriata, fanguinea.

33-34. ELATER thorace atro nitido, ely- limba-

tris teftaceis : limbo nigro. tirs

Habitat Chilonii Dom. Lund.

Starura \& magnitudo E. minuti, cui val. de affinis, at elyura teftacea margine omni nigro.

8 -9. BVPRESTIS elytris tridentatis viri-ruti-

- dibus nigro maculatis: margine aureo. lans

Habitat in Auftria Dr. Schulz.

Media. Caput virefcens antennis fufcis.

Thorax fcaber viridi-nitens margine aureo. Elytra tridentata, ftriara, viridia margine aureo punctis numerofis nigris. Corpus fubtus viride, nitens.

$22-23$. BVPRESTIS elytris integris, aurea Tro. nitidiffima, dorfo elytris pedibusque vi. chilhis ridibus.

Habitat in Auftria Dr. Schulz.

Statura \& magnitudo B. 8 guttatae. Caput 


\section{6}

\section{सลำ}

aureum antennis viridifufcis. Thorax aureus, nitidiffimus dorfo coeruleo linea media viridi. Elytra integra, laeuia, viridia, nitida. Corpus aureum, nitidiffimum. Pe. des virides, nitidi.

plebeia 28-29. BVPRESTIS elytris emarginatis cupreis fufco maculatis. Habitat in Indiis Dr. Schuiz.

Corpus magnitudine \& ftatura B. rufticae. Antennae nigrae. Caput \& thorax obfcura, fcabra. Elytra emarginata, obfcure cuprea maculis plurimis fubconfluentibus fufcis.

- Corpus cupreum, nitidum. Abdomen fupra viride.

higu. 28-29. BVPRESTIS elytris integris obbris

fcuris nigro fcabris, corpore futtus cupreo.

Habitat in Auftria Dr. Schulz.

Corpus magnitudine \& ftatura B. Tenebrionis. Caput obfcurum, grifeum antennis nigris. Thorax obfcurus, grifeus, laenis margine auro pauco nitidulo. Elytra integra, obfcura, grifea punctis plurimis, eleuatis, oblongis, glabris fcabra. Corpus fubtus cupreum, nitidum.

4 ma $3 \mathrm{I}-32$. BVPRESTIS elyrris integris viri. culuta " dis, thorace poftice elytrisque maculis duabus aurcis.

Habitat in India D:. Fothergill.

Statura parua noftratum. Thorax viridis pofti- 
poftice late aureus. Elytra integra viridia maculis cuabus magnis aureis.

39-40. BVPRESTIS elytris integerrimis bigut:

linearibus viridibus puncto albo, abdo. ${ }^{\text {tate }}$ mine cyaneo punctis tribus albis.

Habitat in Anglia Dom. Yeats.

Paullo maior B.viridi. Caput viride fron. te impreffa antennis breuibus nigris. Thorax cylindricus, viridis, immaculatus. Elytra linearia, viridia puncto paruo albo ad futuram. Abdomen fupra cyaneum, nitidum vtrinque punctis tribus albis, quorum anterius parum remotum. Subtus itidem coeruleum virinque punctis tribus albis.

$4 \mathrm{I}-42$. BVPRESTIS elytris in tegerrimis, ${ }^{\text {nitidis: }}$ thorace marginato virinque depreffo, corpore viridi nitido. Linn. Syft. Nat. 2. 662.15. Fn. Sv. 757 .

Habitat in Europa.

Corpus totum viride, nitidum. Elytra paullo obfcuriora, attamen nitida. 4I-42. BVPRESTIS elytris integerrimis Salicis viridis nitens, coleoptris aureis bafi viridibus.

Schaeff. Icon. tab. 3 I. fig. 12.

Habitat in Germaniae Salice Dr. Schulz.

Statura \& magnitudo B. nitidulae. Capur viride, pubefcens antennis fufcis. Thorax depreffus, marginatus, viridis maculis duabus cyaneo-impreffis. Elytra integra rufo- 
aurea bafi in primis ad futuram viridibus. Subtus viridis immaculata.

punctu-3-4. DYTISCVS niger, clypeo elytrolatus rumque margine exteriori albis; elytris Atriis tribus punctatis.

Dyticus fulcus margine coleoptrorum thoracisque flauo Geoff. Inf. 1. 185. 1.

Roef. Inf. 2. Aquatil. r. tab. 2.

Frifh. Inf. 13. tab. 1. fig. 7 .

Habitat Chilonii in riuulis fyluaticis Dom. Lund.

Magnitudo \& ftatura omnino D. marginalis. Caput atrum clypeo albo. Thorax ater nitidus margine folo laterali albo. Elytra nigra, nitida ftriis tribus punctatis exarata margineque exteriori albido, qui tamen color apicem elytrorum haud attingit. Cor. pus nigrum tibiis anticis pallefcentibus.

Facmina fulcis decem dimidiatis elytrorum vii in D. femiftriato.

gibus 14-15. DYTISCVS gibbus ferrugineus, elytris nigris apice acuminatis.

Habitat Chilonii in aquis ttagnantibus Dom. de Seheftedt.

Statura D. erythrocephali at paullo.minor. Caput ferrugineum bafi parum nigricante. Thorax ferrugineus margine poftico nigro. Elytra laeuia, nigra bafi margineque obfolete ferrugineo maculata. Corpus \& pedes ferruginea abdomine apice nigro. 


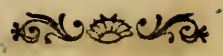

Variat interdum capite thoraceque to. tis ferrugineis.

2I-22. DYTISCVS ater, capire ferrugi- 6 puftu. neo, elytris maculis tribus rufis: bafeos latus maiore.

Habitat in Sveciae aquis ftagnantibus.

Minutus. Caput ferrugineum oculorum regione nigra. Thorax niger lateribus ferrugineis. Elytra glabra, laeuia, nigra maculis tribus ferrugineis prima bafeos maiore lunata, reliquis duabus verfus marginem. Corpus atrum pedibus ferrugineis.

25-26. DYTISCVS ferrugineus, elytris inae-

nigris: lateribus inaequaliter ferrugineis. qualis

Habitat in Sveciae aquis ftagnantibus.

Magnitudo D. lineati. Caput ferrugineum oculorum orbita nigra. Thorax ferrugineus poftice niger. Elytra laeuia, nigra margine ferrugineo ramulos inaequales, abbreuiatos exferente. Subtus ferrugineus.

Variat interdum linea media elytrorum flaua a macula bafeos admedium marginis exterioris ducta.

2-3. CARABVS apterus niger violaceo cyaneus nirens, elytris punctis intricatis rugofis.

Habitat in Europa.

Minor C. coriario: Caput atrum antennis apice cinereis. Thorax obcordatus, planus, canaliculatus, violaceo nitens. Elytra haud

conna. 
connata, attamen alas nullas continent. E. lytra punctis eleuatis, intricatis, plurimis rugora, nigra margine in primis violaceo, nitido. Corpus \& pedes atra.

limba. 5I - 52. CARABVS thorace elytrisque vitus ridibus: margine fafciisque abbreuiatis - pallidis.

Habitat Chilonii fub lapidum aceruis Dom. de Seheftedt.

Magnitudo C. melanocephali at latior. Antennae pallidae. Caput virefcens linea frontali antice bifida, albida. Os teftaceum maxillis apice nigris labioque albo. Thorax latirudine fere elytrorum viridis margine antico \& laterali pallidis. Elytra viridia margine pallido, a quo fafciae duae flexuofae abbreuiatae exeunt. Corpus teftaceum pedibus pallidis.

vitia. 56-57. CARABVS alatus, thorace martus

ginato rufo, elytris atris: vitta alba. Habitat in America boreali. Years.

Statura C. crux minoris. Antennae nigrae. Caput rufum. Thorax rotundatus, marginatus, rufus. Scutellum paruum, rufum. Elytra glabra, atra vitta longitudinali alba. Margo rufefcens. Corpus ferrugineum. Pedes nigri.

Morio 9-10. PIMELIA thorace antice rotundato atra, antennis apice rufis.

Habitat in Anglia.

Anten- 
Antennae apice moniliformes articulo vlrimo rufo. Capur atrum. Thorax antice rotundarus, poftice truncatus ater. Elytra itriata. Corpus atrum.

4-5. HELOPS arer, thorace quadrato lae- Morio

ui, elytris punctaro ftriatis.

Habitac in America boreali.

Affinis H. nigritae at paullo maior. Antennae apice moniliformes articulo vlrimo longiori, ouato. Thorax laeuis, quadratus marginibus haud rotundatis, obfcurus. Elytra punctato ftriata, obfcura. Corpus fub. tus \& pedes atra, nitida.

$4-5$. HELOPS ater, thoracis marginibus Nigri-

rotundatis, elytris crenato fulcatis. ta

Tenebrio atratus oblongus ater, elytris fulcatis acutiufculis Syft. Ent. 256. 4 .

Habitat in America meridionali. .

Antennae apice moniliformes. Thorax làeuis margine exteriore rotundato anguio. que poftico acuto. Plantae fubtus lana rufa. It-12. STAPHYLINVS niger, elytris 2 gut. puncto albido, oculis prominulis Linn.tazus Syft. Nat. 2. 685. 15. Fn. Sv. 85 I.

Habitat ad littora maris Balthici de Seheftedt.

Affinis S. biputulato, at differt manifefte thorace rotundiore \& oculis magis prominulis.

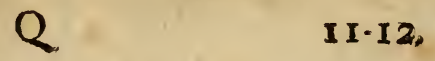


clani. I I - 12. STAPHYLINVS niger immaculacornis tus, thorace rotundato laeui, antennis ex. trorfum craffioribus.

Habitat Kilonii Lund.

Statura \& magnitudo omnino S. 2 guttati. Antennae moniliformes, extrorfum craffio. res. Thorax rotundatus, ater, nitens, lae. uis. Elyrra vix punctara, atra, immaculata. Abdomen \& pedes atra.

thore. I - 2. OXYPORVS nigricans, thorace ru. rieus fo, elytris fufcis bafi albis.

Habitat in Boletis. Captus Kilonii d. I I. Jul. de Sehertedt.

Statura praecedentium at duplo minor. Antennae moniliformes, extrorfum craffio. res bafi pallidae apice nigrae. Caput atrum, nitidum. Thorax rufus, nitidus. Elytra fufca, bafi albida margine tamen craffiori fufco. Abdominis fegmenta picea vel potius bafi nigra apice rufefcentia. Pedes fla. uefcentes.

fyg. 2-3. OXYPORVS nigricans, thorace elywonu trisque pallidis.

Habitat in Boletis Captus Kilonii d. II. Iul. de Seheftedt.

Affinis praecedentiat minor. Caput atrum, nitidum. Thorax obfure pallidus. Elytra pallida margine cralliori, fufco. Abdomen magis nigrum. 


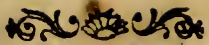

I -2. PAEDERVS niger, thorace rufo, ely-ruficoltris cyaneis.

Habitat Kilonii frequens fub lapidibus littoralibus de Seheftedt.

Minor P. ripario. Caput arrum, nitidum antennis moniliformibus nigris. Thorax gibbus, rufus, nitidus. Elytra abbreuiata, cyanea, nitida. Abdomen \& pedes atra. 22. MANTIS thorace cylindrico flauefcen-pufine te, elytris alisque hyalinis immaculatis. Mantis pufilla Pallas fpecill.Zool. fafic. IX. pag. I 5. tab. I. fig. 9.

Habitat in Africa.

Vix Raphidia Ophiopfi maior.

22-23. GRYLL.VS thorace fubcarinato, fibisi. antennis clauatis, tibiis anticis ouato cla-cus uatis + Linn. Syft. Nat. 2. 701. 5 I.

Gryllus clauimanus Pall. Spic. Zool. fafc. IX. p. 2 I. tab. I. fig. I I.

Habitat in Sibiria.

7-8. ONISCVS cauda quadridentata. linea.

Linn. Syft. Nat. I 1. 1060. 9. Amoen. acad. ris.

6. 415.100 .

Onijcus vngulatus Pall. fpic. Zool. fafc. IX. pag. 62. tab. 4. fig. I I.

Habitat in Occano Indico.

17-18. ONISCVS oualis, cauda obtufa, afimi. murica Linn. Syft. Nat. 2. I06 I. I 3.

Onifcus globator Pall. fpicill. Zool. fafc.IX. pag: ;0. rab. 4. fig. I8?

$$
\mathrm{Q}_{2} \text { Buft. }
$$


244

Baft. Subfe. p. I 44. tab. I 3. fig. 3 .

Habitat in Oceano Europaeo.

fignata I. PODVRA fubglobora furca, abdominis lateribus fuluo maculatis.

Podura furco nigra, abdomine globofo fignaturis ferrugineis Geoff. Inf. 2. 607.1.

Habicat in locis humentibus.

Antennae longitudine fere corporis.

- Halte 4-5. EPHEMERA cauda trifeta fufca, ab. rata domine albido apice fufco.

Habitar Kilonii frequens.

Parua. Caput \& thorax fufca, immaculata. Abdomen album apice fufcum. Cauda feris tribus corpore triplo longioribus. Alae duae magnae, albae margine craffiori nigricante. Pecies antici porcecti, albi.

grifeus 1-2. HEMEROBIVS alis grifeis alboma. culatis.

Habitat in Africa Dom. Yeats.

Antennae defunc. Sratura H. pectinicornis at minor. Caput \& thorax ferruginea nigro-varia. Alae magnae, grifeae triga punctata media punotisque fparfis apicis al. bis. Alae polticae bafi nigrae.

sizidu-s-6. HEMEROBIVS alis fufco nitidulis, lus corpore teftaceo, pedibus pallidis.

Habitat in Germania de Hattorf. Magnitudo H. hirti. Antennae longitu. dins 
dine corporis fufcae. Caput teftaceum oculis magnis nigris. Thorax \& abdomen teftacea, immaculata. Alae corpore multo maicres, fufcae auro rubroque nitidiflimae, immaculatae. Pedes pallidi.

7-8. HEMEROBIVS niger ore pedibus- long:que pallidis, antennis longioribus fufcis. cornis Habitat Kilonii in praedio nobiliffimi comitis Holk Ekhoffticto.

Paullo $\mathrm{H}$. hirto minor. Antennae corpore tripla longiores fufgae, immacularae. Caput nigrum ore pallido. Thorax \& abdomen nigra, immaculata. Alae albae neruis punctoque marginali furcis. Pedes pallidi.

6. PANORPA alis anticis flano fufcoquelinlte. variegatis; pofticis longiffimis fufcis : ma-rcita culis tribus albis.

Panorpa bulterata Forfk. difcript, anim. 97. tab. 25 . fig. E.

Habitat in Oriente.

Statura \& fumma affinitas P. Coae. Antennae filiformes, nigrae. Corpus nigrum. Alae anticae magnae, erectae, Aauo fufcoque variegatae. Pofticae longifimae, lineares, apice parum latiores, nigrae maculis tribus albis tertia alam terminante.

51-52. ICHNEVMON ater, abcomine polyce lineari longiffimo, tibiis pofticis clauatis. rator Habitat in India.

$$
\text { Q } 3 \text { Magni- }
$$


246

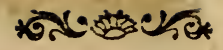

Magnitudo I. manifeftatoris. Corpus totum atrum, nitidum. Abdomen longilfimum, lineare fegmenris cylindricis. Alae breues, albae. Pedes atri tibiis porticis claủatis.

neca. 74-75. ICHNEVMON niger, abdomine tor flawo apice nigro, pedibus flauis.

Roef. Inf. 2. Vefp. IV. tab. 4 .

Habitat in Phalaenarum laruis, quas folliculis aflociatis albis obregunt.

Minutus. Antennae fetaceae, nigrae. Thorax niger, nitidus, immacularus. Abdomen flaum apice nigrum. Pedes flaui. Alae hyalinae macula coltali nigra.

margi-3-4. ANDRENA thorace pubefcente, abNata

domine ferrugineo: fegmentorum marginibus cinereis; primo toto atro.

Habitat in Germania de Hattorf.

- Parua ftatura A. heluolac. Caput \& thorax nigra lana cinerea pubefcentia. Abdominis primum fegmentum atrum reliqua ferruginea marginibus cinereis.

foroe. 8-9. APIS hirfuta atra, ano albo. enfis Habitat in Daniae nemoribus. Dom. Schlanbufch.

Statura omnino reliquorum at tota atra folo ano albo.

forum I 3 - I 4. APIS hirfuta nigra; thorace antiforum ${ }^{1}$ ce flauo, ano rubro.

Habi- 
Habitat in Daniae fyluis Dom. Schlanbuich.

Statura \& magnitudo A. hortorum. Caput nigrum fronte pilis flauis. Thorax hirtus, niger antice fafcia flata \& poftice pilis rariflimis flauis. Abdomen hirtum nigrum ano late rufo.

$22-23$. APIS hirfuta atra, fcutello abdo mnio. mineque pallefcentibus, ano rufo.

Habitat in Chilonii nemoribus Dom. de Seheftedt.

Praecedentibus valde affinis at paullo minor. Caput \& thorax hirta, atra, immaculata. Scutelli regio vti \& abdomen pilis pallidis tectr. Anus rufefcens. Pe: des nigri.

54-55. APIS nigra, abdomine cylindri-4 cinco; fafciis quaruor albis, pedibus flauis. Eta Habitat in Daniae nemoribus Schlanburch.

Magnitudo A. florifomnis. Antennae fupra fuicae, fubtus fuluae. Corpus nigrum pube parua cinerafcente. Abdomen cylindricum fegmentorum quatuor marginibus albis anteriorum interruptis. Pedes flaui.

2. TERMES thorace dentato. $\dagger$

Termes ard Forfkahl defcript. anim. pag. 96. n. 61. tab. 25. fig. A.

Habitat in Aegypto fornices cylindricos progrediendo inaedificans. De.

$$
\text { Q4 }
$$

Atruens 
Aruens cibaria, arbores, fructus omniaque. Praecedenti valde affinis an diftincta.

Cylin. 33-34. CANCER thorace bifulcato: latedrus ribus dilatato cylindricis apice fpinofis.

Habitat Tranquebariae.

Statura fingularis. Corpus paruum. Frcens obtufa, canaliculata. Thorax globofus falcis duobus magnis vnicoque antico transuerfali impreffins intus hirtis. Latera thoracis vltra longitudinem corporis dilatata, cylindrica, albida punctis rubris fabra apiceque fpina alba, valida armata. Cauda fub abdomine infiexa, albida, fcabra in medic longirudinaliter bifulcata. Pedes mihi defunt.

grofis- I. GAMMARVS manibus adactylis lonpes gitudine corporis.

Cancer groflipes Linn. Syft. Nat. 2.1055.80. Aftucus muticus pede antico fubulato edentulo longiffimo crafiffimo Gronov. Zooph. 989. tab. 17. fig. 7 .

Onifcus volutator Pallas Spic. Zool. fafcic. IX. p. 59. tab. 4. fig. 9.

Habitat in Europae aquis ftagnantibus. nabita 3 . AGRION alis erectis: pofticis fupraviridi-fericeis apice atris.

Habitat in America meridionaliSpengler. Statura \& magnitudo A. Virgo. Corpus totum viride, nitidum. Alae anticae reticulatae, 
culatae, obfcurae, pofticae viridi fericeae, nitidae apice \& fubtus atrae.

4. AGRION alis reticulatis, abdomine lon- lineagillimo lineari. ris

Habitat in India Dr. Fothergill.

Sratura A. puellae at maior. Corpus fufum abdomine lineari, longiffimo. Alae porrectae, reticulatae, anticis macula apicis oblonga, alba, pofticis furca.

3-4. ARANEA virefcens, thoracis lateri-fignata

bus abdominisque lineis duabus nigris.

Habitar in nemoribus Kilonienfibus capt. d. XI. Iul. .

Parua. Caput virefcens atomis aliquor nigris. Thorax itidem virefcens lateribus fuperne late nigris. Abdomen globofum, virefcens vtrinque linea lata e maculis quaruor transuerfis nigris, quae tamen lineae nec bafin nec apicem abdominis attingunt. Papilli textorii prominent. Pedes virides punctis nigris.

8-9. ARANEA viridis, abdominis dorfo dorfafufco.

Habitat in nemoribus Kilonienfibus.

Parua. Caput, thorax \& pedes viridia, inmaculata. Abdomen ouatum, fubtus pallidum fupra fufcum limbo pallefcente.

33-34. ARANEA cinerea, abdominis cineres dorfo fufco: punctis octo cinereis.

$$
\text { Q } 5 \text { Habi. }
$$


Habitat ad littora finus Kilonienfis.

Media. Maxillae cinereae vnguibus nigris. Oculi quatuor inferiores minuriffimi quatuor fuperiores multo maiores. Thorax cinereus, immaculatus. Abdomen ouatum dorfo obfuro punctis quatuor parium cinereis, minutiffinis. Pedes cinerei fufco an. nulati femoribus immaculatis.

myopa $35-36$. ARANEA virefcens, abdominis dorfo late fanguineo.

Habitat in praedio nobiliffmi comitis Holk Ekhoff dicto.

Caput \& thorax pallide virefcentia maxillis apice nigris lineisque duabus dorfalibus thoracis obficurioribus. Abdomen ouatum, pubefcens fupra dorfo fanguineo punctis aliquot nigris, lateribus flauefcentibus, immaculatis. Papillae textoriae apice nigrae. Pedes elongati, virefcentes tibiis anticis apice nigris.

Remts 16-17. PAPILIO, E. T. alis dentatis fubconcoloribus nigris: polticis verinque maculis flauis marginalibus.

Papilio Hippolytbus Cram. Inf. I. 13. tab. 10. fig. A. B.

Seba Mul. 4. rab. 46. fig. I I. 12.

Habitat in Amboina.

Magnus Alae pofticae fubrus paullo albidiores. Margo alarum pofticarum cingitur vtrinque maculis fex inaequalibus fauis. 
22-23. PAPIL.IO. E. T. alis dentatis nigro Andro aeneis: anticis macula quadrifida flaua, geus pofticis fubtus lunulis rubris, cyaneis flauisque.

Papilio Androgeus Cram. Inf. 2. tab. 16. fig. C. D.

Habirat Surinami.

Affinis P. Polydamas.

23-24. PAPILIO. E. T. alis dentatis arris: Ly $y$ ananticis ftriga alba, pofticis macula media der alba lunulisque rubris.

Habitat in India Dr. Fothergill.

Magnitudo \& ftatura P. Aeneas. Alae anticae atrae ftriga media alba. Pofticae dencatae, atrae macula media magna alba pofticeque lunulis tribus anguloque ani rubris.

30-3r. PAPILIO. E. A. alis dentato bicaul Cafor datis fuluis margine nigris : fubrus falcia maculisque albis nigra foetis.

Papilio Caffor Cram.Inf.4. tab.37. fig.E.F.

Habitat in Guinea.

Statura praeceđentium. Alae fubtus purpurafcentes bafi maculis variis albis nigra foetis, in medio fafcia alba apice maculis ocellaribus.

Conf. Papilio Pelias Cram. Inf. I. tab. 3. fig. C. D. vix diftincta fpecies videtur. 30-3I. PAPILIO. E. A. alis denrato - bi- Pollhix caudatus furcis fafcia flaua: fubrus fafçia maculisque albis nigra foetis. 
Papilio Pollux Cram. Inf. 4. tab. 37. fig. C. D.

Habitat in Guinea.

Nimis praecedenti affinis. Differt tamen colore fupra fufco punctisque marginalibus coeruleis \& fubtus defectu macularum ocellatarum.

Cre- 40-4r. PAPILIO. E. A. alis candatis: fupra fufcis, fubtus glaucis, fafcia verinque alba.

Habitat Surinami Dr. Schulz.

Paruus. Antennae extrorfum craffiores haud capiratae. Corpus fufcum. Alae anticae fufcae bafi ftrigis aliquot obfeurioribus, in medio fafcia lata alba, apice nigrae punctis fex aur feptem albis. Subtus oflaucae fafcia alba ftrigisque fuluis. Pofticae fufcae friga continuata alba, quae tamen angulum ani haud attingit. Margo pofticus ftrigofixs maculis tribus ocellaribus atris iride alba. Ad angulum áni macula parua rufa. Cauda elongata atra margine albo. Subtus glaucae. fafcia laca alba ftrigisque fuluis poftice punctis tribus atris punctoque ani rufo.

orfila
chats - 4 r. P.APILIO. E. A. alis caudatis furcis: anticis farciis duabus, pofticis vnica albis, fubtus bali albis fafcia fulua.

Habirat Surinami Dr. Schulz. Affinis praecedenti eiusdemque ftaturae \& magnitudinis. Alae anticae fufcae fafciis duabus 
duabus albis pofteriore lineari, fubtus bafi albae fafcia fulua, apice fufcae ftrigis duabus glaucis, exteriore extrorfum bifida. Pofticae fufcae fafcia continuata alba, quae angu. lum ani haud attingit. Maculae duae atrae iride alba adangulum ani. Angulus ani appendiculatus ferrugineus. Cauda elongata, atra margine albo. Subtus bafi albae fafcia fulua, apice fufcae ftriga glauca. Margo nigro-ftrigofus. Cauda nigra margine albo. Angulus ani macula rufa puncto atro.

60-6I. PAPILIO. E. A. alis dentatis nigris Amphto fafcia inaequali flaua: pofticis fubrus ftri-trion ga e punctis flaris lunulisque cyaneis.

Papilio Amphitrion Cram. Inf. 1. tab. 7. fig. A. B.

Seb. Muf. 4. tab. 8. fig. 7.8.

Habitat in America.

Niagnus. Corpus nigrum, immaculatum. Alae anticae concolores, nigrae maculis quatuor ouatis fafciam fere conftituentibus interruptam. Pofticae nigrae fafcia inaeğuali verfus angulum ani attenuata flaua, quae tamen margines haud attingit. Subtus nigrae ftriga e punctis feprem magnis orbiculatis flauis \& alia ftriga e lunulis feptem coeruleis, quae ad angulum ani puncto flauo termina. tur. Margo ipfe finubus flauis. 66-67. PAPILIO E. A. alis angulato-re-Aura. pandis fufcis: fubtus liuidiufculis ocellomedon anguli anis

Popja 
Papilio Automedon Cram. Inf. 4. tab. 4I. fig. A. B.

Habitat Surinami.

Magnitudo \& ftatura P. Teucer. Alae maris coeruleo colore nitidae, foeminae obfcuriores. Subtus lucidae ftriga obliqua bafeos alba verfusque angulum ani occllo coe. rulefcente.

Hecale 80-8I. PAPILIO $\mathrm{H}$. alis oblongis integerrimis nigris: anticis fafcia pofticis fubtus punctis marginalibus albis.

Papilio Pafithoe Cram. Inf. 2. tab. 17. fig. A. B.

Habitat Surinami.

Magnus. Caput atrum flauo punctatum. Corpus nigrum abdomine fubtus flauo. A. lae anticae nigrae fafcia lata alba, in qua: puncta aliquot nigra, poftice bifida. PunEta alba verfus apicem, fubtus concolores. Pofticae fupra atrae, immaculatae, fubtus nigrae bafi parum fauefcentes \& apice ftriga punitorum albidorum.

Bra00. 81 -82. PAPILIO H. alis oblongis integris lis fufcis : anticis flano maculatis, pofticis fubtus fanguineo radiatis.

Papilio Bellona Cram. Inf. 2. tab. 13. fig. E. F.

Habitat Surinami.

Statura P. Myrti. Alae anticae vtrinque flauo maculatae, pofticae fupra immaculatae, fubtus rubro radiatae.

$8 \mathrm{I}-82$. 
8I-82. PAPII.IO. H. alis oblongis integris Thales fubconcoloribus atris bafi rubro radiatis: anticis flano maculatis.

Papilio Thales Cram. Inf. 4. tab. 38. fig. C D. Aub. Mifcell. tab. 72. fig. 3.4. Habitat Surinami.

Praecedentibus affinis. Alae omnes bafi rufo radiatae, anticæ flauo virinque maculatae. 83-84. PAPILIO. H. alis oblongis integris Aegle atris: anticis maculis, pofticis difco hyalinis.

Habitat in India Dr. Schulz.

Statura omnino P. Pfidii at triplo minor. Alae anticae fupra atrae macula magna cuneiformi bafeos fafcia atra diuifa. Verfus apicem maculae duae maiores \& tres minores hyalinae. Subtus concolores at inter maculas litura fulua \& puncta tria apicis alba. Pofticae fupra atrae difco hyalino fafciaque fubmarginali abbreuiata fulua. Subtus difco hyalino, qui includitur linea atra, tunc maiori fulua margine tamen ipfo atro punctis tribus apicis albis.

126-27. PAPILIO. D. C. alis rotundatis Eduse integerrimis albis fufco maculatis: pofticis fubrus virefcentibus albo maculatis.

Habitat Chilonii Dom. de Seheftedt.

Statura \& magnitudo P. Cardamines. Antennae fufcae claua apice alba. Alae anticae albae in medio maculis duabus nigris altera 


\section{6}

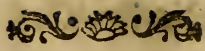

ad marginem craffiorem, altera ad tenuio. rem; apice nigrae albo punctatae. Pofti. cae fupra albae margine nigro maculato. Subtus anticae concolores at maculis magis virefcentibus, pofticae late virides maculis tribus bafeos, fafcia media admarginem tenuiorem interrupta maculisque marginalibus albis.

Lencip-132-33. PAPILIO. D. C. alis integerrimis ps fuluis: pofticis fupra flauis.

Papilio Leucippe Cram. Inl. 3. tab. 36. fig. A. B. C.

Habitar in India orientali, Amboina.

Magnus. Alae anticae fupra fuluae punCtis marginalibus atris, fubtus fuluae imma. culatae. Pofticae fupra flauiffimae (foeminae) maculis marginalibus nigris, fubtus pallide fuluae, atomis nigris.

Iphige- $136-37$. PAPILIO D.C. alis integerrimis nia

albis apice atris: pofticis fubtus flauefcentibus fafcia media atra; ftriga abbreuiata fulua.

Habitat Surinami Dr. Schulz.

Medius. Alae omnes fupra albae anticis apice taris. Margo pofticus nigrefcit. Subtus alae anticae concolores, pofticae flauefcentes ftriga bafeos atra. In medio fafcia lata ábbreviata atra, in qua ftriga etiam ab. breuiata fulua. In margine ipfo maculae nigrae, quarum anteriores maiores. 
144-45. PAPILIO D. C. alis rotundatis fla. Sefa uis apice (medio fuluo) atris': pofticis fub. tus maculis feprem ocellaribus albis.

Habitar in America Dom. Spengler.

Medius. Antennae clauatae, nigrae claua apice ferruginea. Alae anticae flauifimae apice nigrae gracula media fulua. Pofticae rotundatae, flauiflimae margine nigro. Subtus omnes flauifimae punctis margin: 1 bus atris \& in polticis puncta feptem alba iride ferruginea cincta.

160-61. PAPILIO D. F. alis integerrimis Cypa niogris: fafciis duabus albis; anteriorum rifias obliquis, pofticarum punctatis.

Papilio Duedalus Cram. Inf. t. tab.r. fig.A.B. Habirat in America meridionali.

Antennae clauatae claua acuminata. Alae nigrae certo fitu viridi colore fplendentes. 167-68. PAPILIO D.F. alis integerrimis Galas fupra arris' fanguineo - fafciatis : anticis this punctis duobus apicis albis.

Papitio Galanthis Cramer Inf. 3. tab. 25. fig. D. E.

Habitat Surinami.

Medius. Alae anticae atrae bafi fafciaque fanguineis. Puncta duo parua alba approximata oblonga apicis. Pofticae atrae fafcia obligua fanguinea. Subtus anticae flauae fuluo irroratae fafciis duabus oliuaceis pofteriore apicis. Pofticae bafi fufcae apice flauefcentes fafcia oliuacea:

R $\quad 172 \cdot 73$. 
Gilip. 172-73. PAPILIO D. Fialis integerrimis pus concoloribus fuluis albo maculatis: margine atro punctis albis.

Pupilio Gilippus Cram. Inr.3. tab.26. fig.C.D. Habitar in America merudionali.

Statura omnino P. Mifippi at paullo minor. Alae omnes fuluae albo maculatae. Margo pofticus ater ftrigis tribus punctorum alburum.

Lucin- 184-85. PAPILIO D. F. alis integerrimis nigro fafiatis : fupra coeruleis, fubtus fulvis.

Papilio Lucinda Cram. Inf. 1. tab. 1. fig. E. F. Seb. Muf. 4. tab. 13. fig. 25. 26.

Habitat Surinami.

Paruus ftatura P. Morpheus. Striga punEtorum nigrorum verus marginem in anti- cis fubtus, in pofticis vtrinque.

Lairus 187-88. PAPILIO D. F. alis integerrimis fufcis: pofticis fupra ocello fubcus duobus; poftico fesquialtero.

Pupilio Iuirus Cram. Inf. r. p. 9. tab. 6. fig. A. B.

Habitar in India orientali.

Magnus. Alae omnes integerrimae, fufcae anticis fafcia, pofticis bafi albidis. Ocellus magnus coeruleus iride flaua pupillaque alba alarum pofticarum \& fubrus duo eiusdem coloris, quorum pofteriori ocellus minor itidem pupillatus adnatus. 


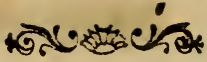

189-90. PAPILIO D. F. alis integerrimis Pbilo. furcis: fubrus anticis ocello, pofticis li-cles neis transuerfis vndatis. Linn.Syft. Nat. 2. 791 . 240. Muf. Lud. Vlr. 321 . Clerk. Icon. tab. 45 . fig. 3 .

Habitat in Indiis.

Variat alis fupra atris fafcia coerulefcente maculaque magna alba ani $\&$ alis fufcis lineis transuerfis vndatis fafciaque alba.

189-90. PAPILIO D. F. alis integerrimis croefus cyaneis ftrigis atris numerofis: anticis fu. pra macula ocellari tripupillata.

Habitat Surinami Dr. Schulz.

Alae anticae fupra cyaneae frigis aliquot apiceque atris. In medio macula magna atra punctis tribus paruis albis. Snbtus cyaneae, nitidae arcu apiceque atris. Pofticae vtrinque cyaneae Atrigis numerofis vndatis atris. 20I - 2. PAPILIO D. F. alis integerrimis Daums

fuluis : anticis ocellis duobus, porticis fex coecis, fubtus pupillatis.

Habitat Hamburgi Dr. Schulz, Kilonii Seheftedt.

Medius. Alae anticae fupra fuluae ocellis duobus atris coecis tertioque minutilfmo vix diftincto; fubtus fafcia alba ocellis duobus pupilla alba. Pofticae obfcuriores ocellis quinque aut fex coecis; fubtus grifeae fafcia interrupta alba ocellis fex atris pupilla alba pofteriore didymo.

$$
R_{2} 216-17 \text {. }
$$




\section{0}

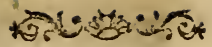

Ocype. $216-17$. PAll.1O N. G. alis dentatis fute prafufcis immaculatis fubtus glaucis Rri. gis tribus obfcuris: pofticis ocellis quinque. Habitat Surinami Dr. Schulz.

Paullo maior P. Penelope. Alae fupra omnes fufcae, immacularae friga marginali flauefente. Subrus omnes giancae, anticis Atrigis rribus obfiuris, poiteriore vndata, pofticis trigis quatuor bafeos fere obfoleris apicis vndata. Oselli duo obfoleti, minuri in apice alae anticae \& quingue maiores atri iride flaua pupilla alba in polticis inter Atrigas vltimas. Ocellus 2. 3. obfoleti.

ocirr. 216-17. PAPILIO IN. G. alis dentatis fuboe

pra albis apice fufis, fubrus fufcis: fafciis duthus albis, polticis ocellis quinque.

Habitat, Surinami Dr. Schulz.

Statura praecedentis. Alae anticae fupra albae apice furcae, fubrus fufcae fafciis dua. bus albis. Ante marginem pofticum ocelli quaruor parui pupilla alba. Margo iple glau. cus Arigis duabus obfcursoribus: anteriore vndara. Pofricae fupra albae margine frigis duabus vndatis punctoque ante marginem nigris. Subtus fufcae fafciis duabus latis albis. Ocelli quinque ante marginem 1.4. maioribus atris, 5 minore atro, 2, 3 minoribus furcis pupilla duplici argentea. Margo ftrigofus.

Auraca 217-18. PAPILIO. N. G. alis fubdentatis fufcis: 
fufcis: pofticis coerulefcentibus; fubtus ocellis quinque.

Habitat Surinami Dr. Schulz.

Statura praecedentis. Alae anricae fupra fufcae, immaculatae, fubrus frigis duabus obliquis obfcurioribus. Verfus apicem ocelli ires exteriori pupilla duplici, interioribus obfolecis. Pofticae fupra cyaneae, niridae; fubtus cyaneae frigis duabus obliquis fufcis. Ante marginem ocelli quinque 1. 4. maioribus atris, reliquis fuficis. Margo ftrigofus. 226-27. PAPILIO N. G. alis dentatis fu-peri. fcis: anticis ocello obfoleto; fubtus ftri: boes ga fauefiente, pofticis punctis ocellaribus átris.

Habitat Surinami Dr. Schulz.

Mectius. Alae anticae fufcae ocello magno atro iride flauefiente pupilla alba, at ob.foleta ad marginem anticum. Subrus grifeae ftriga fauefcente punctis duobus minutiri. mis albis. Pofticae fufcac ocello paruo obfoleto margineque ftrigolo. Subtus grifeae fligga faueficente punctisque $5-6$ paruis ocellaribus atris.

230-3I. PAPILIO N. G. alis dentaris fu- Hefru-

fic lubrus triga obliqua alba: anticis 0 -se cellis duobus pofticis fefqui tertiis.

Papilio Hefone Cram. InC. I. tab. I I. fig. C.D.

Habitat Surinami.

Alae fupra immaculatae. Subtus fafcia

$\mathrm{R}_{3}$

alba 
alba margines haud atringit. Ocelli fufci pupilla alba iride fulua annulo nigro coeruleo. que cincta.

Doris 232-33: PAPILIO N. G. alis dentatis fufcis: fubrus coeruleis nigro fafciatis ocellis trium parium.

Papilio Doris Cram. Inf. r. tab.8. fig.B.C. Habitat Surinami.

Starura praecedentium parua. Alae omnes fupra furcae margine poftico alarum poficarum parum albicante. Subrus omnes coeruleae, nitidae fafiiis quatuor nigris. In fafcia tertia ocelli fex per paria approximati nigri iride fulua pupillaque albida. Primum par ad marginem exteriorem alae anticae, fecundum ad marginim exteriorem alae po. ficae, \& tertium denique ad angulum ani.

Hiera $236-37$. PAPILIO. N. G. alis dentatis fu-

fcis: anticis vtrinque ocello fefqui altero, pofticis fubtus nebulofis ocellis fex.

Schaeff. Icon. tab. 58. fig. 2. 3 .

Habitat in Europae pratis fyluaticis.

Affinis P. Iurtina artamen diftincta videtur. Alae.anticae fufcae verinque litura flaua. $O$. cellus magnus ater pupilla alba in altero fexu duplicata. Inter hunc \& apicem ocellus minutilfimus pupilla alba. Pofticae fupra fufcae ocellis tribus pupilla alba exteriore coeco; fubtus fufco cinereoque nebulofae ocellis fex interiore duplicato. 
236-37. PAPILIO N. G. alis dentaris fu- Tififeis: anticis ocellis vtrinque duobus po phone fticis fex: pupilla violacea.

Papilio Tifiphone Naturforfch. C. I8. tab. 1. fig. I -2 .

Habitat in Germaniae fyluis.

Magnitudo \& ftatura praecedentis. Alae anticae fufcae fafcia abbreuiara flata. Verfus apicem ocelli duo nigri iride flaua pupillaque violacea. Pofticae fufcae verfus marginem potticum ocelli fex nigri iride Raua pupillaque violacea fubtus omnes concolores. $242-43$. PAPILIO N. G. alis crenatis ni-Clau. gris area fanguinea: pofticis fubrus mar-dia moratis ocellis feprem.

Habitar in India Dr. Schulz.

Magnitudo P. Tulbaghiae. Palpi albi apice nigri. Corpus fufcum. Alae fupra omnes nigrae area lata laete fanguinea. Sub. tus anticae rubrae macula alba tribusque marginalibus atris, apice nigrae ftriga maculisque duabus obfoletis, marginalibus, cinereis. Pofticae bafi nigro cinereoque marmoratae. In medio ftriga fiexuofá fiaua coerulefcensque, apice teftaceae ocellis feptem atris pupilla coerulea: interiore duplicata. Striga marginalis atra. 247-48. PAPILIO N. G.alis dentatis atris: Califs pofticis faficia fanguinea ocellis fupra quin. que fubtus feprem. 


\section{4}

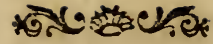

Papilio Califto Cram. Inf. 2. tab. 24 . fig. A. B. D'Aubenton mifcell. tab. 20. fig. 2. 3 . Seba Muf. 4. tab. 44. fig. 12. 13.

Habitat in Africa.

Magnus. Alæ pofticæ fupra atræ fafcia lata anrice alba poftice rubra ocellis quinque atris pupilla coerulefcente, fubrus fufcre fafcia rubra ocellis feptem vlrimo didymo.

250-5 I. PAPILIO N. P. alis bicandatodentatis fuluis ftrigis nigris: pofticis fubtus glaucis nigro punctaris.

Habitat in America meridionali D. Spengler.

Magnirudo P. Troglodyræ. Antennæ clauatæ fupra nigræ, fubtus albæ. Corpus fupra ferrugineo hirtum, fubtus albidum. Alae anticæ falcatæ, dentatæ, fuluæ firigis tribus margineque exteriori nigris. Ante ftrigam priorem lineola transuerfa puncta. que quatuor parua nigra. Inter ftrigam I. 2. lineola transuerfa \& ądangulum ani litura nigra. Subtus fufco glaucoque variegatæ. Pofticæ dentatæ; bicaudatæ cauda interiori breuiori, fuluæe ftrigis quatuor nigris. Adangulum ani puncta duo nigra annulo albo cincta lunulæque dure albæe inter caudas. Subrus glaucæ, bafi obfcuriores firiga obliqua fulca, verfus marginem pofticum firiga punctorum arrorum fibocellatorum.

Progme 264-65. PAPILIO. N. P. alis caudato dentatis 
tatis fuluis punctis margineque albo punctato nigris: fubtus grifeis.

Papilio Progne Cram.Inl. 1. tab. 5. fig. E.F.

Habitat in America meridionali.

Simillimus P. C. albo, at margo pofticus alarum niger in pofticis albo punitatus.

27i-72. PAPILIO. N. P. alis dentatis fla. Hypli-

uis rigro variegatis apice radiats: pofti-pyle cis punctis feptem rubris.

Papilio Hypermnefira Scop. Ent. 425. Roef inf. 4. tab. 7.

Catesb. Carol 2. 95. tab. 95.

Habitat in Europa auftraliori, America. 280-81. PAPILIO N. P. alis dentato cau. Hippo. datis flawo nigroque varis: pofficis pun. ctis quatuor albis.

Habitat in India Dr. Schulz.

Magnus. Alæ antice dehtate apice interiori truncatæ \& fere emarginare fupra bafin fulur, tunc nigre fafcia lata maculis duabus apicis flauis, fubrus variegaræ. Poftica apice truncatæ, dentatre cauda elongata bafi fulur apice arra punctis quaruor albis. Subtus glanco fufcoque variegatie. 299-300. PAPILIO N. P. alis dentatis a! Herija.

bis: limbo fuluo, pofticis fubrus fuluis, lia faciis duabus punetoque medio albis.

Habitat in India Dr. Schulz.

Paruus. Alæ anticæ fupra albre bafi fubfufcefcentes apice fulua margine dentato R s nigro. 
nigro. Subtus teftaceae macula magna difci punctisque aliquot verfus apicem albis. Po. fticae fupra albae limbo fuluo nigro marginato. Subtus fuluae fafcia bafeos alba inte. gra, tunc punctum medium album, tum fa. ficia e maculis feptem albis, demum maculae feptem albae obfoletae marginales. Margo ipfe tenuiffime niger.

Byige $304-5$. PAPILIO N. P. alis dentatis fuluis nigro punctaris: pofticis bafi fupra fufcis, fubtus albidis.

Papilio Hy.llus Cram. Inf.4 rab.43. f. B.C. Habitat in Oriente.

Minor P. Cinxiac. Alae anticae vtrinque fuluae nigro-punctatae fupra margine fufco. Pofticae nigro punctatae fupr bafi fufcae apice fuluae, fubrus bafi albidae apice fuluze.

Cynara $_{3} 08$-9. PAPILIO N. P. alis dentatis fuccis atro flauoque variis: polticis libtus viridibus maculis tribus fafciisque duabus argenteis.

Papilio Maja Cram. Ind. 3. tab. 25. fig. B. C. Habitat in Oriente.

Statura P. Paphia. Alae omnes fupra fufcae margine flauo atro maculato. Subtus anticae fuluae nigro maculatae, pofticae virides maculis tribus bafeos \& verlus apicem fafiiis duabus argenteis fuluo marginatis adangulum ani coeuntibus.

Faums 321 -22. PAPILIO P. R. alis tricandatis fufcis: fubtus albis ftrigis duabus fuluis. 


\section{Papilio Faunus Drury Inf. 2. tab. I. fig.4.5. Cram. Inl. 4. tab. 39. fig. B. C.}

Habitat in Sierra Leon. Africae.

Alae porticae ftriga poftica alba. Caudae albae ftriga poftica fubrus marginalis.

322-23. PAPILIO P. R. alis fubtricaudatis Petion

coeruleis auro punctatis: limbo furco.

Papilio Pelion Cramer Inf r. rab.6. fig. E.F.

Habitat in America meridionali.

Statura praecedentium. Alae tricaudatae cauda interiori breuifima, coeruleae punctis aureis numerofis limboyue fufco. Subtus fufcae albo fact tae bali obfcurrores, anticis punćto paruo coccineo.

322-23. PAPILIO P. R. alis fubtricaudatis Aums

coeruleis limbo atro: fubtus nigris albo-

fafciatis.

Papilio Aunus Cram. Inf. 2. t.23. fig. E.F.

Habitat in Curacao Americae.

Paruus, alae tricaudatae cauda interme. dia longiore ..nce apicem alba.

323-24. PAPILIO P. R. alis bicaudatis coe-Gany. rulercentibus limbo furco: fubtus bafi vi-medes

refcentibus punctis aureis.

Papilio Ganymedes Cram.Inf.4.tab.40.f.C.D. Habitat in India.

Alae fupra coeruleae, niridae puncto centrali anticarum limbogiue omni furcis. Sub. tus omnes bafi virefientes punctis numero. fis aureis: In medio anticarum frigae duae albre 


\section{8}

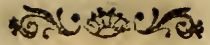

albæ vnicaque purpurea albæ adnata, pofticarum fafcia alba, purpurea viridisque ap. proximata. Margo pofticus fufcus punctis aliquot aureis ad angulum ani.

Mars 324-25. PAPILIO P. R. alis bicaudatis fufis: pofticis macula rufa, fubrus punctis duobus fafciaque obliqua alba.

Habitat in America meridionali Dom. Spengler.

Statura priecdentium. Antennæ albo nigroque annulate clana apice ferruginea. Alæ antica fufcre macula media obficuriore. Subtus cinerece fafcia obliqua alba. Poftica caudare: caudis fufcis apice albis; exteriore multo breviore, fufire macula ante marginem rufa. Subrus cincrere punctis duobus faficiaque obligua albis. Macula magna Celerio rufa ante angulum ani.

$3-4-25$. PAPILIO. 1'. R. alis bicaudatis albis, fubrus fafciis fulcis albisque alternis; angulo ani ocello triplici rufo.

Pupilio Celerio Cram. Inf. 3. tab. 3 r. fig.C.D. Habitat Surinami.

Ala fupra alba anticis apice ponticis margine punctato nigris.

Tele $325-26$. PAPILIO $P$. R. alis bicandatis coemat ruleis nitidis: polticis fubtus ltriga natginali angulata atra.

- Papilio Telemus Cram. Inf r. tab. 4. fig. D.E. Habitat in America meridionali. 
Alae omnes coerulex anticis fupra macula media atra. Caudar dux nigræ. $325-26$. PAPHLIO P. R. alis bicaudatis fu. Hemos pra fufcis immaculatis: pofticis fubtus an: gulo ani farciis tribus coeruleis.

Papilio Hemon Cram. Inl. 2. tab. 20. fig.D.E. Habitat Surinami.

Alæ fubtus pallidiores anticis frigis dua. bus dimidiatis nigris', poftcis puncto bafeos atro pupilla lateraii alba, verfus angulum ani ftriga incurua abbreuiata alba \& verfus marginem ftriga tres nigrex, qux ad angulum ani fafciis tribus coeruleis feparantur.

34 $\mathrm{I}$-42. PAPILIO P. R. alis caudaris albis Linus apice fufcis : fubtus albo atroque falciatis;

angulo ani punctis tribus albis. Habirat Surinami Dr. Schulz.

Alre anticx albæe puncto medio apiceque late fufcre. Subtus fafciis-quatuor albis atrisque alternis, intermediis duabus atris abbrewiatis. Margo ipfe ftriga abbreniata, ferruginea. Pofticx albæ margine nigro ftriga alba. Cauda nigra terminatur puncto albo. Subtus fafciis fex albis atrisque alternis adangulum ani coeuntibus. Fafcia exrerior \& incerior ferruginex. Angulus ani ater punctis tribus albis.

348 - 49. PAPILIO P. R. alis integris fupre Icarus albis fafciis fufcis: fubtus fafciis albis nigrisque alternis. 
270

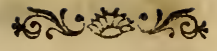

Papiiio Philemon Cram. Inf. 2. tab.22. f.G.H. Habitat Surinami.

Alæe fupra albæ fafcis quatuor punctoque intra primam \& fecundam fufcis. Subrus fafciis albis nigrisque alternis poftica nigra in alis pofticis punctata.

Hippo- 353 - 54. PAPILIO P. R. alis integris marthoe gine albo: fubtus cinereis punctis ocella. ribus numerofis.

Pupilio Hippotboe Linn. Syft. Nat. 2.793. 254. Fn Sv. 1046.

Roef. Inf. 3. tab. 37. fig. 6.7.

De Geer. Inf. 2. tab. 2.

Habitat in Europæ pratis fyluaticis.

Color alarum fuperne nimis variat. Interdum omnes fuluae margine maculaque enteriarum nigris, interdum fufea fuluo maculatæ nigroqu- punctatæ, interdum fuluo coerulefcentes nigro punitatæ. Margo vero femper tenuiffime albus.

Calius 360-6r. PAl'ILIO P. R. alis integris fupra

albis: anticis limbo fulco, polticis fimbria punctata.

Papilio Cafjus Cram. Inf.2.tab. 23. fig. C.D. Habitat Surinami.

Paruus. Alæ anticæ limbo maculisque duabus difci fufcis. Macula bafeos coerulea. Poftica albre margine poftico punetisquinque nigris, qua ftrigis duabus includuntur. Subtus omnes albæ nigromaculatix margine poftico nigro punctato. 


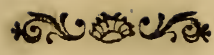

$38 \mathrm{r}$. PAPILIO P. V. alis caudatis atris fafciis Licas. duabus albis: angulo ani rubro bimaculato. fis Habirat Surinami Dr. Schulz.

Alæ anticæ atræ fafciis duabus albis, fubtus concolores lineola punctoque bafeos rubris. Pofticæ atræe fafciis duabus obliquis albis pofteriore obfoleta. Cauda elongata obtufa pun btis aliquot obfoletis albis. Adangulum ani puncta duo rubra. Subtus concolores, at intermaculas anales puncta duo parua cyanea.

$38 \mathrm{I}-82$. PAPILIO P. U. alis caudatis fu-Meli-

fcis: anticis ftriga pofticis duabus fangui. boeus neis, fubtus cyaneo nitidiflimis.

Habitat Surinami Dr. Schulz.

Alæ anticæ fufcæ ftriga obliqua fanguinea. Subtus cyaneæ nitidiffimæ fafcia margineque atris. l'ofticæ fufcæ ftrigis duabus rubris, quarum anterior marginem exteriorem, pofterior interiorem haud attingit. Subtus cyaneæ fafcia lata atra. Angulus ani puncto rubro alboque.

39I - 92. PAPILIO P. U. alis rotundatis in Ara-

tegris fufcis: pofticis fubtus grifeis ma-cintbur culis ocellaribus albis.

Habitat in Auftria Dr. Schulz.

Antennæ albo nigroque annulatæ clana ouata ferruginea. Corpus fufcum fubtus albicans. Alæ anticæ fufcr litura parua flauefcente ad marginem craffiorem. Subtus fu. 
fcæ apice flauo maculatx. Pofticæ fupra fufcæ, immacularæ, fubtus cinereæ maculis ocellaribus albis duodecim annulo nigiro cinctis 2. 4. 6. vltimis fex confluentibus.

Menip-397-98. P.IILIO P. U. alis integerrimis pus frriatis fufcis: fafcia lata alba.

Habitai Surinami Dr. Schulz.

Antennæ nigræ clata acumirata. Corpus nigrum. Ale antice fupra ftriatæ, fufcæ fafcia media lata alba puncto centrali fufco. Subur concolores ar magis albidæ. Polticæ ftriatre fufcre fafcia latiore alba, immaculata. Subrus albidæ apice fufcr.

lufca $2-3$. SPHINX alis angulatis obfcuris puncto arro: pofticis atris fafcia fulua.

Habitat in America meridionali $D$. Spengler.

Statura S. lugubris. Allæ anticæ cinereæ fufco repando fafciatæ. In medio alæ pun. ctum atrum (interdum duo.) Subtus obfcure grifex. Poltice fupra atræe falcia lata fulua, g!r marginem ienuiorem haud attingit. Angulus ani cinereus litura fulua. Subtus grifee, immaculatæ.

fene- $3-4$. SPHINX alis erofo dentatis fufco aureis: maculis duabus feneftratis.

Sphinx foneftrina Schiefferm. Prodr. 44. Habitat in Auftria Dr. Schulz.

Magnitudo maioris Mufcæ. Corpus fufomm palpis albidis. Abdomen cingulis duobus 


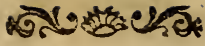

bus albis anteriore tenuiore. Alæ concolores fufcn aurex, nitidæ punctis flauis fparfis. In medio macula duæ approximata fene. ftratre in pofticis fere fafciam conftituentes. Margo potticus niger maculis duabus albis. 6-7. SPHINX alis dentatis nigris frigis Cacss tribus approximatis pallidis: pofticis flauis nigro ftriaris.

Sphinx Cacus Cram. Inf.4. tab. 46. fig. E. Habirat Surinami.

- Magnitudo S. Ello. Alæ anticæ dentatæ nigræ Atrigis rribus incurvis pallidis. P'oftcæ flaux margine poftico ftrisque octo bafin haud atringentibus nigris. Corpus nigricans abdomine cingulis cinereis nigrisque alternis.

I6-I7. SPHINX alis integris grifeis: pun. plebeje cto medio albo, abdominis lateribus albis nigro marginatis.

Habitat in America Infula It. Crux D. Spengler.

Magnitudo S. Pinaftri. Alæ anticæ grifeæ lineolis aliquot indiftinctis nigris punctoque medio albo. Pofticæ vti omnes fubtus nigra margine poftico renuifrme albo. Abdomen fupra grifeum linea dorfali nigra. Latera alba vtrinque nigra. Subtus album linea punctorum fufcorum.

I7 - I 8. SPHINX alis integris virefcentibus Gallie vitta alba: pofticis pallidis bafi Itrigaque atris, antennis furcis. 
Spbinx Gallii Schieff. Prodi: pag. 42.

Sphinx Jexta Scheff. Icon. tab. 78. fig. I. 2. Sphinx francofurtana Pallas spicileg. XI.

Roef. Inf. 3. tab. 6. Larua.

De Geer In . 2. p. 236.

Habitat in Germanize Galio.

Nimis affinis S. Euphorbiz. Differt tamen antennis vix apice albis, abdominis pun. ctis dorfalibus albis alisque fubtus oofcurioribus.

Pluto 22-23. SPHINX alis integris virefcentibus: pofticis fufcis fafcia fulua, abdomine fubtus aureo.

Habirat in America meridionali D. Spengler.

Corpus medium fupra virefcens capite thoraceque linea laterali cinerea. Abdomen linea dorfali punctorum aureorum. Pectus $\&$ abdomen fubtus aurea. Alæ anticæe fupra virefcentes obfcuro fubfafciatæ lituraque apicis alba. 'Subtus virefcentes bafi fubflauefcentes. Pofticæ fufcre fafcia lata fulua, fubtus flauefcentes itriga fufca atomisque virefcentibus. Apex alæ virefcit.

Melas $2-3$. SESIA alis feneftratis: margine atro, abdomine cyaneo bafi atro: cingulis tribus flauis.

Spbinx Melas Cramer InC.4. tab.45. fig. G. Habitat Surinami.

Magnitudo S. Hylas. Antennæ fubfilifor mes. 
formes. Caput flauum. Thorax niger lineis duabus thoracem cingentibus flauis. Abdomen bafi atrum fafciis tribus flauis, apice cyaneum fegmentorum marginibus atris. Alæ omnes feneftraræ margine poftico atro. I-2. ZYGAENA atra, alis anticis viridi. Pytbia bus maculis tribus oblongis approximatis fanguineis, pofticis rubris.

Spbinx fecunda Schaff. Icon. tab. I6. f.4. 5 . Habitat in Germania Dr. Schulz.

Affinis Z. Filipendula. Antennæ clauatæ, atræ. Corpus villofum, atrum. Alæ anticæ virides maculis tribus elongatis, approxımatis, fanguineis ad bafin 2. 1. Pofticæ fanguineæ margine cyaneo. Subtus concolores.

1 -2. ZYGAENA cyanea, alis anticis vi- Fuluia ridibus punctis quinque rubris, pofticis fanguineis immaculatis.

Spbinx quinti Schæff. Icon. tab. 7r. fig. r. Habitat in Auftria Dr. Schulz.

Nimis affinis Z. Filipendulæ. Antennæ extrorfum craffiores, atræ. Thorax cyaneus, albo macularus. Abdomen coerrlefcens, immaculatum. Alæ anticæ virides maculis quinque fanguineis duabus bafeos connatis. Margo parum albicat. Pofticæ fanguineæ,immaculatæ. Subtus concolores. 5-6. ZYGAENA atra, alis anticis cyaneis carnio. punctis quinque fanguineis fubocellatis, lica pofticis rubris: limbo nigro. 
Sphinx carniolica Scop. Ent. 478.

Sphinx Jeptima Schref. Icon. tab. 8r. f.4.5. Habitat in Auftria.

Thorax albo maculatus. Macula alarum annulo albo cinćtae, poftica transuerta. Ab. domen atrum rarius cingulo poftico fanguineo.

Bro- 10-10. ZYGAENA ferruginea, alis hyamus

linis: margine omni nigro.

Splinx Bromus Cram. Inf. 3 tab. 35. f. G. Habirat Surinami.

Antennæ pectinatix. Corpus totum obfcure ferrugineum, immaculatum. Alre hyalinæ margine omni nigro.

Hely. 14-15. ZYGAENA atra, abdomine lineis mus tribus aureis.

Spbinx Helymus Cram. Inf. r. tab. 2. fig.D.E. Habirat Surinami.

Antennæe vix pectinatæ, atræ. Alæ atræ, fupra immacularæe, fubtus linea pofticarum baleos aurea. Abdomen atrum fupra lineis tribus latis aureis.

Eri. 16-17. ZYGAENA virefcens, alis poftipbia cis atris: fafcia alba, antennis pectinatis.

Habitat Surinami Dr. Schulz.

Antennæ fufiæ pectinatæ. Caput \& thorax obfcura. Abdomen virefcens vtrinque puncto bafeos albo, fubrus ftriis duabus albis. Alæ anticæ fupra virefcentes, immaculatae, fubtus virefcentes margine interio: 
ri albido. Pofticx fupra atræ vitta lata alba. Subtus virefcentes, immaculatx. 19-20. ZYGAENA alis atris: anticis fa- Eynficia obliqua teftacea.

Habirat Surinami Dr. Schulz.

StaturaZ. glaucopis. Antenna atrx. Corpus atrum, immaculatum. Alæ anticæ atræ fafcia obliqua teftacea. Poftica atre, immaculatre. Subtus concolores at bafi coeruleo nitidifima. Abdomen fubtus lineis dua. bus punetorum albidorum. 21 -22. ZYGAENA alis flano hyalinis api- candace furcis, corpore auro maculato. tas Spbinx coarctuta Cram. Inf.I. tab. 4. f.F.G. Drury Inf. 2. tab. 17. fig. 2. Famina. Seba Muf. 4 tab. 25. fig. 17. Fimina. Pall. Spicil. Zool. I r. tab. 2. f. 8. Mas. Habitat in America meridionali.

Media. Antennæ pectinatæ. Corpus fufcum linea thoracis dorfali maculisque plurimis abdominis aureis. Alæe concolores flano hyalinæ margine fufco. In anticis etiam macula centralis fufca. Cauda maris corpore longior, villora.

8-9. BVMEYX alis patentibus caudatis Semiverficoloribus puncto feneftratis: caudis ramis longillimis.

Pbultuena Simiramis Cram. Inf a. tab. I 3. f.A. Habitat inSacharo Americæ meridionalis. Magna. Alæe bafi flisuæ apice verficolo-

$$
S_{3}
$$




\section{8}

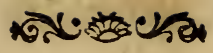

res puncto triangulari feneftrato. Pofticæ bafi fuluæ puncto orbiculari feneftrato. Caudæ corpore triplo longiores, fufcæ apice albæ. Penelo-10-I I. BOMBYX alis parentibus flauepe

fcentibus fufco irroratis ocelloque centrali feneftrato.

Pbalaena Penelope Cram. Inf. 4. tab.45. f.A. Habitat in India.

Magna \& craffa. Antennæ pectinatæ apice feraceæ. Thorax ferrugineus. Abdomen flauefcens fegmentis bafi ferrugineis. Alæ omnes concolores, flauæ fufco irrora. tæ Striga angulata bafeos \& alia recta transuerfa fufcæe. Macula centralis feneftrata annulo nigro cincta \& præterea in anticis puncta duo parua \& fere obfoleta feneftrata.

Thyrr- 10-II. BOMBYX alis patentibus grifeis bea

ftrigis albis ocelloque centrali atro: pupilla feneftrata.

Pbalacna Thyrrbea Cram. Inf. 4. Tab. 46. f.A. Habitat ad Cap. B. S.

Corpus magnum, ponderofum. Antennæ pectinatæ. Thorax grifeus antice ftriga alba. Abdomen fubreftaceum. Alx antic $x$ grifex ftrigis duabus albis: anteriore bafeos valde flexuofa, fofteriore verfus marginem pofticum duplicata, vndata. Inter ftrigas ocellus magnus ater iride alba pupillaque feneftrata. Pofticx bafi teftacex apice grifex ftrigis duabus, altera bafeos angulata, altera verfus 
verfus apicem duplicata, vndara. Ocellus inter frigas ater iride flauefcente pupilla feneitrata.

60-61. BOMBYX alis deflexis Aauiftimis: fulpors.

ftrigis duabus obliquis obfcurioribus.

Habitat in Germania de Hattorf:

Magnitudo B. curtulx. Corpus totum flauiffimum. Alx anticx itidem flaux ftrigis duabus, quarum anterior a medio marginis craflioris verfus hafin marginis tenuioris, pofterior ponemedium marginis craflioris ad angulum ani ducitur. Alie poftica immaculatx.

$64-6 ;$. BOMBYX alis deflexis fubdenratis Gnoma cinereo albis: vitta marginali arra; macula alba.

Habitat Hamburgi Dr. Schulz.

Statura \& magnitudo omnino $N$. Verbafci. Antennx filiformes, vix pestinarx. Thorax grifeus ftriga antica pofticaque nigris. Al $x$ antic $x$ niuex ad marginem tenuiorem cinerex vitta arra, in qua a margine poftico macula atra afcendit. Verfus a picem marginis craftioris macula fufca lineolis duabus atris maculaque alba. Subrus grifex. Poficx albidx, fubtus macula ad marginem exteriorem fufca. Abdomen grifeum ano albo. 69-70. BOMBYX alis compreffo adfcen condentibus niueis: macula communi fufca, prefa centrali grifea : lunula alba.

$$
\mathrm{S}_{4} \text { Habi- }
$$


Habitat in Germania.

Parua in hoc genere. Antennz fimplices, fulcix. Alx valde comprefr.x poftice adfiendentes, niuex anticis macula communi magna fufca \& in medio macula magna transuerfali grifea lunula parua niuea. Verfus marginem pofticum lunulx fufcx \& margo iple fulcus. Ale poftice niuex. Subtus anticx grilex pofticx niuex.

8rige 83-84. BOMBYX alis deflexis flanis riuubris

lis punctisque atris: pofticis fufcis.

Phalacna fulphuralis Linn. Syft. Nat. 2. pag. 881. 333.

Schxff. Icon. I. tab 9. fig. 14. 15. mal. Habitat in Germania.

Statura B. Plantaginis. Al $x$ antic $x$ defex $x$ flauefientes lineis duabus latis apicem həud attingentibus ad marginem tenuiorem, in medio puncta duo \& ad marginem craffiorem tria, verfus apicem denique ftrigx dux e punctis concatenatis arris. Pofticis fufcx margine tenuiffime albo. Subtus omnes variegatx.

Tor $86-87$. BOMBYX alis deflexis? cinereis quimizs macula media atra: linea ramum exferénte alba.

Pbaldena Tarquinius Cram. Inf. I. tab. 4. fig. B. C.

Habitat Surinami.

Sequenti duplo minor. Antennx pectinatie 


\section{*ลง}

nat.e. Caput \& thorax arra, immaculata. Abdomen rufum. Alæ antice cinerex atomis paucus nigris maculaque media triangulari atra, quæ linea vniramofa alba in tres diuiditur. Poftice rufie macula media atra farciisque duabus obfcurioribus.

86-87. BOMBYX alis deflexis? anticis ni- Tar.

gris linea hamata inter ftrigas cluas albas. quinia

Phalaena Tarquinia Cram. Inf.r.tab.4. fig.A.

Habitat Surinami.

Affinis præcedenti differt tamen colore alarum anticarum abdomineque nigro annulis rubris.

95 -96. BOMBYX alis incumbentibus gri-Coles feo-fufcis: punctis ducbus nigris diftantibus.

\section{Habitat in Germania de Hattorf.}

Magnitudo B. Furculæ. Antennæ nigræ peđtinatæ. Palpi nigri. Thorax hirtus grireus. Pectus albidum. Alæ planæ incumbentes obfcure grifex punctis duobus nigris altero ad bafin altero pone medium. Subrus obfcure puncto medio fulco.

99- 100. BOMBYX alis conuolutis atris, Umber

fronte abdomineque fuluis.

Phalaena Umber Cram. Inf. 2. tab. I 5. fig. F. Habitat Surinami.

Antennæ pectinatæ. Alæ atræ pofticis bafi palhidioribus.

106 -7. BOMBYX alis incumbentibus atris amm-

niueo maculatis, tibiis albo annularis.

$$
\mathrm{S}_{5} \text { Habi- }
$$

latas 
Habitat Hamburgi Dr. Schulz.

Caput \& thorax nigra albo variegata." Ab. domen grifeum. Alæ anticæ atræ bafi macula alba nigro pundtata, tunc litura marginis tenuioris ftrigis duabus nigris. In medio fafcia lata ad marginem tentiorem incerrupta ad craffiorem bifida alba. Verfus apicem ftriga vndata, qux ad marginem craffiorem macula ouata terminatur. Subtus fufcæ margine albo punctato.

fulmi- 106 - 7. BOMBYX alis incumbentibus grifeo fufcoque variegatis, thorace antice al. bo ftriga nigra.

Habitat in Germania Dr. Schulz.

Antennæ pectinatæ ferruginex. Thorax grifeus antice albus ftriga tenui nigra. Ad latera vtrinque lunula alba. Ala antica bafi albida lituris nigris, tunc grifere, in medio fafcia lata fufca, qux antice pofticeque a triga vndata alba includitur. Maculce ordinarize albidæ in hac fafcia. Alæ apice grifere ftriga vndata nigra. Poftic grifex.

Boleti $21 \div 22$. NOCTVI lauis alis depreffis planis fufco irroratis, antennis pectinatis.

Habitat Kilonii in Boleto verficolore.

Parua ftatura Tineze at palpi huius generis. Antennæ parum pectinatæ. Alæ anticæ cinereæ atomis maculisque furcis numerolis, pofticæ fufcæ margine craffiori cinereo.

vire. $27-28$. NOCTVA leuis alis deflexis virefcentibus: ftrigis tribus faturatioribus. 
Habitat in Americæ Infula ft. Crux.

Media. Corpus virefcens. Antennæ linguaque ferrugineæ. Palporum fuperior articulus breuis. Alæ anticæ vireficentes ftrigis tribus obliquis faturatioribus. Pofti$c \rightsquigarrow$ albæ margine poftico litura ferruginea. Subtus omnes albr.

33-34. NOCTVA lauis, alis deflexis ci-Robo. nereis: Arigis duabus vndatis albis, ma-ris cula centrali niuea: lunula nigra. Roef. Inf. 1. Phal. 2. tab. 50.

Habitat in Germaniæ Quercu.

Media. Antennæ fetaceæ, fimplices. Strigae alarum albæ fufco marginatx.

Lavua glabra viridis verinque lineis duabus longitudinalibus flauis.

Puppa nigra.

42-43. NOCTVA lacuis, alis deflexismonilis

brunneis: punctis quatuor approximatis albis, antennis pectinatis.

Habitat in Anglia.

Antennæ ferrugineæ, pectinatæ. Caput \& thorax ferruginea. Abdomen pallidum. Alæ anticæ brunnex puncto medio obfuro $\&$ ad marginem tenuiorem puncta quatuor approximata transuerfim pofita alba, quorum I, 3. minora. Verfus apicem itidem puncta quatuor flauefcentia at obfoleta. Pofticæ pallidiores fubtus ftriga obfcuriore. 50- $\mathbf{I}$. NOCTVA læuis, alis lanceolatis lanceo. cinereis: anticis fufco irroratis.

Habi. 


\section{4}

Habitat in Germania Dr. Schulz.

Antennæe longitudine corporis nigræa apice albr. Alre lanccolati acuræ, cinerex anticis fulco irroratis, pofticis immaculatis. vimi- 67-68. NOCT'VA criftata, alis incum: bentibus: bali fufcis; ftrigis vndatis fuluis, apice cinereis.

$$
\text { Roef. Inf. 3. tab. ir. }
$$

Habitat in Germaniæ Salice.

Margo pofticus alarum nigro punctarus. Larua virefcens lineis quinque longıtudinalibus ftrigisque aibis.

Puppa vix folliculata, brunnea.

eque. II - I2. PHALAENA pectinicornis, alis fravia angulatis: anticis fufeefcentibus fafcia lata flata, pofticis flauis.

Habitat Hamburgi Dr. Schulz.

Alar antice angulare fufce in medio fafcia flaua. Poitica angulato-dentata flawe apice obfuriores. Subrus antica flatiefcentes puncto medio nigiro, apice obfcurie margineque fauo variegato. Poftice obfurx bafi pallidxe punctoque medio nigro.

ilyra. 1\%- I8. PHALAENA pectinicornis, alis via angulatis viridibus: anticis ftrigis tribus fulcis.

P'alaena Ilyrias Cram. Inf. r. tab. Io. fig. E. Habitat Surinami. Anus rufo barbatus. Alæ fubtus ferru. giner. 
15-16. PHALAENA pectinicornis alis moni. dentatis viridibus: ftriga punctorum ni laria grorum, pofticis punctro duplici albo.

Habitat in India Dr. Forhergill.

Alæ dentatæ virides. Anticæ in medio puncto nigro, pone medium ftriga e punctis nigris. Poltica in medio, puneto gemino albo \& apice ftriga e punctis nigris. Subtus omnes plumber. Fiemina fere fericornis.

24-25. PHALAENA pectinicornis, alisrors.

flauis fufco irroratis: anticis apice nigris. ria

Habitat in Europa.

Alae omnes vtrinque flanae atomis plurimis fufcis irroratae. Margo pofticus alae anticae fupra late aiger.

Variat rarius absque margine alarum antiearum.

26-27. PHALAENA pectinicornis, alis profas lutefcentibus atomis ftrigisque tribus fu-piaria fcis: tertia maculari.

Phalaena profapiaria pectinicornis alis lu. tefcentrbus: farcuis verinque duabus faturatioribus Linn. Syft. Nat. 2. 864. 222. Fn. Sv. 1252 . Clerk. Icon. Phal. tab. 3. f. I.

Vdm. diff 66.

Habitat in Europae nemoribus.

Striga anterior reliquis latior, media ad marginem craffiorem bifida, tertia macularis. Margo alarum punctatus. 
birta. $30-3 \mathrm{r}$. PHALAENA pectinicornis, alis ria

cinereis : ftriga fufca vndata albae innata. Habitat in Europae pratis fyluaticis. Antennae pectinatae, fufcae. Alae anticae cinereae in medio ftriga obfolera fufca $\&$ verfus apicem alia dentata albae innata. Margo pofticus nigro punćtatus.

ditaria 33-34. PHALAENA pectınicornis, alis viridibus: maculis margınalibus ferrugineis.

Habitat Hamburgi Dr. Schulz.

Antennae pectinatae, cinereae rachi alba. Alae anticae virides ftrigis obfoletis albis \& macula magna ferruginea ad apicem marginis tenuioris. Pofticae rotundatae virides margine albido ftriga renuilima nigra. Ma. cula magna ferruginea ad angu!um ani $\&$ altera ad apicem marginis tenuioris. Subtus omnes pallidae.

margi. 40-4I. PHALAENA pectinicornis, alis naria

albidis puluerulentis: omnibus ftriga marginali punctorum nigrorum.

Habitat Hamburgi Dr. Schulz.

Duplex eft varietas; altera alis albidis an. ticis ftrigis tribus pofticis ftriga punetoque centrali fufcis; altera alis flauidioribus apice obfcuris, pofticis puncto centrali fufco. Conueniunt veropunctis nigris marginalibus diftinctis vtrinque in omni ala.

cynara $47-48$. PHALAENA feticornis, alis angu- 
latis furco albo nigro fuluoque variis: pofticis fubrus albis.

Phaliena Cynara Cram.Inf.2.tab.14.fig.C.D.

Habitat Surinami.

49-50. PHALAENA feticornis, alis emar-finuata ginato-grifeis: punctis duobus furcis inter Atrigas albidas.

Habitat in Germania.

Affinis P. falcatae. Corpus grifeum capite fufco. Alae anticae apice emarginatae grifeae ftrigis duabus flexuofis altera ante, altera pone medium albis vtrinque fufco terminatis. In medio puncta duo approximata, fufca. Emarginatura alae fulua. Pofticae grifcae ftriga alba punctoque centrali fufco. Subtus omnes rufefcentes puncto nigro. 49-50. PHALAENA feticornis, alis angu-manta.

latis fufcis: fafcia obfcuriore; anteriarum $t a$ puncto ocellari atro.

Phaldena Manto Cram. Inf. I. tab. IO. fig.F. Habitat Surinami:

Alae valde angulatae. In centro alae anticae punctum atrum iride ferruginea.

54-55. PHALAENA feticornis, alis den-obfar

tatis grifeis: ftrigis pallidioribus vndatis rata obfoletis.

Habitat in Germania Dr. Schulz.

Media. Alae omnes valde dentatae, grifeae Atrigis indiftinctis pallidioribus. Bafis alae anticae fufcefcit.

$$
55-56
$$


288

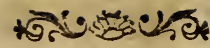

nitata 55 - 56. PHALAENA feticornis, alis fubdentatis obfcure grifeis: fubius pallidio. ribus punto fafciaque furcis.

Habitar in Germania Dr. Schulz.

Parua. Alae omnes fupra vndatae, obfcure grifeae punctis aliquot minutilfimis fere cbioletis nigris. Subrus omnes cinereae puncto centrali fafciaque vndata fufcis.

eque. 65-66. PHALAENA feticornis, alis omnifraze bus nigris: fafcia fulua.

Habitat Hamburgi Dr. Schulz. Antennae craffae, filiformes, nigrae. Cor: pus nigrum. Alae rotundatae, concolores, nigrae fafcia lata fulua, quae tamen marginem exteriorem alae anticae haud attingit.

coerz- 67-68. PHALAENA feticornis, alis obfculata re viridibus fulco fafciatis fafciisque duabus coeruleis.

Habitat Hamburgi.

Antennae fufcae. Caput \& thorax virefcentes. Abdomen cinereum. Alae anticae obfcure virefeentes fafciis ftrigisque fufcis. Ad bafin fafcia obliqua ad marginem tenuiorem dilatata $\&$ in medio alrera latior laete coerulefcentes. Pedes pallidi tibiis nigro annulatis.

grifata $72-73$. PHALAENA feticornis, alis grifeis: anticis ftriga fafcia punctoque furcis. Habitat Hamburgi Dr. Schulz. Antennae cinereae. Slae anticae grifeae: ftriga 
ftriga bafeos fafciaque lata poftica fufcis. Punctum fufcum ante fafciam. Ala pone fafciam obfcurior. Pofticae grifeae fafcia lata fufca, in qua punctum nigrum \& pone faciam obfcuriores. Subrus omnes grifeae puncto centrali frigaque poftica fufcis.

77-78. PHALAENA feticornis, alis plum fim-

beis: fafcia lata fufca flauo marginata. briata

Pbalaena XIII Schaeff. Icon. 1. tab.80. f.6.7.

Habitat in Germania Dr. Schuiz.

Punctum centrale partum atrum in fafcia lata fura.

77-78. PHALAENA reticornis, alis grifeo quadrifufcis: fafcia lata nigra; puncto fubocel fafcialari nigro. Linn. Fn. Sv. 1253 .

Habitat in Europae pratis fuluaticis.

Alae fubrus albidae puncto centrali ftrigisque nigris.

79-80. PHALAENA feticornis, alis albi-riuuladis: fafciis duabus nigris: pofteriore ter-ta minali.

Habitat in Germania Dom. de Hattorf. Caput \& thorax fufca. Abdomen cinereum dorfo fafciculis duabus erectis, breuibus. Alae anticae bafi albae litura marginis craffioris fufca. In medio fafcia fubfinuata fufca, pone hanc alae albae litura marginis craffioris obfoleta, fufca. Margo pofticus fufcus ftriga punctorum nigrorum. Pofticae obfcurae. Subtus anticae fufcae maculis ob- 
foletis albis, pofticæ albæ puncto centrali fafciisque duabus fufcis.

Cen.. 83-84. PHALAENA feticornis, alis fertumno. rugineo fufcoque variis: fafcia media gritata

fea C. atro notara.

Pbalaena centumnotata Naturf. 6. tab. 4. fig. 4 .

Habitat in Germania.

Ruftica media ftatura P. Chenopodiatæ. lunula-84-85. PHALAENA feticornis, alis fufcis in poftice ftrigis vndatis flauis.

Habitat in Germania Dr. Schulz.

Media. Corpus fufcum. Alæanticæ fufcæ margine antico flauo punctato. Verfus marginem pofticum ftrigie tres e lunulis flauis, quarum anterior macula maiori terminatur. Margo ipfe flauo punctatus. Pofticæ fufcæ apice ftrigis rribus vndatis margineque poftico punctis flauis. Subtus omnes bafi cinerex, a pice obfcuriores ftrigis pallidis. media-89-90. PHAL.AENA fericornis, alis omta

nibus grifeo vndatis puncto centrali fufco margineque nigro punctato.

Habitat in Germania D. de Hattorf.

Affinis $P$. punctarae. Alae omnes cinereae ftrigis vndatis obfoletis obfurioribus. centra. $90-9$ I. PHALAENA feticornis, alis flaueta feentibus fufco vndatis : anticis puncto centrali nigro.

Habitat Hamburgi Dr. Schulz.

Anten. 


\section{बूर्य}

Antennae breues, albae. Alae anticae flauefcentes fafciis plurimis anaftomofantibus obfcurioribus punetoque centrali nigro. Poficae rotundatae flatefientes fafciis vndatis plurimis fufcis. Subtus concolores at obfcuiores.

92-93. PHALAENA feticornis, alis om varie. nibus purpureis maculis margineque flauis. gata

Habitat Hamburgi Dr. Schulz.

Corpus fufcum cauda flavefcente. Alæ antica purpurea macula magna media margineque poftico flauis. Poftic purpurex puncto centrali margineque flauis. Subtus concolores at obfcuriores.

99-100. PHALAENA feticornis, alis atris Melata albo macularis, ano rufo.

Pbalacna Melite Cram.Inf.2.tab. 18. fig.D. Habitat in America boreali.

Caput \& thorax atra. Abdomen atrum albo maculatum ano rufo. Alæ fafciis anti. carum tribus pofticarum duabus macularibus albis.

107-8. PHALAENA fericornis, alis flauif-eleuat

fimis fufco punctatis fubtus immaculatis.

Habitat in America meridionali.

Paullo maior P. indicata. Corpus flauefcens. Alæ anticæ flauiffimæ punctis numerofis fparfis fufcis. Pofticæ flauifimæ pun. ctis paucioribus fulcis. Margo pofticus omnis alæ ciliis argenteis. Subtus omnes flauæ, immaculatæ.

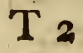

$7 \cdot 8$. 
292

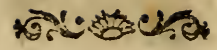

Leeara 7-8. PYRALIS alis plumbeis: lineolis tri. bus maculaque magna apicis ferrugineis. Habitat Hamburgi Dr. Schulz.

Statura P. vncanæe at duplo minor. Corpus fufcum. Alre plumber. Lineola marginalis a bafi ad medium ducta, altera *erfus marginem tenuiorem a bafi ad angulum ani ducta, tertia in medio a centro ad ma. culam apicis. Punctum paruum inter lineolam fecundam tertiamque. Macula apicis orbiculara.

palli 9-:0. PYRALIS alis pallide flauis: ftrigis dana duabus obliquis ferrugineis.

Habitat Hamburgi Dr. Schulz.

Alæ anticæ pallide flux in medio ftrigis duabus obliquis, renuilfmis, rufis. Pone. has lineolæ aliquot abbreuiatæ, ferrugineæ. serna. $15-16$. PYRALIS alis anticis fufcefcenti-

bus: macula centrali fulua, bafi flauis.

Habitat in Germania Dom. de Hattorf.

Magnitudo P. miniftranx. Alæ anticæ bafi Hauæ, medio fufice macula magna cen. trali fulua apice fere auratix ciliis niueis ma. culaque fufca. Pofticæ cinereæ.

afpera. 35-36. PYRALIS alis anticis bafi albis sa apice fufcis fcabris.

Habitat Kilonii de Seheftedt Hamburgi Dr. Schulz.

$\therefore$ Media. Corpus fufcum. Alæ antica bafi albæ, immaculatæ, apice furcæ punctis eleuatis atris fcabræ. Polticæ cinerex. 
35-36. PYRALIS alis anticis pallidis: duplapunctis duobus approximatis bafeos nigris. ${ }^{n a}$

Habitat Kilonii Dom. de Seheftedt.

Statura omnino P. afperanx. Caput cum antennis cinereum. Alie albidre apice paullo obficuriores. "Ad marginem tenuiorem bafeos puncta duo oblonga, approximáta at tamen diftincta. Alra fubtus cinerex.

47-48. PYRALIS alis arris: macula mag- Sib-

na communi, ftrigis atomisque coerule-Atedia-

fcenti argenteis.

Habitar in Chilonii Alneris Dom. de = Seheftedr Norvagus Hiftoria na. turalis cultor felicifimus.

Statura \& magnitudo P. F bricianæe. Antennx albo nigroque annulatx. Thorax \& abdomen atra, ímmaculata. Alre anticæ atra bafi \& ad marginem craffiorem atomis plurimis coerulefcenti al'genteis, nitidiffimis. In medio macula magna, communis, coerulefeens. Poftice ftrigge dure in. rerruptix ad marginem tenuiorem coeuntes coerulefientiargentex. Margo pofticlis ciliis albis. Alex poftica atra margine craffiori albo. Pedes nigri tarfis albo annulatis. 49-50. PYRALIS alis teftaceis fafciis pun. Schn?

ctisque argenteis, medioque litura atra. ziaia Habitat in Germania Dr. Schulz Harnburgus.

Magna in hoc genere. Alæ antica tefta.

$$
\text { T } 3 \quad \text { cex }
$$


ceæ bafi punctis aliquot argenteis, tunc fafcix dua argentex ad marginem craffiorem bifidæ \& inter has litura duplicata atra punctis tribus argenteis fere obfoletis, apice fafcia interrupta argentea. Alæ fubtus nigricantes maculis coftalibus flauis. Pofticæ. cinereæ.

Lunda. 53-54. PYRALIS alis bafi fufcis linea femine circulari pallida, apice auratis: margine craffiori nigro pallidoque ftriato.

Habitat in Chilonii Quercu Dom. Lund.

Norwagus Botanicus eximius \& Entomologus oculatus.

Magnitudo \& ftatura P. ftriganx. Alæ anticæ linea lata femicirculari alba a bafi mar. gitiis craffioris ad medium marginis tenuioris ducta, maculam dorfalem atram includens. Pone medium fere auratæ ftriga obliqua obfoleta, argentea. Margo craflior ftrigis pallidis nigrisque variegatus apice acuminatus, ater. Margo pofticus ciliis albis. Alæ polticæ fufcæ.

appla. 56-57. PYRALIS alis depreffis fufcis: na

punctis tribus centralibus albis.

Habitat Chilonii Dom. de Seheftedt.

Palpi recurui, medio crafficres, apice acuti. Ala anticæ cinereo fufc $x$ punctis tribus minutiffimis albis in centro i na pone al. teram pofitis, quorum ancerius puncto par. uo atro terminatur. Margo exterior apice ftriatus. Subtus cinereæ. 
3-4. TINEA alis oblongis grifeis, anten- Spiffi. narum articulis duobus inferioribus in- cilla craffaris.

\section{Habitat Chilonii Dom. Lund.}

Antennæ corpore breuiores articulo primo fecundoque incraffatis, diffinctis, pubefcentibus. Thorax poftice criftatus, cinereus. Alæ grifer medio pallidiores punctis aliquor diftinctis nigris.

29-30. TINEA ális niueis: arcu communi arcella maculisque duabus marginalibus fufcis.

Habitat in Germania Dr. Schulz.

Parua. Caput \& thorax nivea, immaculata, pilofa. Alæ anticæ niueæ bafi ad marginem cralfiorem macula oblonga, ante medium arcus dorfalis communis $\&$ in medio macula ouata ad marginem craffiorem fufcis. Verfus apicem punata aliquot indiftincta fufca. Subtus cinereæ.

33-34. TINEA. alis linearibus teftaceis; elons-
antennis mediocribus. Pbalaena elongella Linn. Syft. Nat. 2. 890. 285 . Fn. Sv. 1436.

Habitat in Europre nemoribus. $34-35$. TINEA alis anticis linearibus fu-cylin. fcis: maculis tribus flauis. drellas

Habitat Hamburgi Dr. Schulz.

Media, elongata. Caput flauefcens antennis pallidis. Thorax fulcus dorfo flaue. fcente. Alæ anticæ elongatæ, lineares, in-

$$
\mathrm{T}_{4} \text { cumben- }
$$




\section{6}

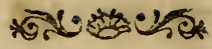

cumbentes, furcae maculis tribus magnis; oblongis, flauis. Alae fubrus flauae. $\mathrm{Pe}$ des faui fufco annulati.

bipun. 3.8-39. 'TINEA alis fufco cinereis: puncto stella marginali albo.

Habitat Hamburgi Dr. Schulz.

Parua. Antennae filiformes. Caput \& thorax fufca f. obfcure cinerea. Aląe obfcu. rae in medic lineola e punctis tribus nigris punctoque ad marginem crafiorem albo. Pofticae vit omnes fubtus cinereae.

fulphu-45-46. TINEA fufca, capite thorace alarumque bafi maculaque coftali fulphureis. Habitat in Germania Dr. Schulz.

Media. Palpi inflexi, corniformes. Ca: put \& thorax fulphurea, immaculata. Alæe fufio auratae bafi maculaque magna coftali fulphureis. Maculam hanc circulus coeruleus nitidus, tenuiffimus cingit. Apex alae albicat.

Ssppet. $52=53$. TINEA alis auratis: Atrigis duabus argenteis.

Habitat in Anglia Dom. Yeats.

Minuta. Corpus nigrum antennis breuibus. Alae anticae auratae, nitidae ftrigis duabus rectisargenteis. Pofticae anro niridae. Crame- $64-65$. TINEA alis pallide argentes porella

ftice fufis maculis marginalibus argenteis puncto jue terminali atro.

Habitat in Anglia Dom. Yeats. 
Minuta. Alae anticae pallidae, poftice obfintores maculis argenteis nouem, quarum 5 ad marginem craffiorem 4 ad tenuiorem. Macula fecunda transuerfalis longior fere coit cum macula fecunda marginis tenuioris. Apex alae terminatur puncto fubo. cellari atro. Polticae cinereae, immaculatae.

I-2. ALVCITA alis pallide auratis vitra eplipdorfali niuea: fafcia aurea.

Habirat in Europa Dr. Schulz.

Parua. Alae pallide auratae vitta lata com. muni dorfali niuea, in qua fafcia lata aurea. 8-9: ALVCITA alis nitieis: maculis dua-niucella bus marginalibus fafciaque media nigris, capite albo.

Habitat in Anglia Dom. Yeats.

Magnitudo A. granellae. Corpus cinereum capite albo. Alae anticae niueae macula oblonga marginali bafeos nigra. Inmedio fafcia obliqua vnidentata \& verfus apicem macula parua marginalis nigra. Alae pofticae cinereae.

10-I I. ALVCITA alis fufco cinereis pun. fra. Etis nigris eleuatis fcabris.

Phollacina fabrella alis albis: dorfo nigro ftriatis exafperatis, palpis fpinolis Lionn. Syft. Nat. 2.89 1.396. Fn. Sv. I 446. Habitat in Europa boreali.

Pundta alarum nigra in thigas difpofira.

12-13. MEMBRACIS thorace inermi fer-mutio

$$
\text { T. } 5
$$

rugi- 
rugineo: poftice producto carinato lon. gitudine abdominis.

Habirat in America boreali.

Corpus obtufum, ferrugineum. Thorax inermis lineis tribus cinercis, obfoletis, poftice productus eleuato carinatus litura mar. ginali ftrigaque poftica cinereis, obfoletis. Elytra obicura. Pedes ferruginei.

con. Io-II. TETTIGONIA atra, elytris bafi iprarca- flauo maculatis, ano fiauo.

Habitat in India Dr. Fothergill.

Corpus paruum fupra nigrum abdomine fubtus anoque flauefcentibus. Elytra atra. bafi flano maculata. Alæatræ.

2uer. 36. CICADA flauefiens, elytris bafi fancuss guineis, apice fufco inaculatis.

Habitat in Quercu frequens in predio nobilifimi comiris Holk Ekhoff dicto.

Minuta. Caput \& thorax flauefientia ocú. lis nigris. Elytra itidem flauefientia maculis quatuor oblongis fanguineis. Apex macula magna dentata fufca. Alæalbr.

coleop. 2. SIGARA elytris toris coriaceis fufcis: tiata margine exteriori fufco.

Habirat in Chilonii aquis Dom. de Seheftedt.

S. Atriate affinis, at quadruple minor. Caput cum roftro flaum, immaculatum. Thorax fulcus, poftice rotundarus. Elyera tota coriacea, fulca margine exteriori flauefcente. 


\section{พx+2}

fcente. Pectus \& pedes pallida. Abdomen nigrum.

I-2. AC $\$ NTHIA nigra, elytris coriaceis Zofteabdomine longioribus, apice hyalinorac Atriatis.

Habitat Chilonii ad littora maris velociffime fupra Zofteras \& Fucos curfitans. Dom. Lund.

Duplo minor A. littorali. Caput nigrum antennis breuibus oculisque prominulis. Elytra coriacea, corpore longiora apice lineolis quatuor margineque hyalino diaphanis. Corpus nigrum pedibus flauefcentibus. I-2. ACANTHIA aptera, elytris coria-coriaceis grifeis.

Cimex grylloides apterus nigger; elytris ouatis margine luteis abdomine breuioribus Linn. Syft. Nat. 2. 717.13.

Habitat Chilonii Dom. Lund.

Magnitudo A. lectulariæ. Antennæ ni-græa articulis duobus anterioribus craffioribus. Thorax \& elytra grifea. Corpus \& pedes atra.

13.5-36. CIMEX oblongus niger, fcurel-fexgut-

lo maculisque tribus elytrorum flauis.

Habitat in Europa.

Câpur nigrum orbita oculorum flauefcente. Thorax ater linea dorfali punctoque vtrinque marginali flanis. Scutellum flauum. Elytra læuia nigra macula oblonga bafeos flaua, 
flaua, fecunda in medio marginis tenuioris $\&$ tertia apicis quæ terminatur puncto atro. Corpus atrum.

rofeus 138-39. CIMEX oblongus fanguineus, capite elytrorumque apicibus albis, al is fufcis. Habitat in Germania Dr. Schulze.

Paruus. Caput albidum. Thorax, fut tellum \& elytra fanguinea. Elytra spice albida. Alr fufcæ. Femora languinea. Tibire albidre nigro punctatre.

olius. 144-45. CIMEX oblongus, elytris fufen cous. - ferrugineis apice coccineis puncto atro, antennis apice capillaribus.

Cimex quatuor antennarum articulis tertius Schæeff. Icon. 1. tab. 1 3. fig. 2. Habitat Hamburgi Dr. Scinulz.

Caput glaucefcens antennis rufis articulis apice nigris, capillaribus. Thorax oliuaceus, antice nigricans. Scutellum nigrum margine rufo. Elyrra obficura, ferruginea apice coccinea puncto atio. Corpus nigrum.

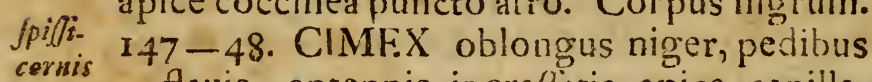
flauis, antennis incraflatis apice capillaribus.

Habitat Hamburgi Dr. Schulz.

Antennæe craffie, nigræ, apice capillares, pallidiores. Corpus nigrum elytris immaculatis. Alæ coerulefcentes. Fedes pallide flauefcentes. latera- 48 - 49. CIMEX oblongus niger, lateri-

bus albidis.

Habi. 
Habitat Kilix Holfatorum Dom. Lund.

Antennæe fetaceæ, nigræ. Caput nigrum orbita oculorum maculaque frontali pallidis. Thorax niger, nitidus lineis tribus flauefcentibus. Scutellum nigrum iinea longituaina. li flauicante. Elytra nigra lateribus albidis. Abdomen nigrum vtrinque linea laterali magna flaua. Pedes nigri.

Variut rarius thorace immaculato.

148-49. CIMEX oblongus viridis imma-pabulio culatus, alis hyalinis. mus

Cimex papulinus oblongiufculus flauefcenti viridis totus Linn. Syft. Nat. 2. 727. 83. Fn. Sv. 947. Scop. Carn. 132.

Habitat in Europæ pratis.

153-54. CIMEX oblongus virefcens fafciis Tilias tribus fufcis: media angulata.

Habitat in Tiliis Holfatiæ Dom. Lund.

Antennæ fetaceæ, nigræ articulo fecundo bafi apiceque pallido. Caput \& thorax viridia linea laterali nigra. Scutellum viride punctis duobus paruis verfus apicem nigris. Elytra viridia fafciis tribus atris anteriore abbreuiata, media antrorfum angulata, poAtica latiore. Pedes albo nigroque annulati. 162 - 63. CIMEX fufcus, alis abbreuiatis, Filum

pedibus longiffimis.

Habitat in India Dr. Fothergill.

Antennx longitudine corporis. Thorax cylindricus, linearis, fufcus. Abdomen elon. 


\section{2}

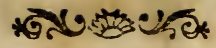

elongatum, cylindricum, furcum. Pedes longiffimi pallidi annulis fufcis.

cinctus $5-6$. REDVVIVS rufefiens, antennis pedibusque flauo nigroque annulatis.

Habirat in America boreali.

Roftrum arcuatum, flauefcens dorfo bafaeos annulis duobus apiceque nigris. Antennæ nigræ articulo primo annulis tribus recundo duobus flauis. Caput flaneficens vertice rigro puncto flauo. Thorax rufe. fcens antice anguftatus vtrinque dente breui, concolore, poftice dente vtrinque fere obioleto nigro. Scutellum \& elytra rufefcentia, immaculata. Abdomen rufefcens margine eleuaro nigro variegato. Pedes annulis nigris flauefcentibusque alternis.

Diade. I I-12. REDVVIVS niger, capite thorama ceque fpinofis.

Habtrat in America boreali.

Antennæe fufcæ. Caput nigrum poftice attenuatum roftro arcuato fpinisque plurimis erectis validis armatum. Thorax niger lobo antico fpinis erectis plurimis validis armato, poftice virinque vnidentatus. Elyrra fufca. Abdomen nigro flauoque varium margine eleuato acuto. Pedes nigri femoribus tibiisque anticis fpinofis.

Acbil. 12-13. APHIS flauefiens, abdomine videae

ridi, antennis pedibusque albidis.

Habitat in Achillæa millefolio Holfatia. 
Antennæ filiformes, albidce. Alæalbidæ. Anus, fylus \& cornicula albida.

12-13. APHIS furea, abdomine virefcen. Mille-

te, antennis pedibus corniculisque nigris. foliz Habitat in Achilliea Millefolio Kilonii.

Caput \& thorax fufca, immaculata. Abdomen viride lateribus albido fubfafciatis. Comicula fylusque nigra. Pedes nigri. Alar compreffice, obfcuriores.

Is - 16. APHIS Fraxini excelfioris.

16. APHIS Fraxini excelfioris. Fraxi.

Aplois Fraxini nigro viridique variegata $n i$

Geoff. InC. 1. 494. 2.

Habitat in Fraxini excelfioris ramis.

Caput \& thorax nigra. Abdomen viride regmentorum marginibus nigris. Antennx pedesque variegati.

22-23. APHIS Aegopodii podagrarix. Aphis Acgnpodii Scop. Carn. 399.

Habirat in Aegopodii podagraria foliis.

Corpus nigrum abdomine roftro pedibusque pallidis.

26-27. APHIS Papaueris fomniferi.
Habitat Kiliæ in Papauere fomnifero.
Caput nigrum antennis pallidis. Corpus

26-27. APHIS Papaueris fomniferi.
Habitat Kiliæ in Papauere fomnifero.
Caput nigrum antennis pallidis. Corpus

Aego. podis nigrum ftylo corniculisque pallidis. Pedes nigri interdum pallidi geniculis nigris. Alæe pallidae cofta fufca. 'Iuniores obfcure vire. fcentes.

2-3. CHERMES Pyri communis Linn. Pyri Syft. Nat. 2. 7.37. 4. Fn. Sv. 1004.

Habi- 
Habitat in Pyri communis foliis.

Corpus paruum, grifeum ftriis lateralibus albidis.

Perfica 6-7. CHERMES Amyogdali Perficr. Chermes Perficæ oblongus Geoff. Inl. x. 506. 4. Reaum. Inf: I. fig. I. 2.

Habitat in Amygdali Perficæ ramis.

Corpus oblongum, ferrugineum.

I-2. COCCVS Indarum arborum.

Aoni- $\quad$ Coccus Aonidum Linn. Syft. Nat. 2. 739.2. ditsm. Habitat in Afiæ arboribus fempervirentibus.

Corpus minus atro purpurafcens. Berula 6 -7. COCCVS Betulæ albæ Linn. Syft.

Nat. 2. 740.7. Fn. Sv. 1017.

Habitat in Betula alba.

Corpus minutum, albidum.

Carpi- 6-7. COCCVS Carpini Betuli Linn. Syft. $n i$

Nat. 2. 740. 8. Fn. Sv. 1018.

Habitat in Carpino Betulo.

Caprea 8-9: COCCVS Salicum. Linn. Syft. Nat.

2. $74 \mathrm{I}$. 14 .

Habitat in Salicibus.

Corpus ouatum, teftaceum.

Zofe- 14-15. COCCVS Zofteræe marina.

Habirat in Zoftera marina maris balthici.

Corpus paruum, orbiculatum, album, deprefio - planum.

minu- $2-3$. THRIPS elytris corporeque glaucis; tijlinia oculis 


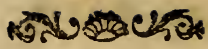

oculis furcis Linn. Syft. Nat. 2. $743 \cdot 3 \cdot$ Fn. Sv. 1028.

Habitat in Europa floribuś.

x. OESTRVS grifeus, facie alba nigro-buecapunctata. tus.

Habitat in Carolina Dom. Yeats.

Facies albida, buccata punctis aliquot nigris, nitidis. Vertex grifea. Thorax grifeus lateribus pallidis. Abdomen grifeum, nigro punctarum. Ala fufcefcentes fquamis halterum elongatis, rocundatis, furcis.

3-4. BIBIO nigra tomenrofa, abdomine nea

xneo.

Habitat in Germania de Hattorf.

Statura omnino Syrphi ruficornis, at anrennæ filatæ huius generis, nigræ, extrorfum craffiores apice fubulatæ, aibæ. Labium obfcure flauefcens. Thorax tomentofus, obfcurus. Abdomen æneum tomen. to ferrugineo pubefcens. Pedes pallidi femoribus nigris.

I. STRA'TIOMYS futello inermi atro, matsin abdomine niueo apice atro.

Habitat in Germania de Hattorff.

Statura præcedentium at parua. Caput atruin fronte puncto albo. Thorax niger. Halteres albi. Abdomen niueum apice atrum anotamen albido. Pedes pallidi.

5. RHAGIO thorace lineato, abdomine ni- lineat gro, alis hyalinis macula apiceque fuccis. 
Tipula lineata Syft. Ent. 754.43.

Habitar in Anglia.

Antennæ cylindrice, incurur, longio. res quam in reliquis. Pedes antici elongati, nigri.

tipuli- 6. RHAGIO fufcus, alis albis apice nigris. formis

Habirat in Germania de Hattorff.

Præcedentibus minor. Antentre breues, cylindricæ. Corpus totum cinereo fufcum, immaculatum. Alx latx, explanatx, albx margine poftico lare nigro.

$m u f j$. $2-3$. SYRPHVS antennis plumatis tomen tanss tofus, thorace fuluo, abdomine virefente.

Habitat in nemoribus Holfatiæ de Se. heftedr.

Magnitudo S. bombylans. Os atrum fronte flaua. Antenna ferruginer feta plumata. Thorax tomentofus, fuluus. Abdomen ouatum, pubefiens, virefcens fufco. obfolete fafciatum. Alæ magnæ albidæ bafi parum rufefcentes $\&$ in mecio macula ma. gna coftali fufca. Pedes nigri femoribus. pofticis elongatis incuruis.

afili- $18-19$. SYRPHVS antennis fetariis, thoformis race tomentofo flauefcente, abdoinine atro: fegmento primo fecundoque albicantibus.

Habitat in Germania de Hattorf. Antennæe clauatæ ferrugineæ feta nigra. Labium 
Labium flaum punctis tribus nigris. Thorax tomentofus, flatefcens. Abdomen nigrum fegmento primo toto, fecundo bafi albidis. Pedes nigri ribiis flauefcentibus. Femora poftica elongata, incurua.

36-37. SYRPHVS antennis fetariis æneus metalnitens, antennis nigris. lima

Habitat in Germania.

Totum corpus, æneum, nitidum, immaculatum. Antennæe breues, fetarix, nigræ. Abdomen dorfo plano. Alx bali ferruginex.

7-8. TABANVS oculis fafciatis niger, ab-pellnt dominis primo fegmento coerulefcente, cens tibiis candidis.

Habitat in Germania de Hattorf.

Antennæ porrectæ, filiformes, nigræ. Caput nigrum fronte villofo, abo. Oculi in mortuo nigri, at fafcias obficuriores video. Abdomen atrum primo fegmento coerulefcente macula media fupra tulca, fubrus pellucida. Reliqua fegmenta fupra immaculata fubrus vtrinque macula coerulefente puncto paruo nigro. Pedes nigri tibiis candidis. 17-18. TABANVS oculis . . ferrugi-hiders neus, abdomine virinque maculis duabus flauis, fcutello bidentato.

Habitar in Aufria Dr. Schulz.

Capur paruum ferrugineum aculis magnis nunc atris. Tharax gibbus, ferrugi$\mathrm{U}_{2}$ neus, 


\section{8}

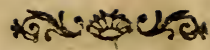

neus, vix lineatus. Scutellum concolor dentibus duobus approximatis validis. $\mathrm{Ab}$. domen ferrugineum fegmento primo macula dorfali fufca, fecundo tertiogue verinque macula marginali fiaua. Pedes ferruginei.

b: pi $_{\text {- }}$ 17-18. TABANVS oculis - - fufcus, $a b$ vofus domine ferrugineo bafi nigro, fcutello bidentato.

Habitat Goetringæ Dr. Schulz.

Thorax pubefcens, fufcus, fublineatus. Scutellum bidentatum, nigrum. Abdomen ferrugineum prirno fegmento nigro, reliquis ferrugineis macula dorfali nigra, late. ralibus fauis obfoletis.

Eptip- $\dot{s}-6$. ASILVS hirfutus ater, thorace bafi tritum albo.

Habitat in Germania de Hattorf.

Caput hittum, atrum antennis connatis. Thorax arer bafi hirfutie alba. Abdomen atrum. Ala fufce. Pedes nigri plantis piceis.

viola- 10-I I. ASILVS hirfutus ater, abdomine reus violaceo.

Habitat in Germania de Hattorf.

Corpus totum pilis ereftis rigidis hirtum, atrum. Abdomen ouatum, violaceum, nitidum. Alze fúcr.

$m$ mea I - 2. STOMOXYS antennis retariss pilofa ris nigra, abdominis fegmento fecundo tertioque rufis. 


\section{Habitat Hamburgi Dr. Schulz.}

Corpus Mufce brafficariæ fimillimum, at roftrum huius generis. Caput flauefcens antennis nigris. Thorax pilofus, niger, fublineatus. Abdomen cylindricum, nigrum fegmento fecundo tertioque rufis linea dorfali nigra. Ala bafi parum rufefcentes fquama halterum fornicata, lactea.

3-4. EMPIS nigra, tarfis anticis incraffa man

to ouatis.

Habitat Chilonii fupra aquas ftagnantes choreas innumeras inftiruens.

Haufellum rećtum vix inflexum longitu. dine probofcidis. Vagina emarginata. Antennæa articulis inferioribus breuiffimis, rotundatis, vltimo longiori fetaceo. Corpus nigrum, immaculatum. Pedes nigri tarfis anticis incraffatis, ouatis. Alæ albæ cofta dimidiata fuica.

Famina pedibus fimplicibus.

II - I2. PEDICVLVS abdomine margina-Buter

to: fegmentis vtrinque punctis duobusnis impreflis.

Pediculus maximus Scop. Ent. 1036.

Habitat in Falcone Buteone.

Corpusfufcum. Thorax læuis lineis tribus longitudinalibus nigris. Abdomen ouatum. 16-17. PEDICVLVS' albus, abdomine orioli

linea dorfali fufca.

Pediculus doliskocephalus Scop. carn. 1039.

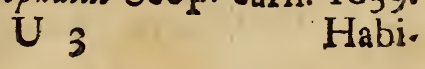


Habitat in Coracia Oriolo.

Glaber, lauis, albus. Caput elongatum. Pbafia.29-30. PEDICVLVS capire ouato mag. ni no, abdomine globofo obtufo.

Red. Oper. I.

Habitat in Phafiano Motmot.

Corpus medium. Caput magnum, oua. tum, obtufum. Thorax breuiffinus. Ab. domen magnum, globofum.

Mota- 32-33. PEDICVLVS capite cordato rufo, cille

abdomine albo bafi attenuato.

Pediculus albiventris Scop. Carn. Ios $\mathrm{r}$. Habirat in Motacilla Troglodyte.

Gryl- 33 - 34. PEDICVLVS fanguineus, pedi. bus albis.

Pediculus roftratus Scop. Carn. I05 2.

Habitat in Acheta Gryllotalpa.

Roftrum elongatum, inflexum, nigrum.

Corpus fanguineum, immaculatum.

Redu. 3-4. ACARVS obouatus planus: macula vius bafeos obouata. Linn. Syft. Nat. 2. 1022.3.

Fn Sv. 1966. It. oel. 62. 126.

Acarus Raj. Inf. 9.

Habitat in Europæ Bobus, Canibus Nimis affinis A. Ricino viderur.

nureo. 7-8. ACARVS obouatus fufcus, lineolis latus duobus maculaque poftica palmata viridi aureis.

Acarus aureolatus Pall. Spicil.Zool. farc. IX.

$$
\text { p. 41. tab. 3. fig. } 10 .
$$

Habitat in America. 





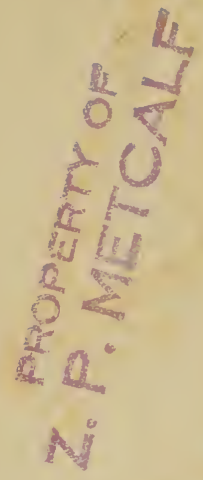



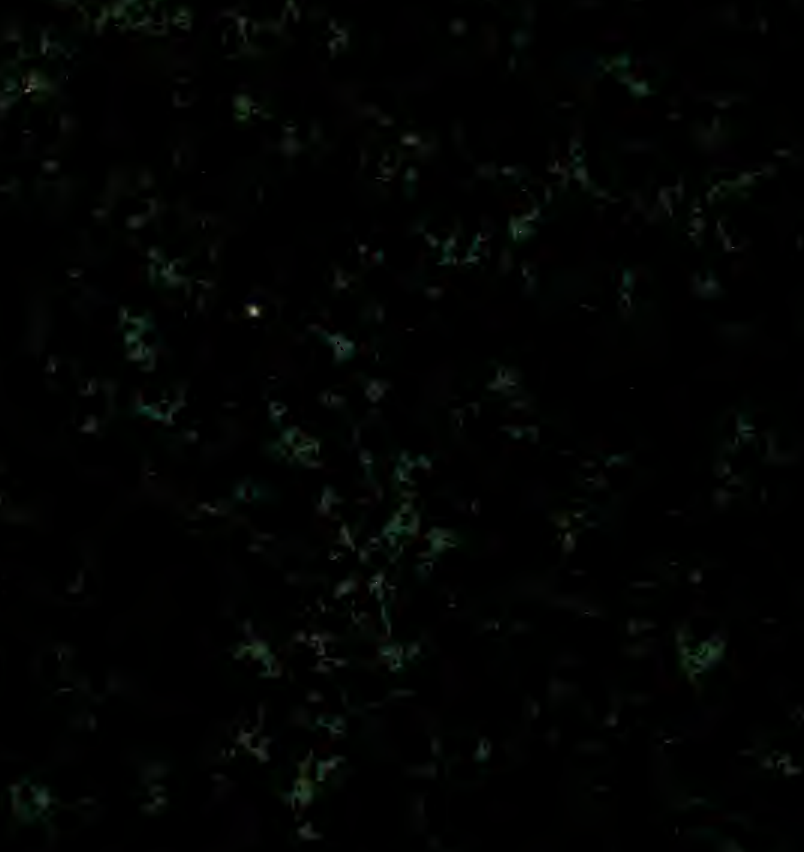

\section{8}
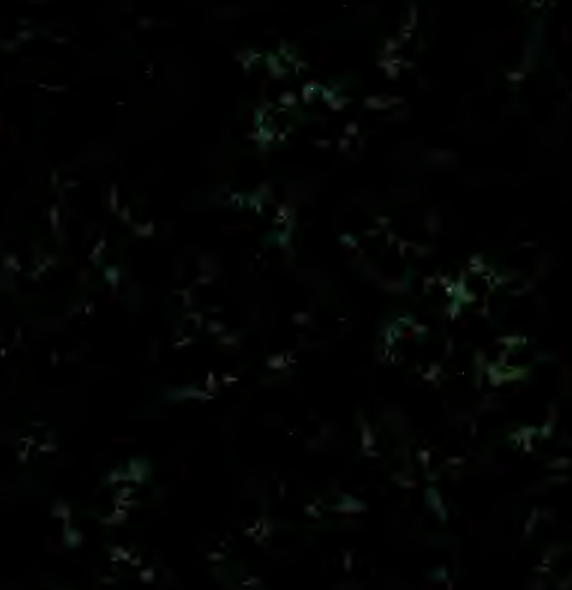

t5 (a)
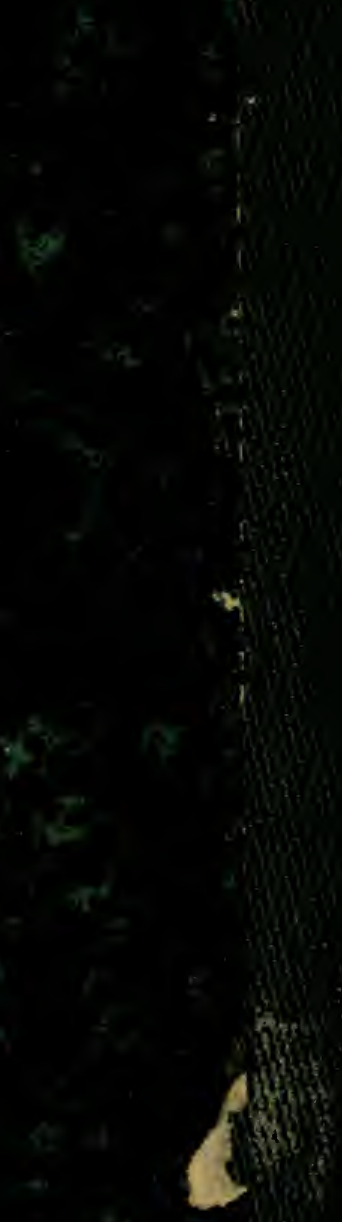

8 